\title{
Vibrant Senior Living: \\ Rehabilitating existing office towers into high-density senior care homes
}

by

Brian Yat Long Cheung

A thesis submitted to the Faculty of Graduate and Postdoctoral Affairs in partial fulfillment of the requirements for the degree of

Master of Architecture

Carleton University

Ottawa, Ontario

(C)2021

Brian Cheung 


\begin{abstract}
This thesis investigates ways to create a more humane, safe architecture to care for seniors. Of course, higher care already exists for those who can afford it, but can such high-quality environments be brought within reach of every citizen through smarter and more efficient architecture? The needs of seniors unable to live fully on their own range from maintaining social, physical, and mental activity for the better abled, to proximity to the most advanced medical care for the less abled seniors.

With increasing remote-work options for white-collar workers as well as increased availability of flexible and shared working spaces, the increase of office tower vacancy provides an opportunity to rehabilitate and to repurpose these existing office towers. While deep office tower floor plates do not lend themselves to residential living, let alone to bright and naturally-ventilated spaces, can they still be remade to meet these needs? These towers immediately provide opportunities for much higher density senior care homes than currently exist, and if reimagined architecturally, can they achieve the same or better level of medical care and quality of life as traditional senior care facility but with reduced costs due to an economy of scale? In this way can a greater number of seniors obtain respectable living standards, and thus can our seniors also be brought to our society's urban centers rather than be relegated to its edges as they are routinely?
\end{abstract}




\section{ACKNOWLEDGEMENTS}

This work can only be achieved by the active and passive support from everyone that guided me throughout my thesis and way finding in the world of architectural studies. I cannot express enough thanks to my thesis advisor Professor Paul Kariouk, $O A A, A I A$ for his guidance and encouragement. Oftentimes new inspirations are drawn from our conversations which enables a vision to an untapped territory.

I would like to express my deep and sincere gratitude to my parents that have given much love and support on the backstage to embark on this endeavor.

Finally, I would like to specially thanks James KM Cheng, CM, FRAIC, Architect $A I B C$, Winston Chong, Architect $A I B C$ and Don Chan for their time to teach and mentor me in the practical challenges in the architectural world. They have challenged my critical thinking on how this project will relevantly respond to the changing dynamic of future senior living in Vancouver. 


\section{TABLE OF CONTENTS}

Title i

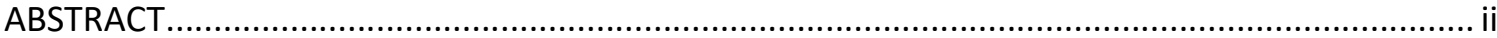

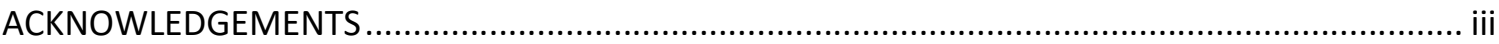

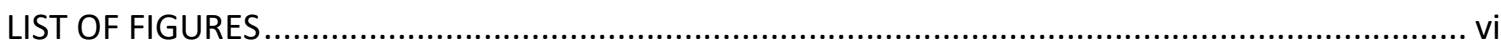

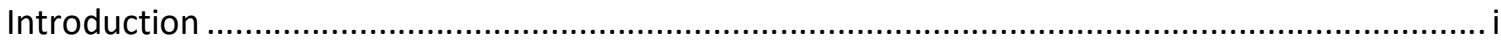

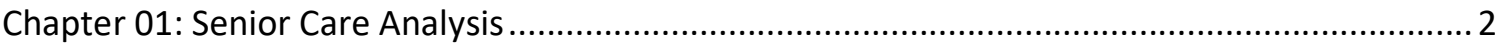

1.1 Senior Demographics: 2021 and the years ahead ........................................................ 2

1.2 Senior Care System: How the system works for BC seniors ............................................ 4

1.3 Residential Types: Alzheimer, Nursing Home, Assisted Living \& Independent ....................4

1.4 Issues with Existing Framework: Problems in architectural and programmatic planning .... 6

1.5 Space Requirement: Existing requirement on sizes and spaces for staff and residents .......9

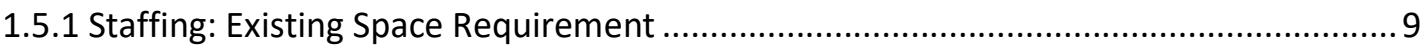

1.5.2 Residential Unit: Existing space requirement and layout ........................................... 11

1.5.3 Building Requirement: Stairs, ramp, hallway sizes ............................................... 13

1.6 Senior Well-Being: Current model for physical and mental health in relation to

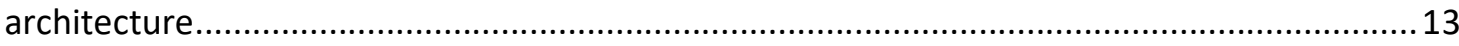

1.7 New Direction: How to improve current model with architectural solutions.....................15

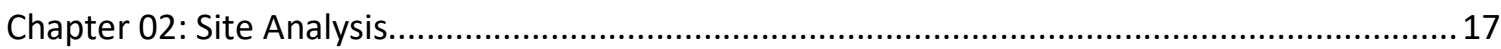

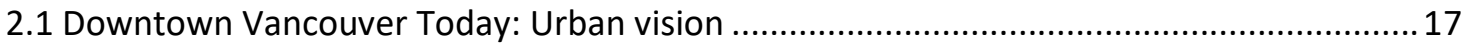

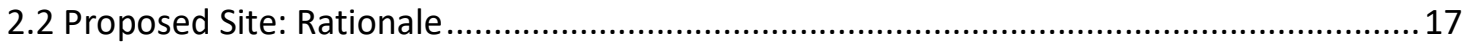

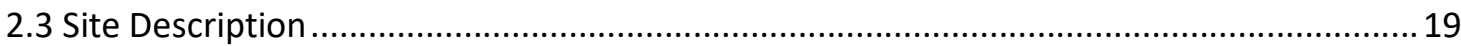

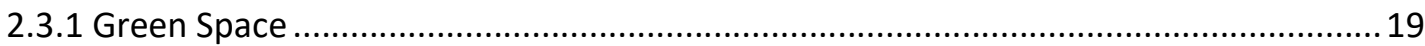

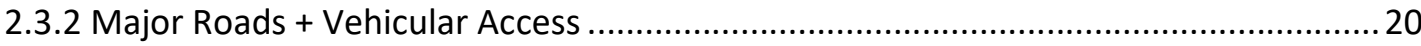

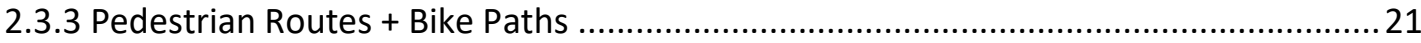

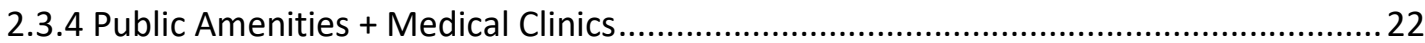

2.4 Goal: High density senior residential tower in the heart of downtown ............................. 23

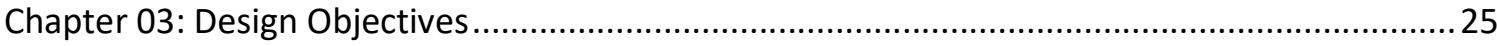

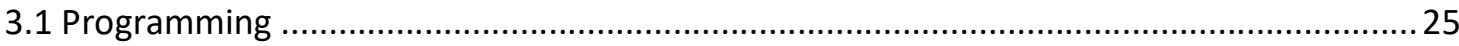

3.1.1 Adjacencies: Relationship between different programmatic zones ...........................26

3.1.2 Social Bubble: Concept of different level of socializing scales.....................................2 27 


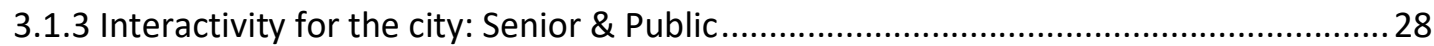

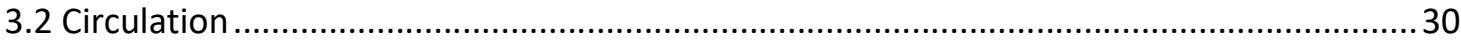

3.2.1 Building Circulation: Interior ramps and circulation for resident ................................30

3.2.2 Public Circulation: Drawing the general public into public amenities ......................... 31

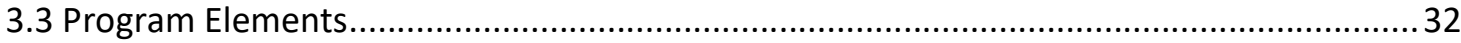

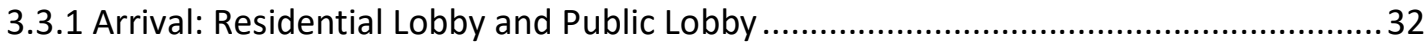

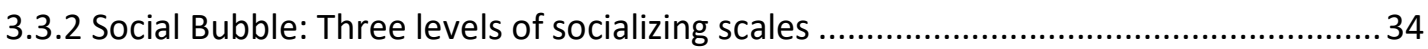

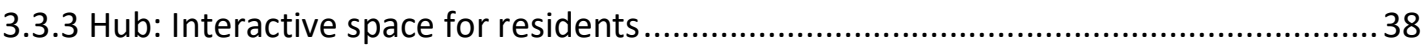

3.3.4 Medical: Staff role \& operational area ….................................................................. 40

3.3.5 Support: Caretaker, Morgue, Administration \& Custodian ........................................ 41

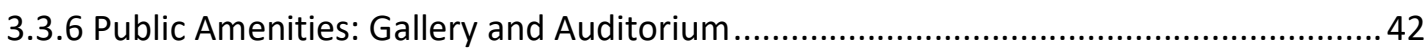

3.3.7 Loading: Emergency, truck, general public .................................................................. 42

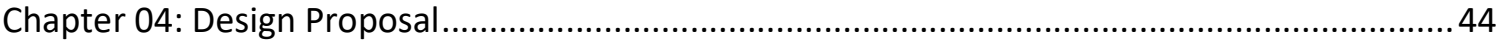

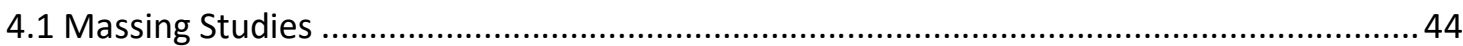

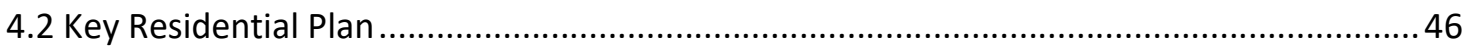

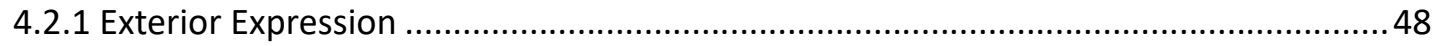

4.2.2 Residential Type - Alzheimer Special Care Home …................................................. 50

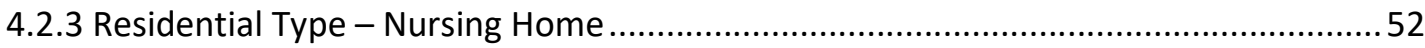

4.2.4 Residential Type - Assisted Living ........................................................................... 54

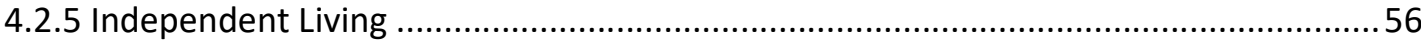

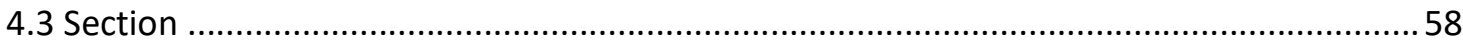

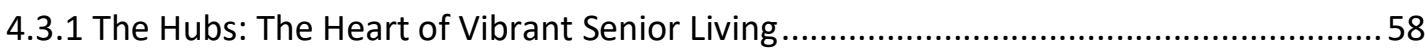

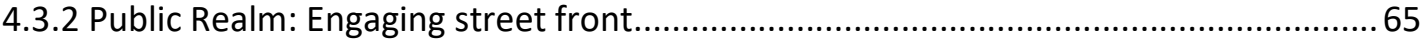

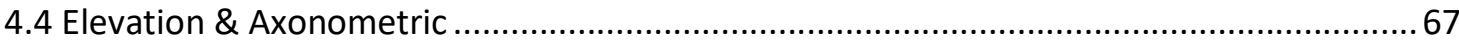

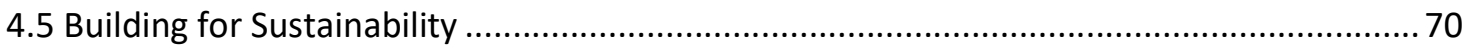

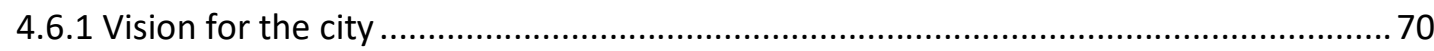

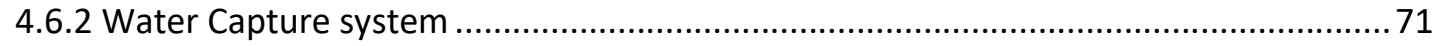

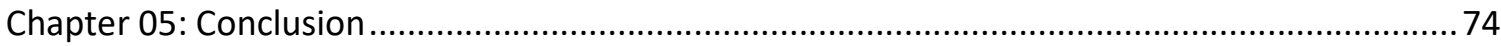

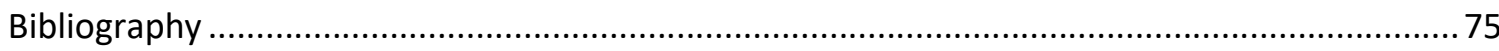




\section{LIST OF FIGURES}

*All images by Author Unless Noted Below

Figure 0.1: Vancouver senior care facility Source: https://www.scmp.com/news/world/united-states-canada/article/3116055/31die-vancouver-care-home-catering-chinese-elders

Figure 0.2: Vancouver Downtown Source: https://www.citynews1130.com/2021/01/15/vancouver-office-vacancycovid19/

Figure 1.1: Senior Demographic Map

Figure 1.2: Senior Demographic Data

Source: Seniors in Vancouver (2010), Social Policy Division, City of Vancouver

Figure 1.3: Current issues in senior home

Figure 1.4: Existing typical senior home floor plan

Source: Winston Chong Architects

Figure 1.5: Existing typical senior home amenities Source: Winston Chong Architects

Figure 1.6: Ratio of Registered Practical Nurse to resident Source: Residential Care Staffing Review (2017), Ministry of Health BC

Figure 1.7: Ratio of Registered Practical Nurse to resident Source: Residential Care Staffing Review (2017), Ministry of Health BC

Figure 1.8: Total Direct Care Hours (HPRD), 2013-2014

Source: Determining Appropriate Staffing \& Care Levels for Quality in Long Term Care, March 2019, BC Care providers Association

Figure 1.9: Acuity Levels in Long Term Care in Canada Source: Determining Appropriate Staffing \& Care Levels for Quality in Long Term Care, March 2019, BC Care providers Association 
Figure 1.10: Nursing Home Unit Design Standards

Source: Design Standards for Nursing Homes version 3.0, Department of Social

Development by Department of Transportation and Infrastructure Building Division, New Brunswick, 2015

Figure 1.11: Physical Well-Being relationship Source:https://www.cdc.gov/physicalactivity/basics/older_adults/index.htm?CDC_AA_r efVal=https\%3A\%2F\%2Fwww.cdc.gov\%2Fphysicalactivity\%2Feveryone\%2Fguidelines\%2 Folderadults.html

Figure 1.12: Ways to help seniors with loneliness Source:https://www.cdc.gov/physicalactivity/basics/older_adults/index.htm?CDC_AA_r efVal=https\%3A\%2F\%2Fwww.cdc.gov\%2Fphysicalactivity\%2Feveryone\%2Fguidelines\%2 Folderadults.html

Figure 1.13: Proposed staff requirement

Figure 1.14: Proposed residential type distribution

Figure 2.1: Project Data

Figure 2.2: Open Space and Park

Figure 2.3: Major Roads and Loading Access Diagram

Figure 2.4: Pedestrian Routes and Bike Path Diagram

Figure 2.5: Public Amenities and Medical Clinics

Figure 3.1: Adjacencies Diagram

Figure 3.2: Social Bubble Diagram

Figure 3.3: Public Realm and View Cone Diagram

Figure 3.4: Building Circulation Diagram

Figure 3.5: Public Circulation Diagram

Figure 3.6: Public Realm and Residential Lobby

Figure 3.7: Public Lobby

Figure 3.9: Level 1 Social Bubble

Figure 3.10: Level 1 Plan 
Figure 3.11: Street Level Rendering

Figure 3.12: Typical Unit Plan - Independent

Figure 3.13: Typical Unit Plan - Nursing Home

Figure 3.14: Typical Unit Plan - Assisted Living

Figure 3.15: Level 2 Social Bubble Plan

Figure 3.16: The Hub Overview

Figure 3.17: Medical Clinic Exterior Expression

Figure 4.1: Massing Diagram

Figure 4.2: Physical Model

Figure 4.3: Existing Floor Plan

Source: Golden Properties

Figure 4.4: Overlay Typical Residential Unit onto typical project floor plate

Figure 4.5: Dual Level Exterior Ramp

Figure 4.6: Open Exterior Ramp

Figure 4.7: Hallway ends fenestration

Figure 4.8: Enlarged Unit Plan - Dementia Special Care

Figure 4.9: Proposed Residential Floor Plan - Dementia Special Care

Figure 4.10: Enlarged Unit Plan - Nursing Home

Figure 4.11: Proposed Residential Floor Plan - Nursing Home

Figure 4.12: Enlarged Unit Plan - Assisted Living

Figure 4.13: Proposed Residential Floor Plan - Assisted Living

Figure 4.14: Enlarged Unit Plan - Assisted Living

Figure 4.15: Proposed Residential Floor Plan - Independent Living

Figure 4.16: Sectional Perspective 
Figure 4.17: Pet Therapy \& Outdoor Playground Rendering (Hub \#1) View 1

Figure 4.18: Pet Therapy \& Outdoor Playground Rendering (Hub \#1) View 2

Figure 4.20: Indoor Botanical Garden and Meditation (Hub \#3)

Figure 4.21: Yoga and Fitness (Hub \#4)

Figure 4.22: Outdoor Running track and fitness (Level 25)

Figure 4.23: Roof Vegetable Garden

Figure 4.24: Public Realm Rendering (Restaurants)

Figure 4.25: Roof Top

Figure 4.26: North Elevation

Figure 4.27: Southeast Corner View

Figure 4.28: Sustainability Overview

Figure 4.29: AquaWeb developed by NexLoop

Source: Nexloop, https://nexloop.us/

Figure 4.30: Water Capture System Diagram 


\section{Introduction}

The current government funded senior care system in BC accounts for a small portion of seniors in the region due to the high demand for government-subsidized facilities far exceeding the supply. Ninety-three percent of seniors live at home while four percent of seniors live in nursing homes and three percent are in assisted living facilities. ${ }^{1}$

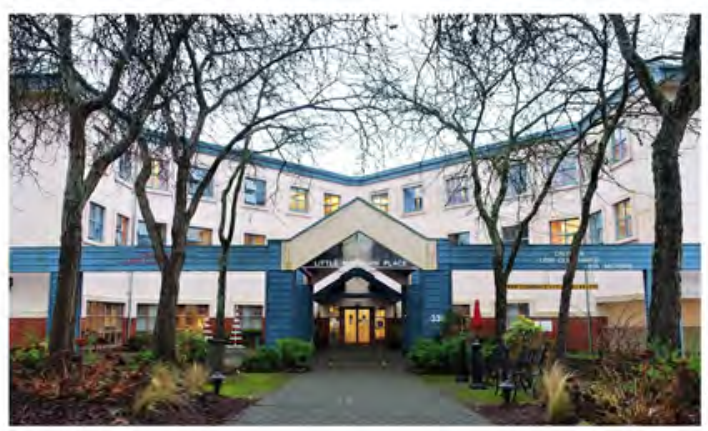

Figure 0.1 - Vancouver senior care facility

While the number of seniors will continue to increase over the next twenty years, the supply of senior care homes will need to increase dramatically in order to meet the demand. The most socially-responsible directions of any proposed high-density senior homes should aim to replace the current exclusive model for private senior care with widely-available, round-the-clock aid.

The government-subsidized facilities for senior care homes are not being built at a rate able to meet current demands, and new facilities will need to accommodate the existing waitlisted seniors and also the projected increase of seniors in the next twenty years. Vancouver's Downtown is evolving under two dynamic factors that contribute to the vacancy of office towers. Regarding the recent pandemic, it is speculated that office spaces could

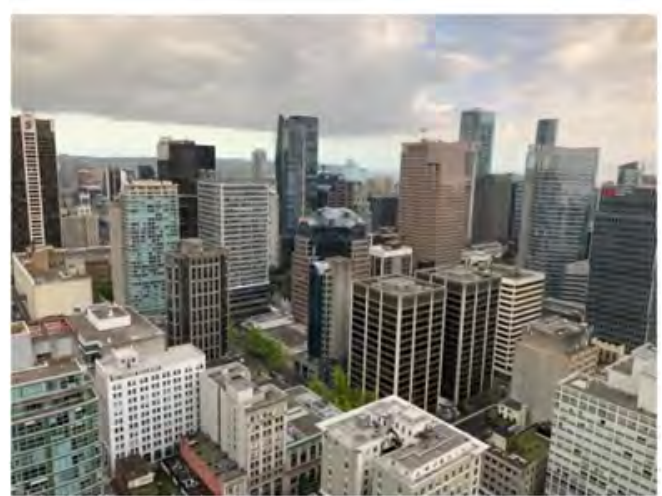

Figure 02 - Vancouver Downtown become less necessary as technology moves to home offices. An secondary factor is the increase of office towers and commercial spaces in the adjacent City of Surrey in the next twenty years, which will increase the vacancy in Vancouver's downtown core.

There are potential opportunities to integrate a senior care home program into a repurposed office tower in order to increase the numbers of seniors being served over the existing models, which would also increase the availability of medical care and the availability of amenities. 


\section{Chapter 01: Senior Care Analysis}




\section{Chapter 01: Senior Care Analysis}

\subsection{Senior Demographics: 2021 and the years ahead}

In Metro Vancouver, the most significant population growth has been witnessed in two age groups: 55-59 years and 90+ years of age. ${ }^{1}$ The increases in this latter age group are especially important to note since, as they age, older seniors tend to require greater amounts of home support, adult daycare, supportive housing, and complex care.

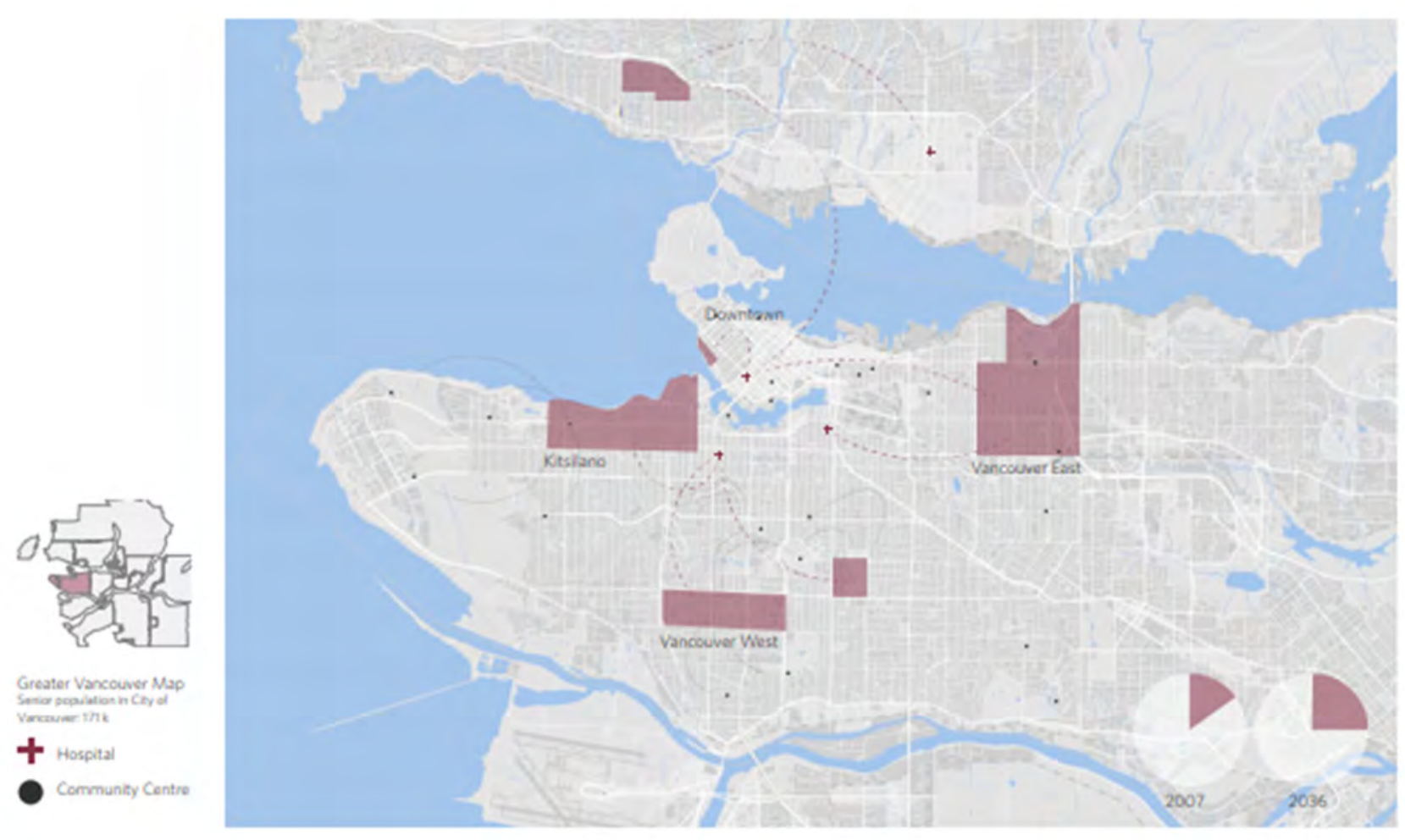

Figure 1.1 - Senior Demographic Map

${ }^{1}$ Kloppenborg, Anne. (2010). Seniors in Vancouver, A discussion paper prepared by the social policy group, social development department, City of Vancouver 
In terms of city area, English Bay \& Kitsilano (West End) have a significant senior population, but the highest percentages of seniors now live in the following four areas: Strathcona, Arbutus Ridge, Oakridge, and Shaughnessy, which are not so close to any city life. Other Local areas with large senior populations are also high-density areas populated with younger age groups, whereby those seniors are closely attached to a family. Typically, those seniors take care of their grandchildren as they live with their own children in the same household or in the same neighbourhood. Each of the four regions identified are suburban in character and thus none are lively beyond the immediate households, nor are they close to any significant medical facility or clinic.
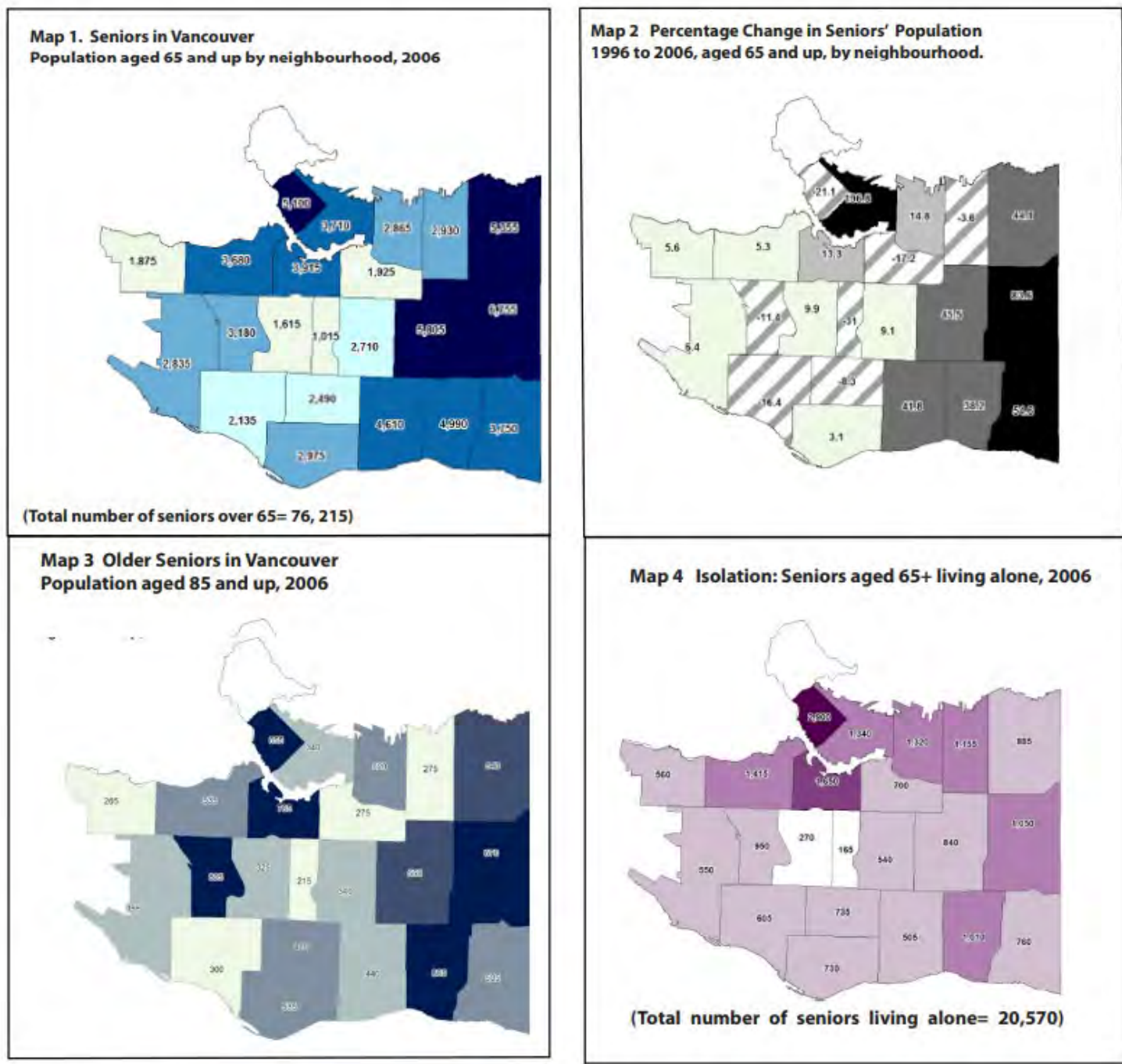

Figure 1.2 - Senior Demographic Data ${ }^{1}$

${ }^{1}$ Kloppenborg, Anne. (2010). Seniors in Vancouver, A discussion paper prepared by the social policy group, social development department, City of Vancouver 


\section{$\underline{1.2 \text { Senior Care System: How the system works for BC seniors }}$}

The majority of $B C$ seniors are living at home and only seven percent of seniors live in nursing homes and assisted living situations. Within the small fraction of dependent-living seniors, government funded home care services are a fraction within that seven percent. The demand for subsidized facilities is already so high such that a long waiting list of seniors cannot access assisted-living and nursing home spaces.

For seniors that have the ability to access private senior care home, they are usually in a housing complex with one-bedroom apartments with minimal amenities and services to support the seniors. The cost of private independent senior facilities is astronomical, thus for the majority of seniors, long-term care is unaffordable. The size of the aging population continues to increase and is expected to become twenty-five percent of the total population by 2040 ,; the burden on the BC social welfare system is expanding beyond sustainability.

In addition to government subsidized facilities, there are also programs where the government subsidizes the hours of local health care workers to visit seniors' personal homes. However, these hours are decline in numbers and at times are "as short as 15-minutes per visit by the care taker or nurse". ${ }^{1}$

\section{$\underline{1.3 \text { Residential Types: Alzheimer, Nursing Home, Assisted Living \& Independent }}$}

Seniors are categorized into specific residential types under a set of criteria called Activities of Daily Livings (ADLs). These are the basic self-care tasks upon which seniors will be evaluated and assigned to a residential-type living situation based on their level of required assistance. ${ }^{2}$

\section{Activities of Daily Living}

- Mobility: Ability to get around the home, sit, stand and walk

- Eating: Ability to feed oneself

- Bathing: Ability to bathe/shower, brush teeth and groom

- Dressing: Ability to dress and undress

- Toileting: Ability to get to and from the toilet and clean oneself

- Continence: Ability to control bladder and bowel functions

Under the above criteria, four residential types can be determined.

\footnotetext{
${ }^{1}$ Culbert, Lori,. Shore, Randy. (2018). Finding care for B.C. seniors: How the system works, what is missing, and why you need deep pockets. Vancouver Sun.

${ }^{2}$ BC Care Providers Assocation. (2019). Filling the Gap: Determining Appropriate Staffing \& Care Levels for Quality in Long Term Care
} 
Independent seniors: Seniors who might be a widow/widower or a couple who wish to live in a community with occupants of similar age and lifestyle.

Assisted Living: Seniors with physical disabilities or inconveniences that require attention in mobility. Special design consideration would be accessibility throughout the space of the building.

Nursing Home: Seniors with medical needs such as the need for a daily check-up, medication attention, and chronic medical condition. Medical supplies and a clinical room are required to accommodate these occupants.

Dementia Special Care: Seniors with memory impairment such as dementia or Alzheimer's disease who require a controlled environment for the occupant to navigate through safely. The controlled environment may need to be separate from others without compromising the ability for occupant to wander around. However, the security measure to prevent one from getting lost would be the objective. 


\subsection{Issues with Existing Framework: Problems in architectural and programmatic planning}

Identifying the existing problems in senior residential homes and their implications

\begin{tabular}{|c|c|c|}
\hline & Identified Problems & Implication \\
\hline 1 & $\begin{array}{l}\text { Seniors are isolated from the city centre } \\
\text { and many seniors reside in the suburb }\end{array}$ & Disconnect with city life and public amenities \\
\hline 2 & Lack of interaction space with the public & $\begin{array}{l}\text { seniors are often kept away from the general } \\
\text { public which makes outsider involvement } \\
\text { in senior home difficult }\end{array}$ \\
\hline 3 & Lack of interaction space with other seniors & $\begin{array}{l}\text { social gathering space and program specific } \\
\text { areas are insufficient to host activities. The } \\
\text { lack of interactive space contributes to the } \\
\text { stigma of growing old }\end{array}$ \\
\hline 4 & $\begin{array}{l}\text { No relationship to individual } \\
\text { gardening space/outdoor space }\end{array}$ & $\begin{array}{l}\text { There is no dedicated outdoor space for } \\
\text { individual senior residents. The sense of } \\
\text { belonging and active living lifestyle are } \\
\text { restricted by not introducing more outdoor } \\
\text { opportunity }\end{array}$ \\
\hline 5 & $\begin{array}{l}\text { Minimal physical exercise } \\
\text { opportunity in a senior home }\end{array}$ & $\begin{array}{l}\text { Usually seniors rely on city amenities such as } \\
\text { community centres and parks in the suburb } \\
\text { to accommodate their physical exercise } \\
\text { requirements. However, an on-site facility is } \\
\text { limited for seniors who do not have } \\
\text { convenient access to physical exercise } \\
\text { amenities }\end{array}$ \\
\hline 6 & Safety of Alzheimer's resident & $\begin{array}{l}\text { Seniors with Alzheimer disease wander } \\
\text { outside of the senior home property pose } \\
\text { safety } \\
\text { concerns for senior resident where there is } \\
\text { no controlled environment. When seniors are } \\
\text { restricted within a building without adequate } \\
\text { amenities, the seniors feel they are being } \\
\text { held as prisoners. }\end{array}$ \\
\hline 7 & Nursing home living quality & $\begin{array}{l}\text { A typical nursing home would be a room } \\
\text { shared by two residents where they are } \\
\text { divided with a thin curtain in between. There } \\
\text { is lack of privacy and noise separation } \\
\text { regardless of their mental and physical } \\
\text { disabilities. }\end{array}$ \\
\hline
\end{tabular}

Figure 1.3 - Current issues in senior home 
Existing Framework: Issues with current models

A typical senior's residential home for independent living resembles a typical residential building design. The majority of units are studio- style with approximately five-hundred square feet including a kitchen and small living room. Units are isolated from each other with minimal common space to interact with other residents on the floor. Outdoor balconies are provided but are isolated from others and are small, limiting use to not more than two people. The corridor only serves the purpose of egress and access into the building. It only has one means of access, which provides security but would be an issue in some emergencies such as a pandemic.

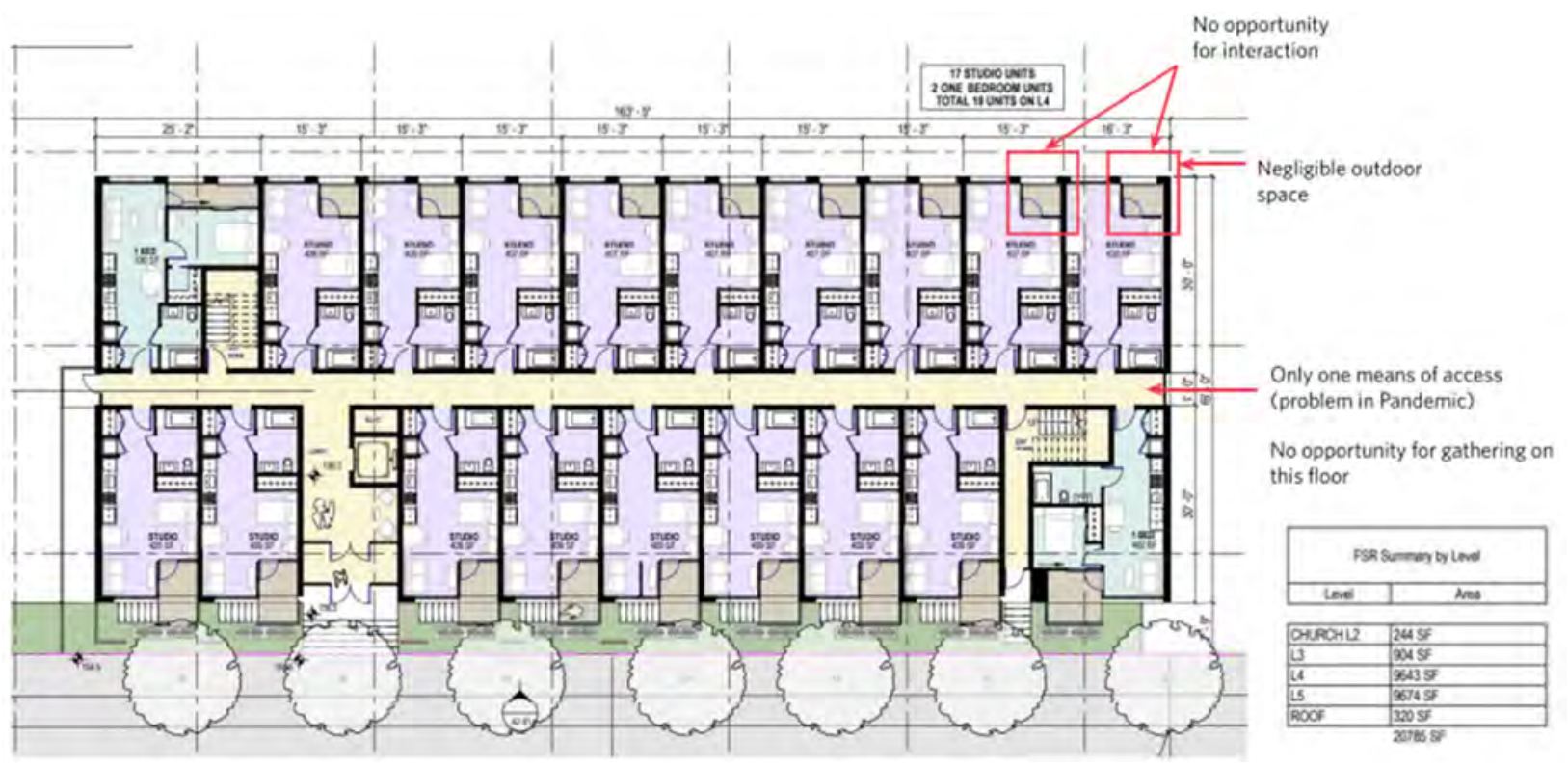

Figure 1.4 - Existing typical senior home floor plan 
Indoor amenities are usually limited and located on a different floor than the living suites. Generally, there is an insufficient variety of amenities and activity rooms for a building with 60 units, so in fact many residents are left without extensive activities. Support staff offices are generally aggregated onto a specific floor instead of being spread out in closer proximity to senior suites. In addition to the paucity of structured activity and recreation areas, narrow and windowless corridors preclude the passive/casual interaction of occupants.
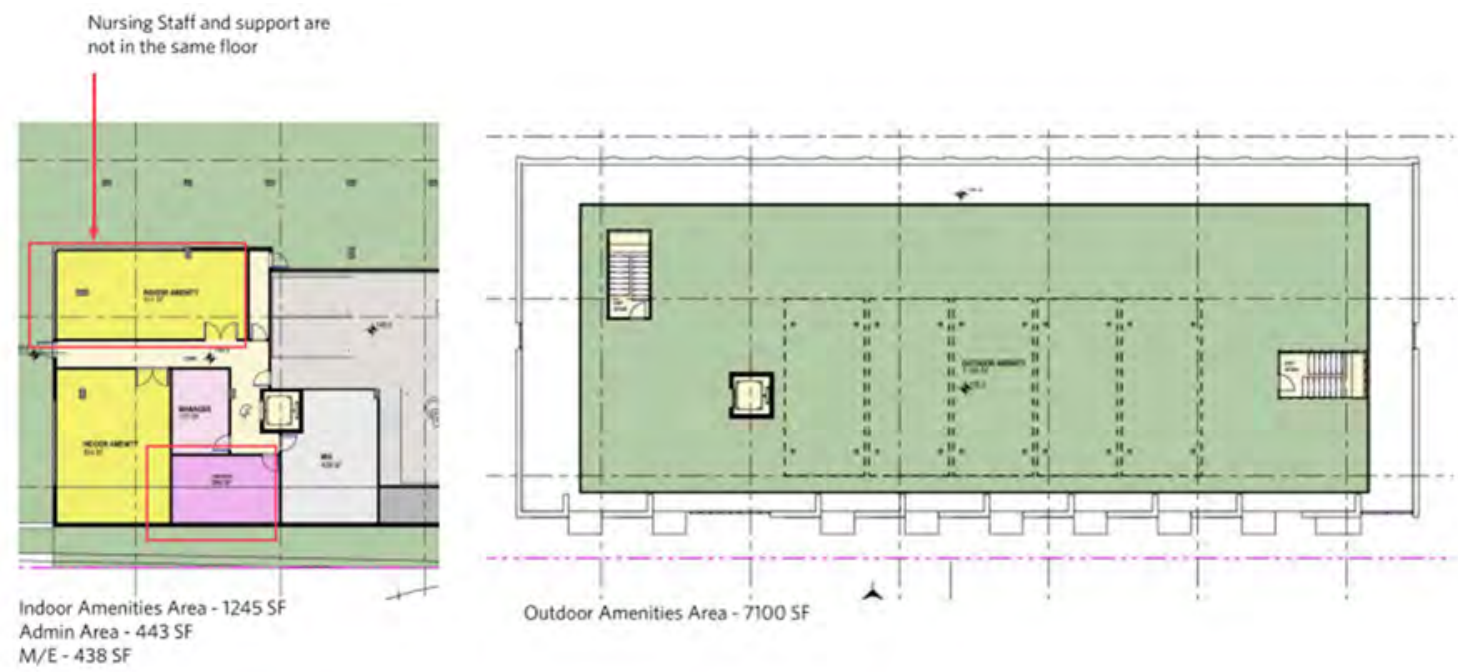

Figure 7 - Existing typical senior home amenities 
1.5 Space Requirement: Existing requirement on sizes and spaces for staff and residents

\subsubsection{Staffing: Existing Space Requirement}

According to a directive for the recommendation of Residential Care Staff Review from the Ministry of Health BC, four deliverables in particular were sited regarding average standard staffing levels and worked-hours per resident per day and clinical support services in residential care facilities. ${ }^{1}$

As per the BC, directive the total is 3.36 worked hours of care made up of direct and allied health care staff. The staff encompasses registered nurses, licensed practical nurse and caretakers.

- Registered nurses: 24 hours/day, seven days/week as set out in the table

\begin{tabular}{|c|c|}
\hline Number of Beds & Number of Registered Nurses 24/7 \\
\hline $0-75$ & 1 \\
\hline $76-150$ & 2 \\
\hline $151-225$ & 3 \\
\hline $226-300$ & 4 \\
\hline
\end{tabular}

Figure 1.6 - Ratio of Registered Practical Nurse to resident

- Licensed practical nurses: one for every 25 residents on day and evening shifts and night shifts in facilities that have more than 75 beds, as set out in the table

\begin{tabular}{|c|c|c|c|}
\hline \multirow{2}{*}{ Number of Beds } & \multicolumn{3}{|c|}{ Number of Licensed Practical Nurses 24/7 } \\
\cline { 2 - 4 } & Days & Evenings & Nights \\
\hline $0-25$ & 1 & 1 & 0 \\
\hline $26-50$ & 2 & 2 & 0 \\
\hline $51-75$ & 3 & 3 & 0 \\
\hline $76-100$ & 4 & 4 & 1 \\
\hline $101-125$ & 5 & 5 & 1 \\
\hline $126-150$ & 6 & 6 & 1 \\
\hline $151-175$ & 7 & 7 & 2 \\
\hline $176-200$ & 8 & 8 & 2 \\
\hline $201-225$ & 9 & 9 & 2 \\
\hline $226-250$ & 10 & 10 & 2 \\
\hline $251-275$ & 11 & 11 & 3 \\
\hline $276-300$ & 12 & 12 & 3 \\
\hline
\end{tabular}

Figure 1.7 - Ratio of Licensed Practical Nurse to resident

- Care aides: one for every six residents on day shifts, and one care aide for every eight residents on evening shifts, and one to thirty-seven on nights

\footnotetext{
${ }^{1}$ Ministry of Health BC. (2017). Residential Care Staffing Review
} 
The three types of health care staff are on rotations to maintain the seniors' well-being in the facilities, however, the number of hours of care for each senior continues to fall under that of other provinces. With the increase upon senior care demand, the number of available staff will also need to grow in order to accommodate a high density model.

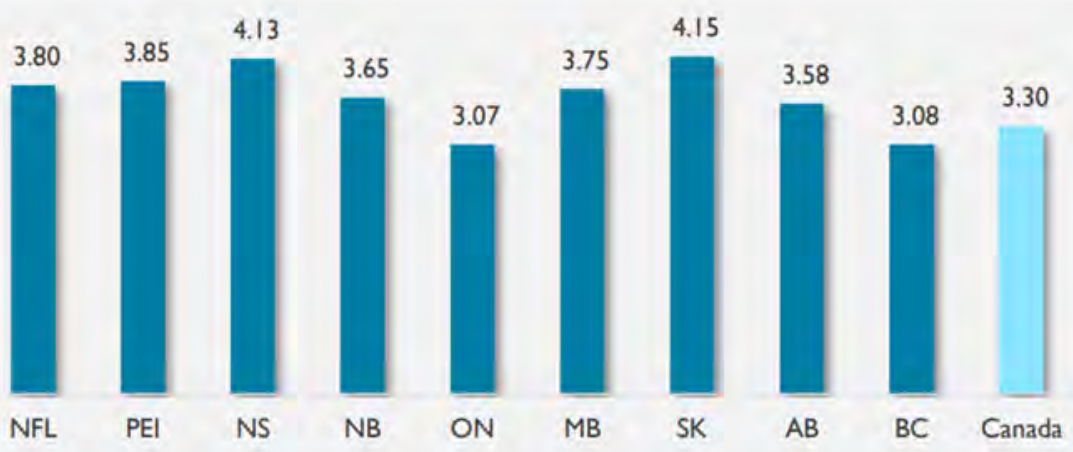

Figure 1.8 - Total Direct Care Hours (HPRD), 2013-2014 ${ }^{1}$

The distribution of dementia resident and nursing home seniors reflects the demand of government subsidized facilities different senior categories, which influence the proposed model of residential type distribution.

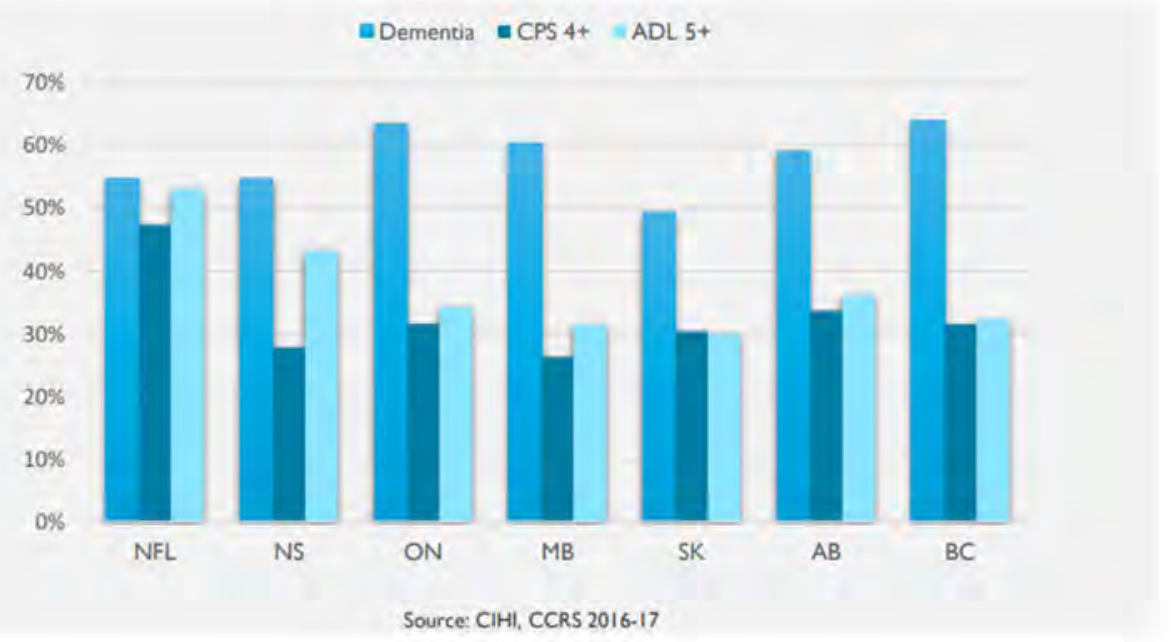

Figure 1.9 - Acuity Levels in Long Term Care in Canada ${ }^{1}$

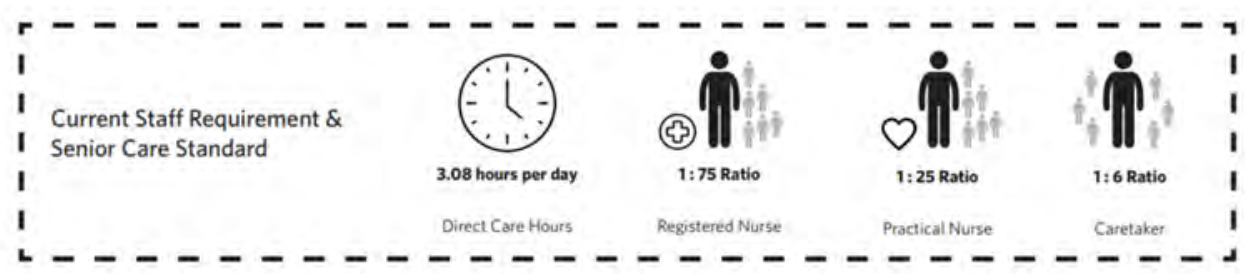

${ }^{1}$ BC Care Providers Assocation. (2019). Filling the Gap: Determining Appropriate Staffing \& Care Levels for Quality in Long Term Care 


\subsubsection{Residential Unit: Existing space requirement and layout}

The specific spacing requirements of different senior care types cater to the medical needs and living lifestyle for the individual senior. Current standards of unit layout, sizes, and minimum distance between specific objects and spaces are outlined in the Design Standards Manual. A conventional unit layout for the Nursing Home would follow many standards of a hospital room whereby residents may require the most medical needs out of each of the residential types. Assisted Living would have standards similar to market accessible units where it follows the standard for the American with Disability Act (ADA). Most Dementia Special Care Units do not have a standard model currently and there are many pilot programs to engage a new direction specifically for dementia residents. For example, Dementia Village in Langley BC would be a controlled area of residential complex specifically designed for dementia residents. Independent Senior unit requirement typically follow suite layouts as with conventional market housing but the residents are all exclusively seniors. 
Typical Nursing Home Design Standards are designed with guidelines for minimum space clearance and distances, however, designers should use these standards as a bottom line to develop a more optimal solution for a higher quality nursing home model. The importance of these standards would mainly affect the clearance for a typical bed and the mobility for residents and their caretakers. ${ }^{1}$
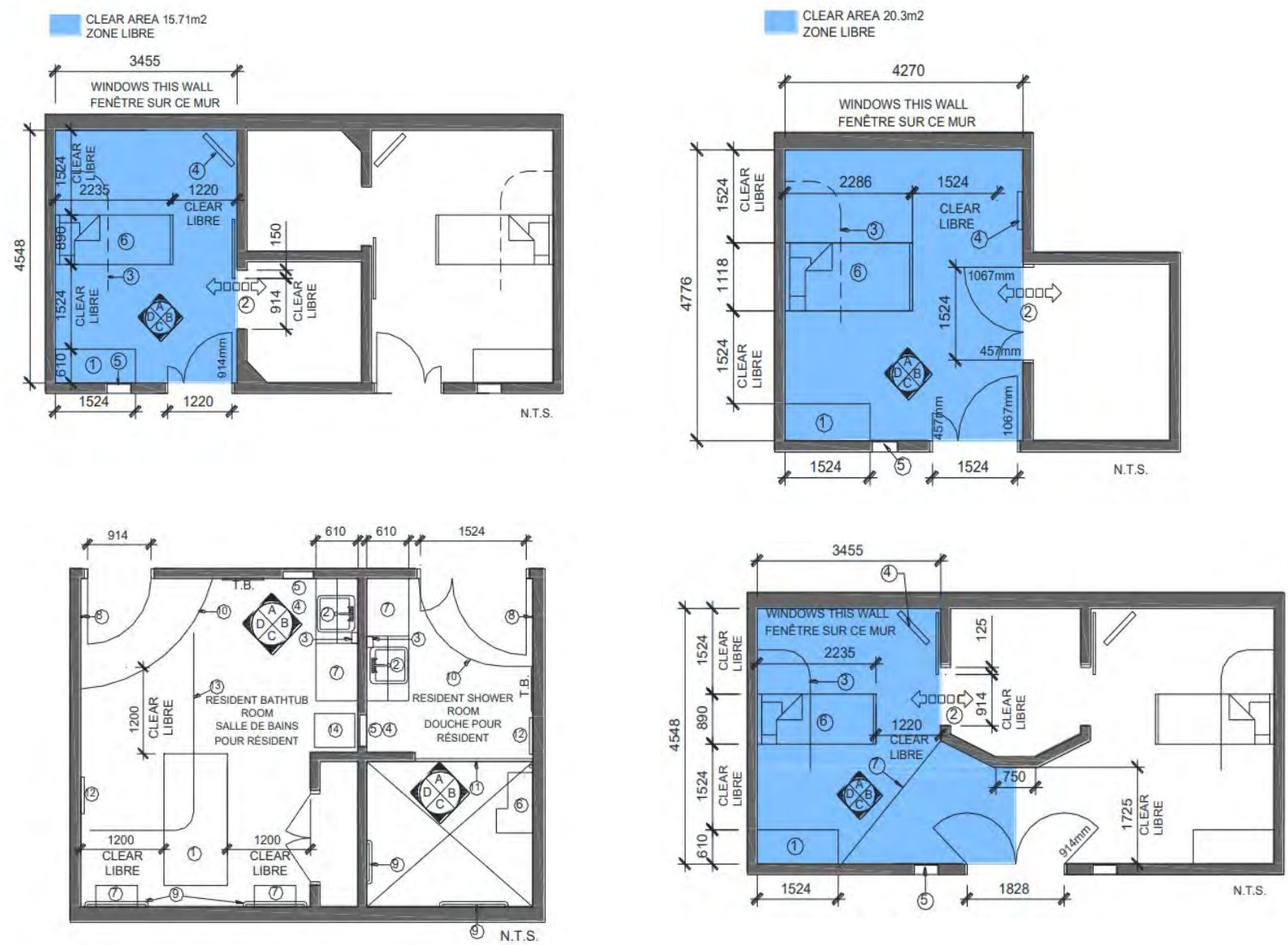

Figure 1.10 - Nursing Home Unit Design Standards

${ }^{1}$ Department of Social Development. (2015). Design Standards for Nursing Homes version 3.0, New Brunswick 


\subsubsection{Building Requirement: Stairs, ramp, hallway sizes}

The typical stairs, ramp and hallway sizes are referencing the current ADA standards for accessible passage ways and egress. In addition to the existing accessibility requirement for residents with mobility deficiency, there is a social distancing of two meters between individuals that is a consideration for future pandemic prevention. Proposed passage ways should consider the above two factors in all ramps, stairs and hallway minimum distancing.

\subsection{Senior Well-Being: Current model for physical and mental health in relation to architecture}

Physical Well-Being

According to the Center for Disease Control and Prevention (CDC), seniors are recommended to maintain one hundred fifty minutes of exercise per week with ten to thirty minutes intervals depending on one's current fitness levels. Four categories of fitness are broken down into Aerobic, Balance, Flexibility and Strength-training. Different exercises are grouped into different categories, which are then associated with a facility. $^{1}$

\begin{tabular}{|l|l|l|}
\hline Exercise & Categorles & Facility \\
\hline Brisk walking & Aerobic & $\begin{array}{l}\text { Walking on ramps, indoor walk + } \\
\text { landscaped roof garden }\end{array}$ \\
\hline Stationary Cycling & Aerobic & Indoor gym \\
\hline Swimming & Aerobic & Swimming pool \\
\hline Squat & Balance & Indoor gym \\
\hline Tai Chi & Balance \& Flexibility & Zen garden \\
\hline Arm weights & Strength-training & Indoor gym \\
\hline Calisthenics & $\begin{array}{l}\text { Balance \& Strength- } \\
\text { training }\end{array}$ & Outdoor \& Indoor training \\
\hline Stretching & Flexibility & No fix location \\
\hline Yoga & $\begin{array}{l}\text { Flexibility, balance, } \\
\text { strength-training }\end{array}$ & Yoga room \\
\hline
\end{tabular}

Figure 1.11 - Physical Well-Being relationship

${ }^{1}$ U.S. Department of Health and Services. (2018). Physical Activity Guidelines for Americans, $2^{\text {nd }}$ edition. Washington, DC. US. Department of Health and Human Services 


\section{Emotional Well-Being}

In order to maintain the well-being of senior residents' mental health, there are multiple ways to help seniors with loneliness. Physical fitness, social activities, hobbies and visits from friends and family decreases lonely time and these would be paired with architectural interventions. Different fitness facilities are required to meet the needs of each senior. The dining experience could vary from an open table policy to conventional restaurant style. Facilities will also need to accommodate the visits of family and friends, therefore, common spaces or guest spaces are needed to be incorporated into the building. Amenity spaces for hobbies and activity clubs would be primary spaces in the proposed building aside from the residential units.

\begin{tabular}{|l|l|}
\hline Remedy & Facility \\
\hline Embrace a positive body image & Physical training and facility \\
\hline $\begin{array}{l}\text { Dine with other people as a way to increase } \\
\text { social connection }\end{array}$ & Shared Dining facility \\
\hline Daily and weekly visits from family and friends & $\begin{array}{l}\text {-Spaces to attract young people to meet } \\
\text { their elder family members }\end{array}$ \\
\hline $\begin{array}{l}\text { Hobbies (Arts \& craft, wood working, cooking, } \\
\text { gardening, bible study, bingo, quilting, card } \\
\text { games.) }\end{array}$ & $\begin{array}{l}\text { Arts \& Craft Room, woodworking shop, open } \\
\text { shared kitchen, Game Hall, Praying Hall, } \\
\text { hobbies room }\end{array}$ \\
\hline Go on outing (visit a museum, library, park, etc) & Transport services (special shuttle bus stops) \\
\hline
\end{tabular}

\section{Figure 1.12 - Ways to help seniors with loneliness}

Both physical and emotional well-being can be accommodated by the intervention of architecture, and the proposed building shall conform to the recommendations outlined by the CDC to provide facilities and amenities for the aging population. In addition to architectural solutions to improve the quality of a senior's daily activity, other opportunities shall be created with its environment. For example, there shall be a dining area where seniors are encouraged to dine with fellow seniors to promote more social engagement within the senior community.

${ }^{1}$ U.S. Department of Health and Services. (2018). Physical Activity Guidelines for Americans, $2^{\text {nd }}$ edition. Washington, DC. US. Department of Health and Human Services 


\subsection{New Direction: How to improve current model with architectural solutions}

Based on the required number of staff-to-resident ratio as outlined in the Staff Review within the Ministry of Health BC, the proposed number of unit types, staff and area are outlined below to fit into a typical office floor plate area in high density residential care model.

The ideal percentage of units allocated for each residential type is based on the level of support that caretaker and medical staff can accommodate within the spaces of the proposed building. Seniors with a higher level of independence take up more units in the building compared to more dependent occupants. This is due to the limitation of support area for less dependent occupants. The demand for living areas for dependent occupants is also relatively greater than for independent seniors. In general, support staff area and accessibility design requirements tend to take up more space per floor for occupants with dementia, nursing needs and assisted living. Often each category of residential type can share caretaker and medical staff within the group. This increases the efficiency of the staff-to-occupant ratio.

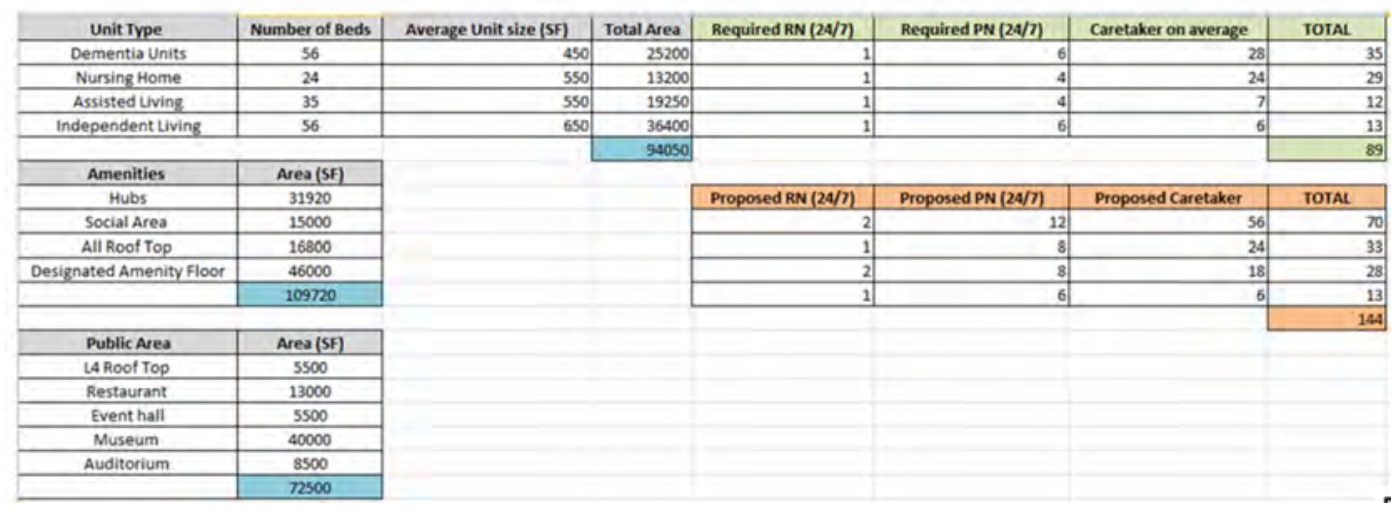

Figure 1.13 - Proposed Staff Requirement

\begin{tabular}{|l|l|l|}
\hline Residential type & Role & Percentage of units \\
\hline Independent Retirement housing & Fully independent & $35 \%$ \\
\hline Assisted Living & $\begin{array}{l}\text { Caretaker to help with } \\
\text { laundry, basic cleaning and } \\
\text { tidying services }\end{array}$ & $25 \%$ \\
\hline Nursing home & $\begin{array}{l}\text { Regular medical checkup } \\
\text { and medical treatment }\end{array}$ & $25 \%$ \\
\hline Alzheimer's special care unit & $\begin{array}{l}\text { Secured area for assisted } \\
\text { living }\end{array}$ & $15 \%$ \\
\hline
\end{tabular}

Figure 1.14 - Proposed Residential Type Distribution 
Chapter 02: Site Analysis 


\section{Chapter 02: Site Analysis}

\subsection{Downtown Vancouver Today: Urban vision}

Vancouver's downtown is the city centre and Central Business District (CBD) of Metro Vancouver in the Lower Mainland regions of British Columbia. The downtown area is fronted by the Burrard Inlet to the North and backed by False Creek to the South.

The waterfront of downtown consists of high-end residential towers where residents overlook the water and mountain views. These areas are among the most prestigious real estate zones in Vancouver. The business district visually blends into the waterfront residential tower area where most of the buildings have full glass façades. The dividing line between the residential and office towers is ambiguous, but generally speaking, the plaza, parks and streets with median street trees are often the barrier from the two zoning types.

With the increase of office towers outside of Downtown Vancouver, many foresee a new future for the current business district. The pandemic has also contributed to the decrease in demand for office space, which allows the opportunity to repurpose underutilized office towers into another and more needed use.

\subsection{Proposed Site: Rationale}

Office towers in city centre allow for high density occupancy with a smaller building footprint. With the trend of moving traditional office spaces to home offices or sizing down to collaborative workspaces, it is realistic that there will be a higher vacancy of office towers, which would provide options to convert former office space into senior care homes. The proposed building that this thesis uses as a model is well located in a city-centre zone where commercial, medical and public amenities are already nearby. 
While the thesis does name a specific site there is a general site selection guideline that can be outlined. The existing office towers that could be fitted for rehabilitating and repurposing shall meet the following criteria.

1) Access to park and open space

2) Multiple access to main road for emergency vehicles and trucks

3) Medium foot traffic for pedestrian and bike paths

4) Access to public amenities and medical clinics

5) Sufficient floor plate dimension and gross area to achieve efficient high density residential use

6) Sufficient tower distance for ventilation and view

The following existing building and site exhibits the above criteria and therefore it is selected for this project as a base model to repurpose an office tower into a high density senior tower.

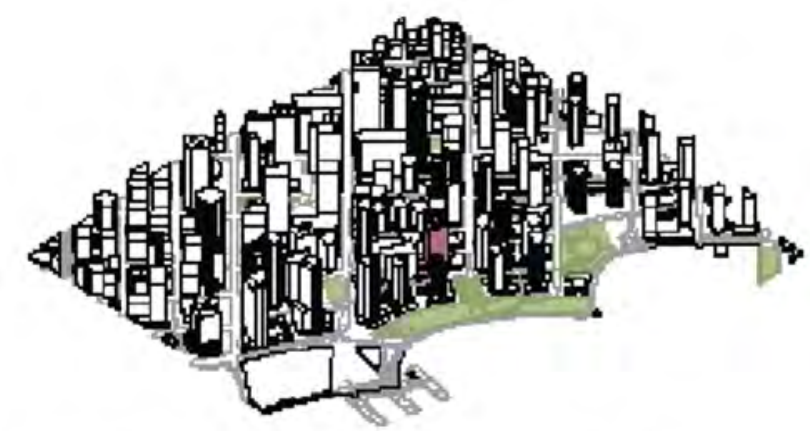

Proposed Site: 1177 W Hastings St, Vancouver, BC (Former: Board of Trade Tower)

Current usage: Commercial

Proposed usage: Mixed-Use/Facility and Residential for Seniors

Floor: $\quad 27$

Meters: $\quad 104.24 m$

Year bullt: 1968

GFA: $\quad 26733$ SM (287,753.76 SF)

Frame material: Reinforced Concrete

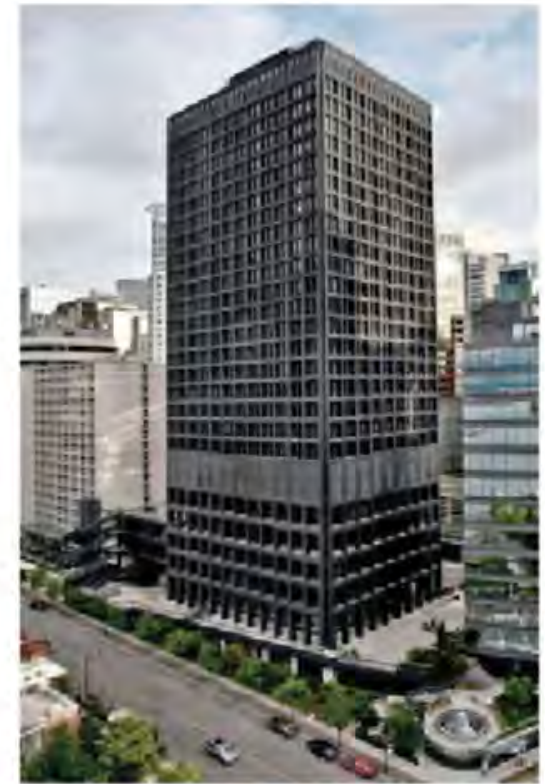

Figure 2.1 - Project Data 


\section{$\underline{2.3 \text { Site Description }}$}

\subsubsection{Green Space}

The open space and park around the site often hosts large city gatherings during festival days where foot traffic and vibrant urban life flows into the neighborhood. On typical days, the waterfront spaces are filled with cyclists, tourists, and city residents who would enable a livelier environment for senior residents nearby. Architecturally speaking, the urban public spaces are all shared between waterfront residential buildings and commercial office towers nearby.
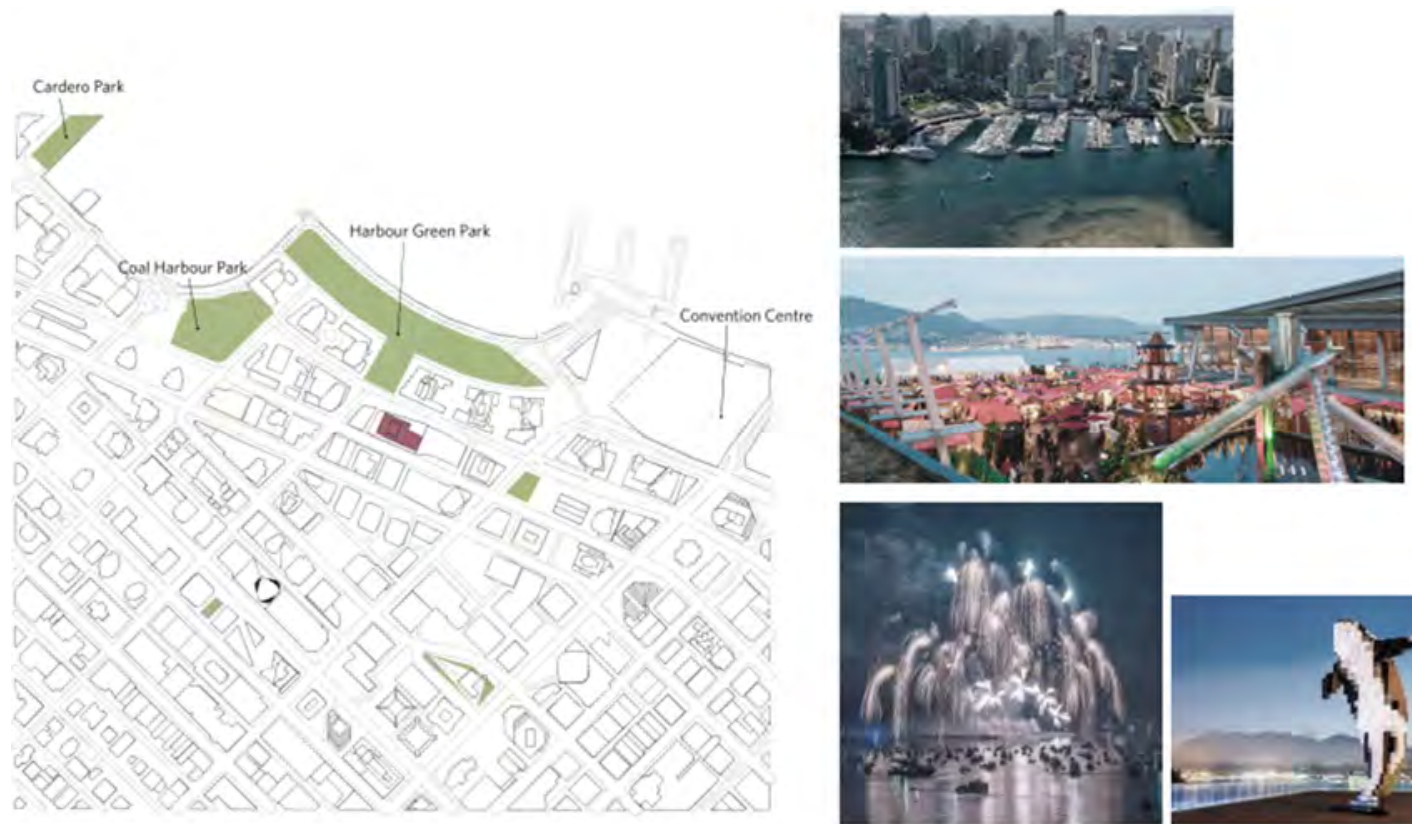

Figure 2.2 - Open Space and Park
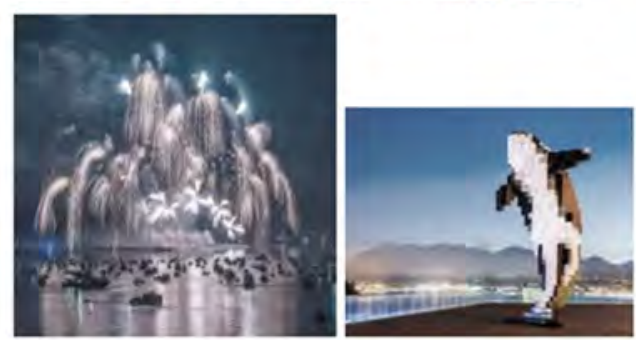


\subsubsection{Major Roads + Vehicular Access}

Multiple accesses to the site building will be necessary as different programs are intended within the tower. Existing loading areas would be kept to deliver medical supplies and supporting goods into the tower on a daily basis. Emergency vehicles also need quick access to the tower as medical attention and transportation to hospitals will be frequent for this type of building program.

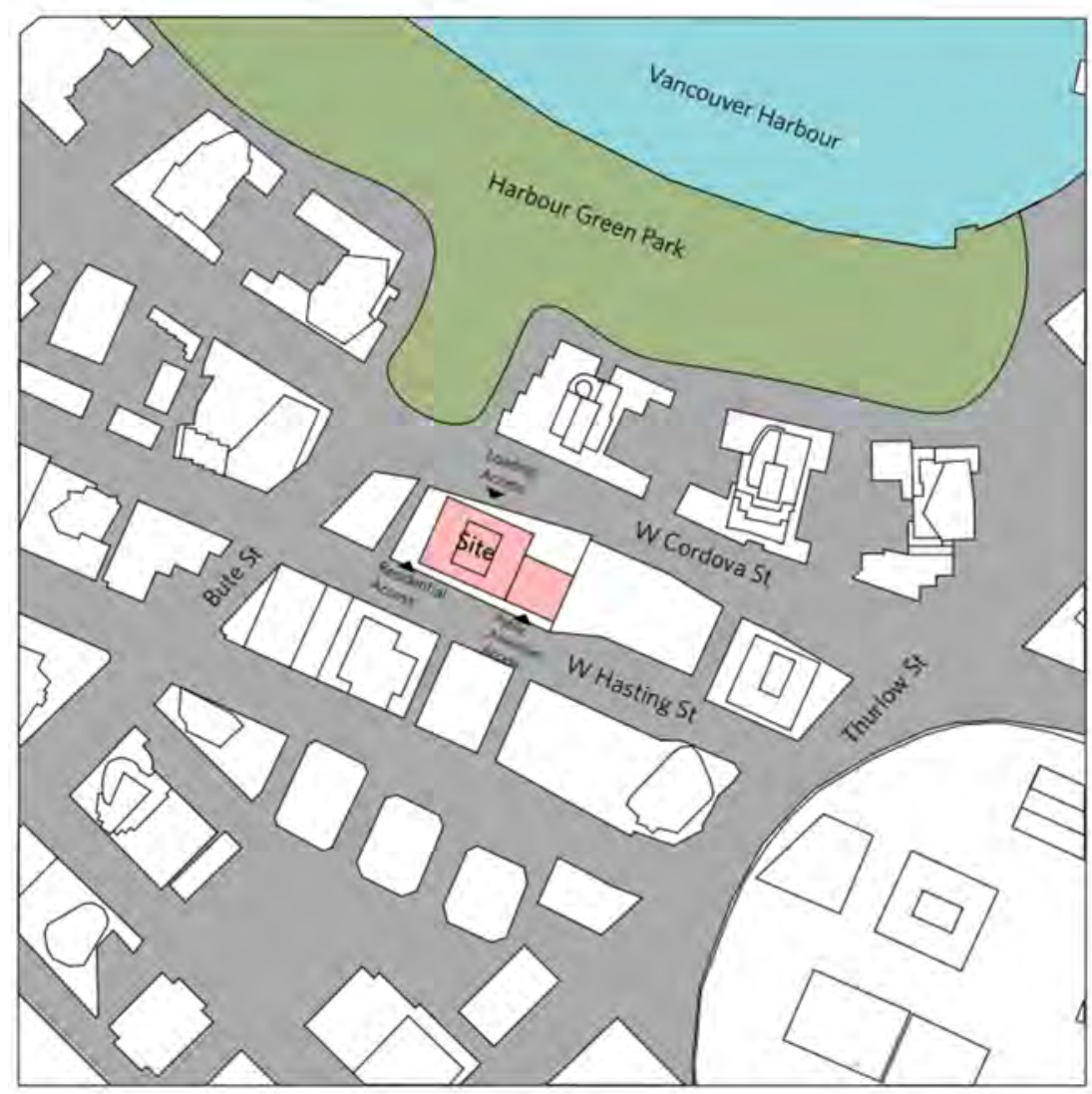

Figure 2.3 - Major Roads and Loading Access Diagram 


\subsubsection{Pedestrian Routes + Bike Paths}

In order to fulfill the needs of passive social interaction and unintended interaction between senior and the public, medium foot traffic around the site is recommended. A continuous pedestrian and bike route to different parks and open areas will direct foot traffic to the subject area and also draw people into the site and even inside certain areas of the re-purposed tower.

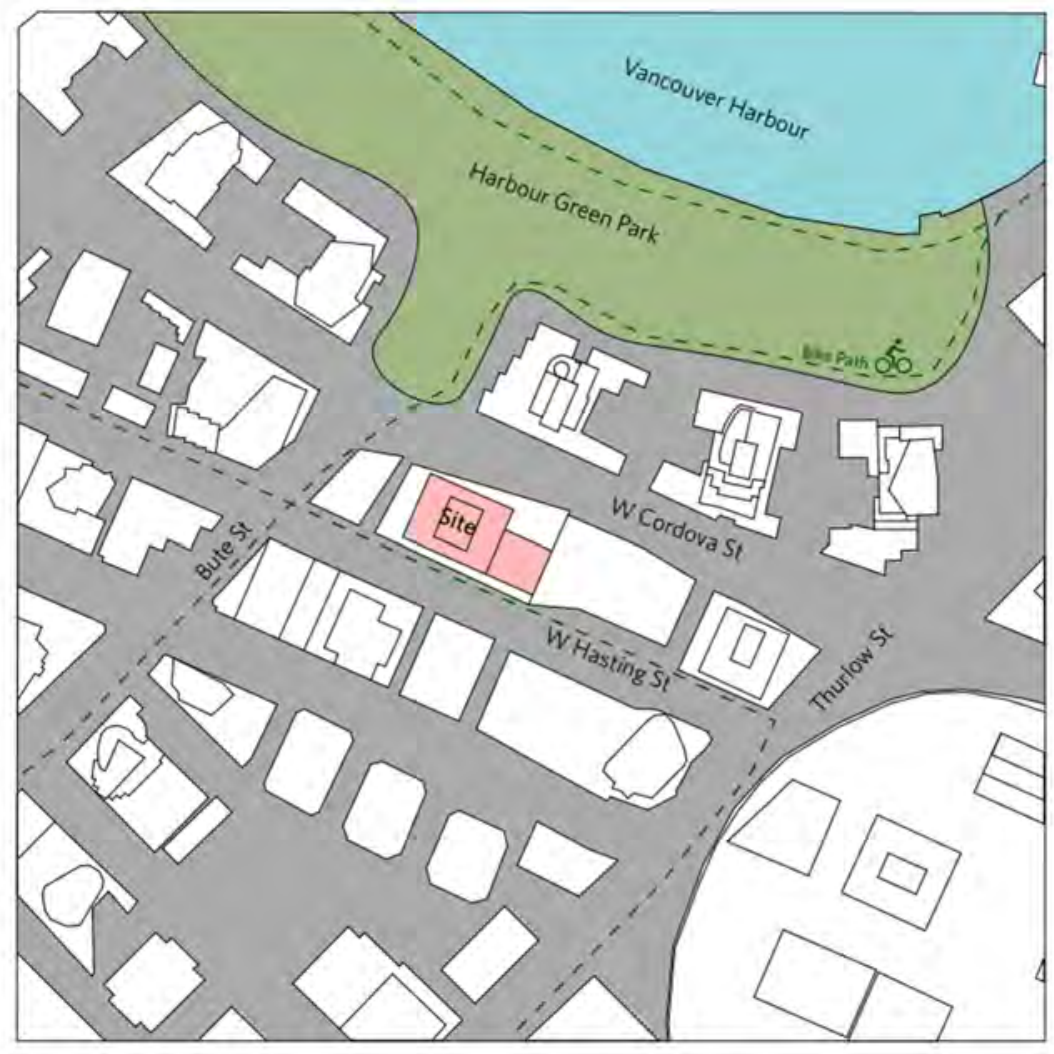

Figure 2.4 - Pedestrian Routes and Bike Path Diagram 


\subsubsection{Public Amenities + Medical Clinics}

The proposed site is in proximity to many pharmacy and health care services that may be crucial to many senior occupants. The connectivity to nearby community centres, recreational space, and arts and cultural institutions is also important to underscore, especially in comparison to typical, socially-isolated, suburban senior care homes.

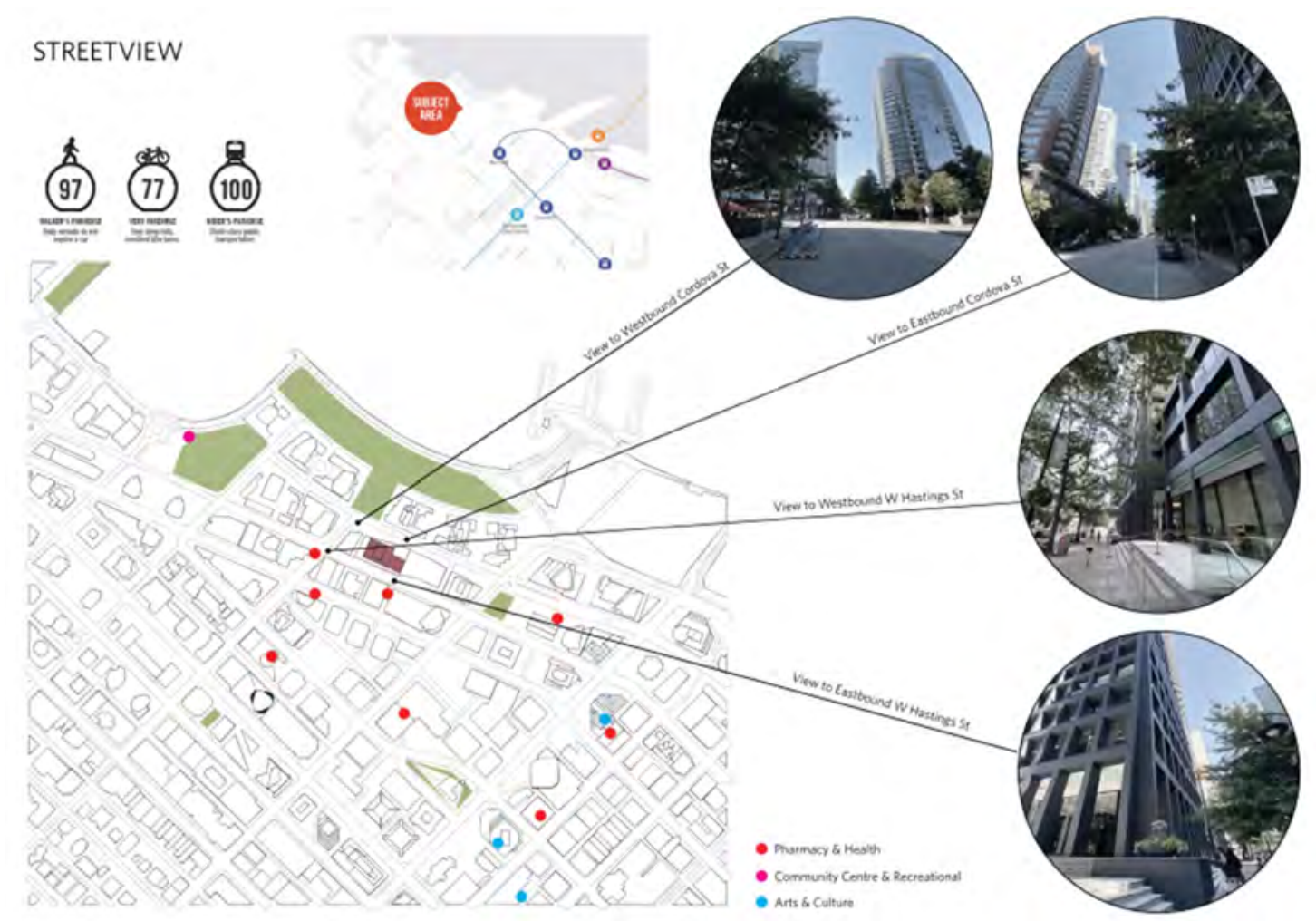

Figure 2.5 - Public Amenities and Medical Clinics 


\subsection{Goal: High density senior residential tower in the heart of downtown}

Downtown office structures are by definition already located near to city activities such as museums, main street cafés, high occupancy city waterfronts, and as such, redeveloping these towers into senior housing provides activities beyond mere "amenity rooms" and simultaneously brings middle-aged urban dwellers into greater contact with an older population. Likewise, locating a senior home in the city centre may also lessen the physical distance between families and friends where it becomes more convenient to frequently visit seniors. Finally, whereas the demographic in a suburban area is not as diverse and its density may not support larger group activities, the mixed demographic and increased density of a downtown location has the capacity to stimulate cross-generational interaction; in redeveloping office towers with their 9-5 white collar populations into buildings used around the clock and the week, leads to opportunities to create amenities in the building that welcome the public into the building for regular functions.

\section{Vision - Mandate - Mission}

What will high density senior care home achieve?

The high-density senior care home intends to centralize four categories of senior living under one roof. Independent seniors, assisted living, nursing home, and memoryimpairment special care will be the four categories of senior residences within the building. The building will have shared amenities for all occupants and it would also be able to interact externally with the growing city.

The idea of 'aging' should break the traditional thinking of living peacefully in a quiet neighborhood that is secluded from the general population. The proposed project is the inverse of the romanticized "pure and peaceful" senior environment, and would invite the seniors to actively and passively participate in the daily ongoings of the city. Nonetheless, the remade tower still needs to respond to provide a peaceful and comfortable environment for the seniors in the midst of the city centre. 
Chapter 03: Design Objectives 


\section{Chapter 03: Design Objectives}

\section{$\underline{3.1 \text { Programming }}$}

High visibility community building for senior and public within the downtown core

Goal: To provide a high-density senior tower in the heart of downtown Vancouver, creating a visible and distinctive image and profile.

- Building design and setting to reflect the different scale of social interaction/ circle/bubble

- $\quad$ Promote passive and active physical activity for seniors by placing series of ramp structures across floor levels as well as designated spaces for physical activities

- Common spaces on ground level and throughout the building would present opportunities for social gathering.

- Compact different community services and public amenities into a single tower in order to reduce travelling time and increase efficiency of public spaces. Community services such as medical clinics, pharmacy, recreational sports, and library. Public amenities would include art gallery, Green spaces, plaza and theatre.

- Ground floor as an extension of public realm, and an atrium for public event space. The goal is to connect seniors to the public with amenities and public spaces that offers activity to the general non-resident

Accessibility

- Different residential type would have different level of staff support to facility their day to day needs. The residential type are also divided into zone within the building, however, one can access anywhere in the building. There are also series of ramps that allow seniors with mobility challenges to move around conveniently 
3.1.1 Adjacencies: Relationship between different programmatic zones

Adjacencies are classified as either mandatory or desired; mandatory connections should be as direct as is feasible, and horizontal whenever possible.

Adjacencies can be both horizontal as well as vertical since there are many multi-level programs within the building and not all adjacencies can be via horizontal connections due to space restrictions.

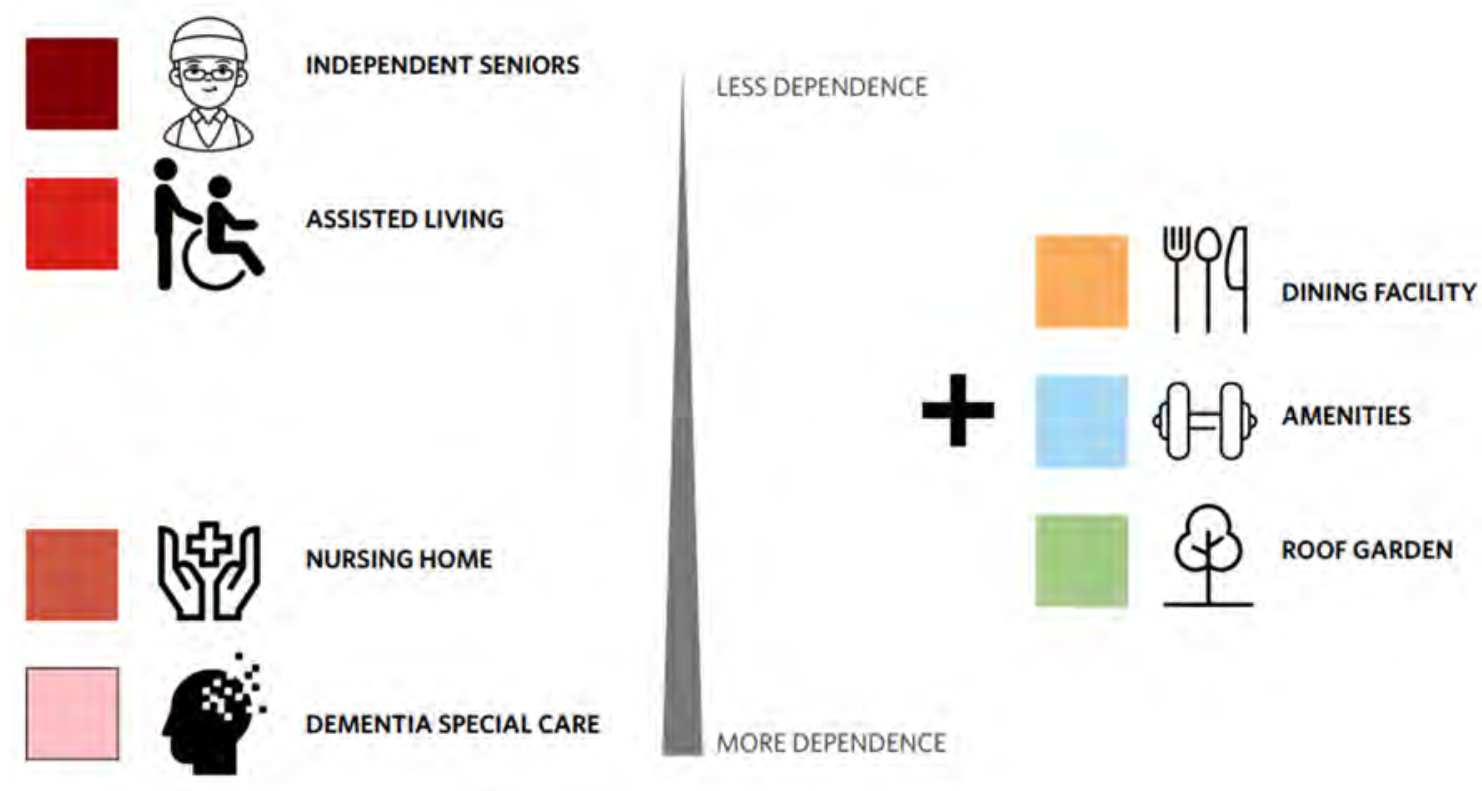

Figure 3.1- Adjacencies Diagram 


\subsubsection{Social Bubble: Concept of different level of socializing scales}

There are different scales of "social bubbles" so as to create a variety of spaces, large and small, allowing for all the different comfort levels amongst individual seniors. Within the more independent senior residential unit type, seniors would share basic areas such as a living room and kitchen.; this would be similar to the experience in a college dormitory where common spaces for seniors are encouraged for social interaction.

A second level of a social bubble would be a gathering space for several living suites where seniors would share a garden or community patio space with seating for seniors to interact.

The largest social bubble would be the Hub located on multiple floors. There are 12 Hubs within the building that house special programs: yoga hub, fitness hub, movie hub, pet therapy hub, etc. These social space are designated with a specific activity where seniors can share their experience with one and another.

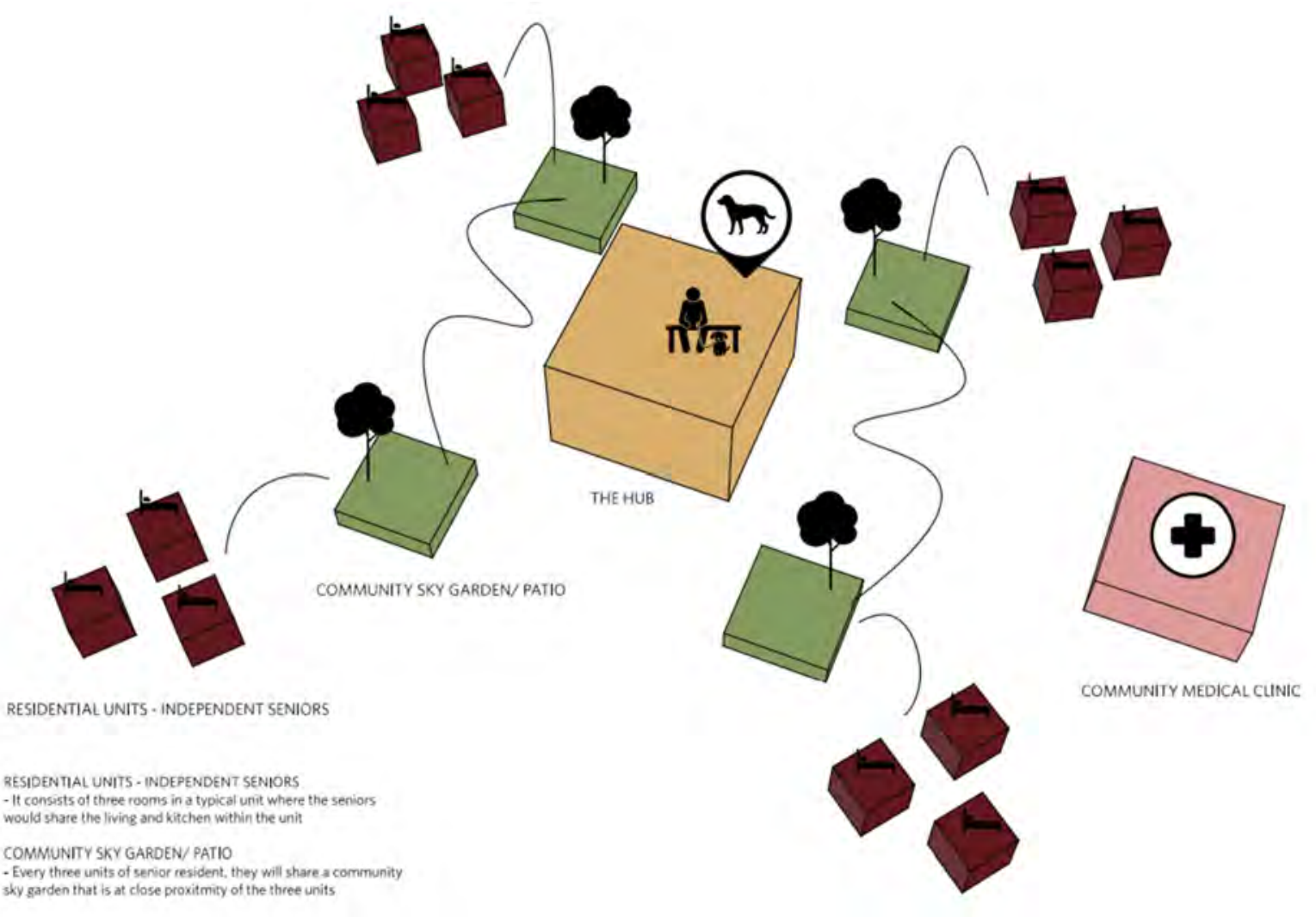

Figure 3.2 - Social Bubble Diagram 


\subsubsection{Interactivity for the city: Senior \& Public}

Interactivity - Physical

Physical interaction helps seniors' brain become more resilient. Simple activities like companion walking helps blood flow to the brain leading to a healthy heart and the more a senor interacts with others, the more it will aid in memory and cognitive function.

Interactivity - Emotional

Staying socially active combats loneliness and depression. By participating in community activities provided in the facility, seniors can maintain friendships and social interaction, which will help reduce some of the challenges of Alzhimer's Disease, lower blood pressure and maintain memory and cognitive function.

Interactivity - Public

Seniors are often isolated into a dedicated community, which may offer peace from the busy life of the workforces. However, the indirect and unintended participation of a city daily life could offer seniors purpose and sense of belonging to the city. Interaction with the public within the facility serves as an important space to connect seniors to the evolving social events of the greater population. 


\section{Create a high-quality Public Realm}

One of the advantages of locating a senior home within a city centre is the chance for still more active seniors to participate in the urban evening life with restaurants and cultural venues, including numerous activities that are free and/or that involve volunteerism. Enabling the involvement of seniors in city life furthers the understanding that while people may be older, they yet remain completely able to participate and contribute to the community.

Aside from the public amenities and commercial establishment around the site, the view from the proposed building would be a design consideration during the design analysis. Each facade faces a unique view and it creates opportunity to cater different program to complement the view.

In order to increase the public realm of the already established city core, the proposed building would have interactive program to invite public into the building and connect with the seniors.
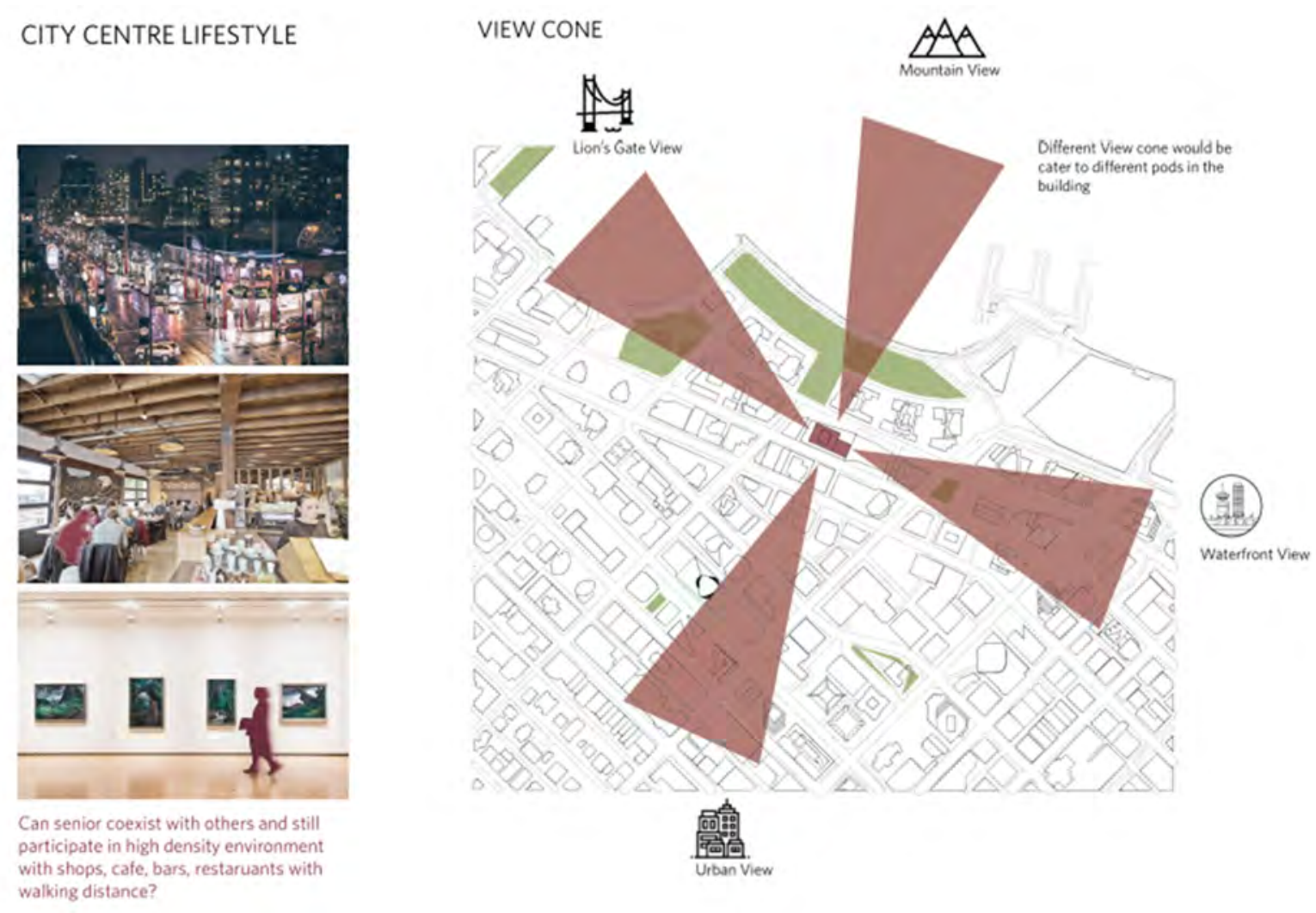

Figure 3.3 - Public Realm and View Cone Diagram 


\subsection{Circulation}

\subsubsection{Building Circulation: Interior ramps and circulation for resident}

Senior residents can be circulated through the building via different routes. The most direct method would be elevator where one can access any floor from one point, however, this method negates positive, unintended social encounters and interaction. A secondary circulation method would be ramps between two residential zones. This would be a long open ramp attached to the exterior of the building. There are also interior enclosed ramps that circulate within each discrete residential zone. Corridors are also designed such that a window opening would be placed at the end of the corridor to improve way finding

Stairs within the building consists of two types: exit stairs and interior circulation stairs. Typical exit stairs will adhere to Vancouver fire code and these are the existing fire stairs of the office tower. The interior circulation stairs service residents and staff within the same residential zone, and specifically are placed between medical spaces and living areas where medical staff can quickly move between floors for medical attention and clinical work.

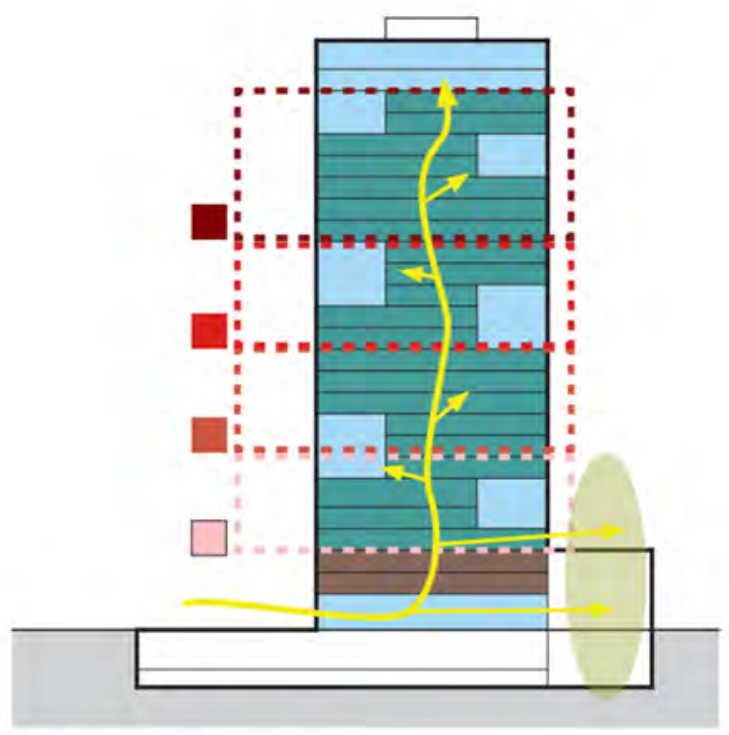

Private Circulation Diagram

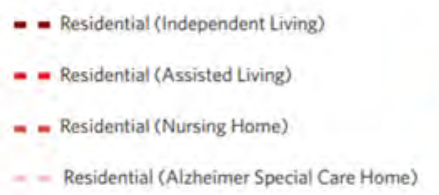

Senior Residential Area

Amenities

Staff Quarter

Public Area (Art Gallery \& Auditorium)

Figure 3.4 - Building Circulation Diagram 
3.2.2 Public Circulation: Drawing the general public into public amenities

An important component of the building design is to draw the general public into the senior care facility. The two types of public interaction would include family members of the senior resident and general public seeking other public programs within the proposed facility.

Family members - family members can use the same circulation access as residents and there are also designated rooms for companions to stay over for the night.

General public - Aside from family visits, other public programs such as a gallery, auditorium, restaurants, and pet therapy area are intended to draw the public into such areas by creating an iconic entrance and dedicated circulation. Areas of Pet therapy would also be a feature to have children and seniors to coexist where the two age group could interact.

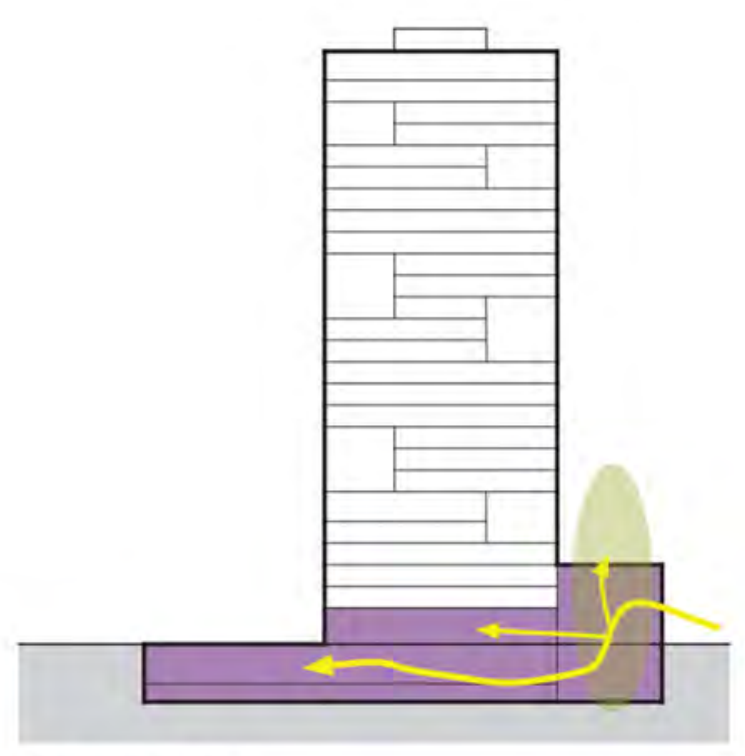

Public Circulation Diagram

Private and Public Crossover Area

Figure 3.5 - Public Circulation Diagram 


\subsection{Program Elements}

3.3.1 Arrival: Residential Lobby and Public Lobby

The main lobby of the senior resident towers will consist of a waiting area as well as exhibition space much like a hotel lobby. The idea is to welcome both residents and their guests into a controlled area with comfort. The lobby is also linked to a restaurant fronting the street, which is also open to public to use. A secondary lobby will be adjacent to the residential lobby. The secondary lobby is the entrance that draws the general public to the underground auditorium and gallery space. The lobby atrium offers an internal glazing from the residential tower to view into the atrium.

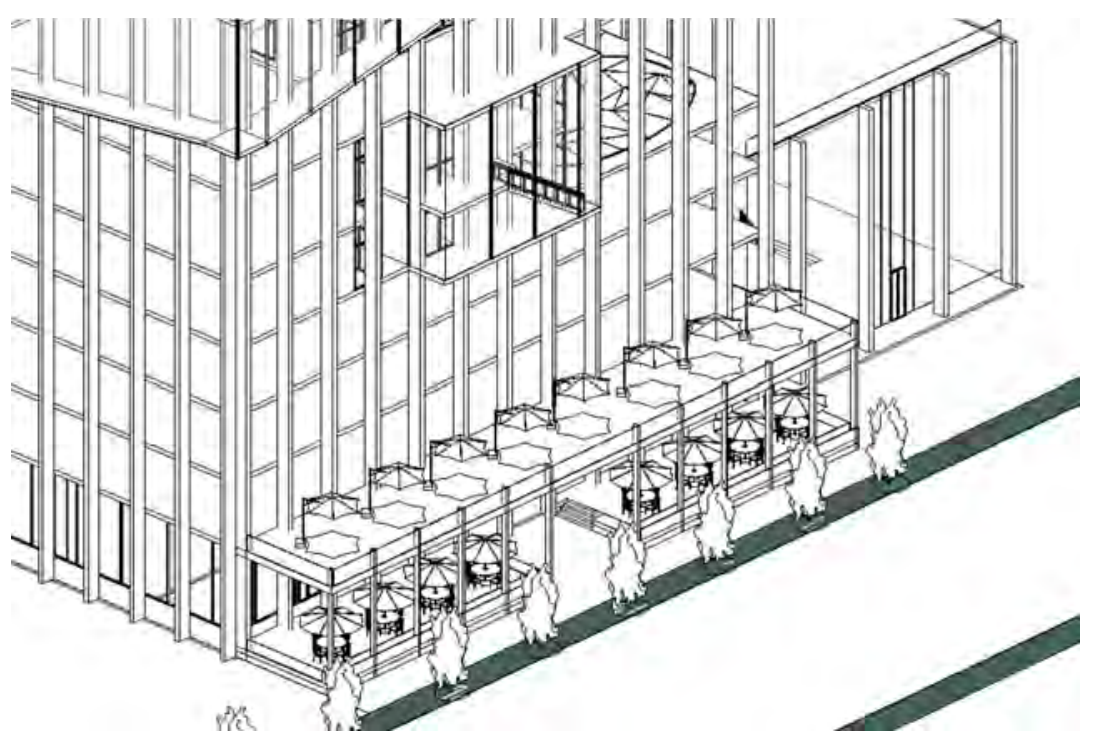

Figure 3.7 - Public Realm and Residential Lobby

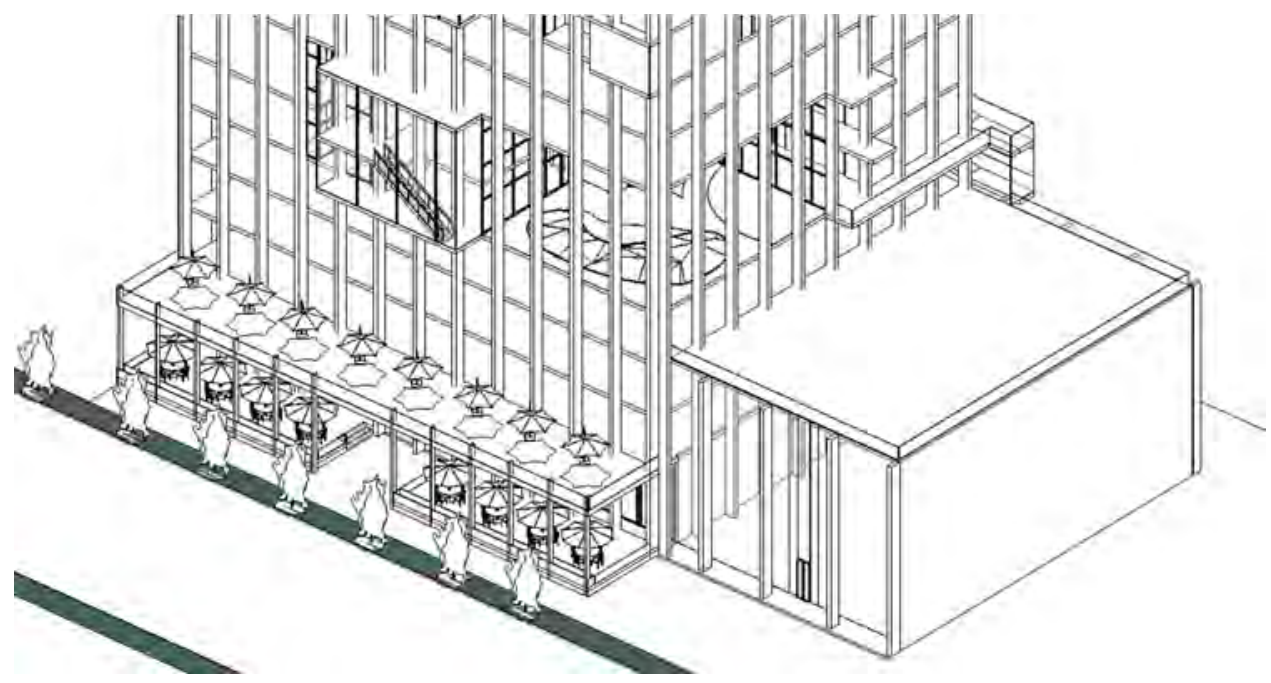

Figure 3.8 - Public Lobby 


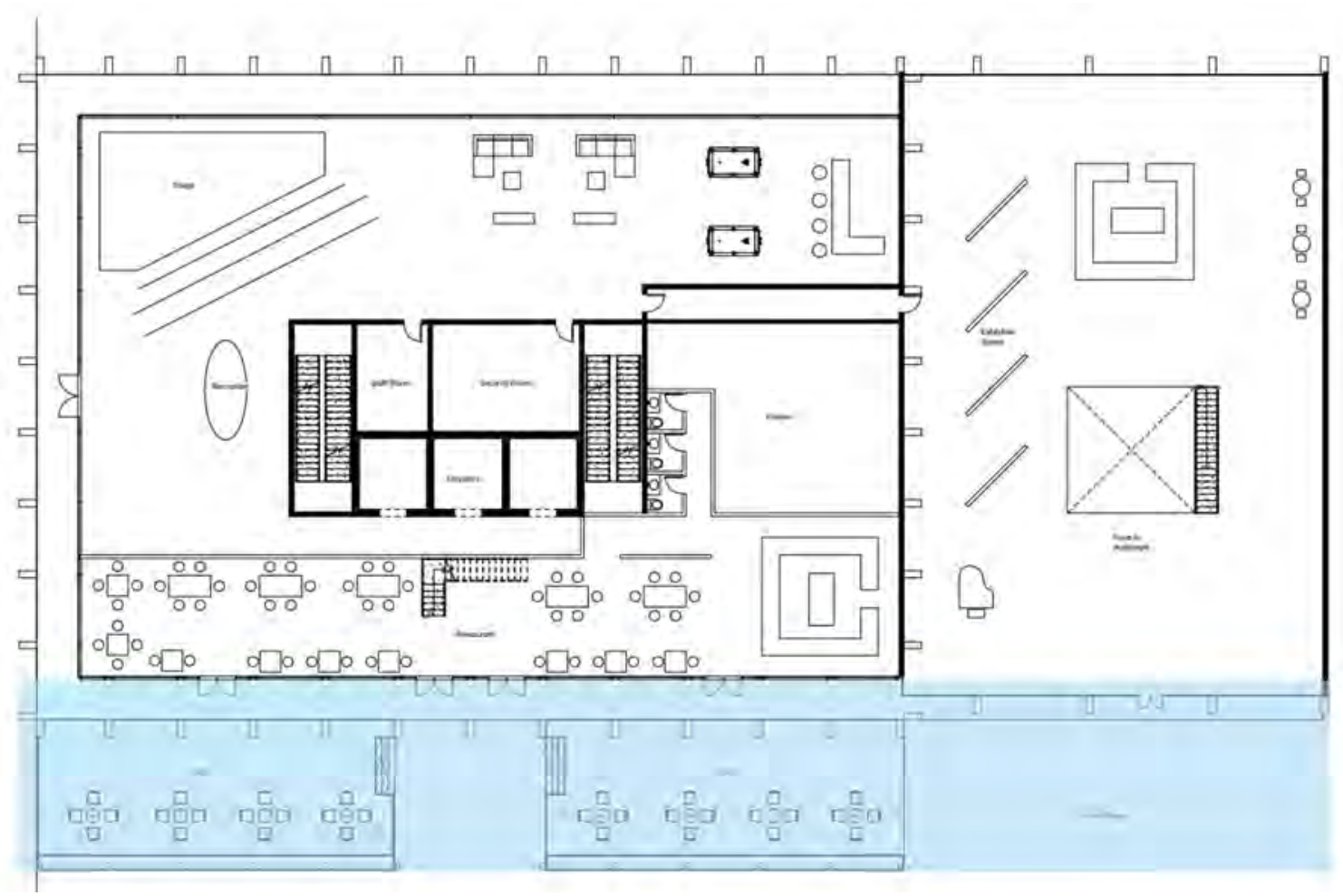

Figure 3.9 - Level 1 Plan

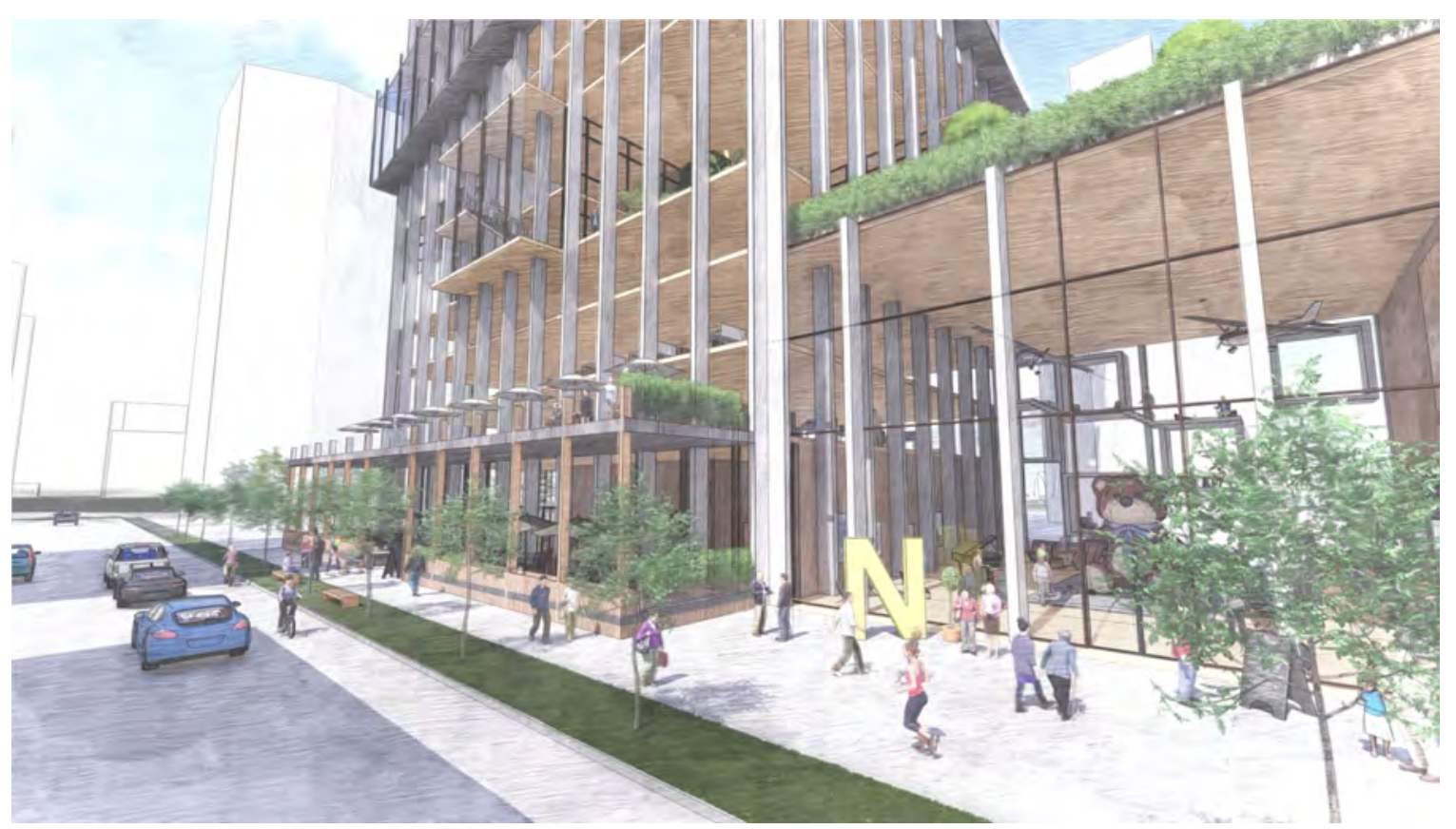

Figure 3.10 - Street Level Rendering 
3.3.2 Social Bubble: Three levels of socializing scales

As mentioned in 3.1.2 Social Bubble: Concept of different level of socializing scales, the social bubble is divided into 3 levels of scales.

\section{$\underline{\text { Level } 1 \text { Social Bubble - Residential Unit (Independent) }}$}

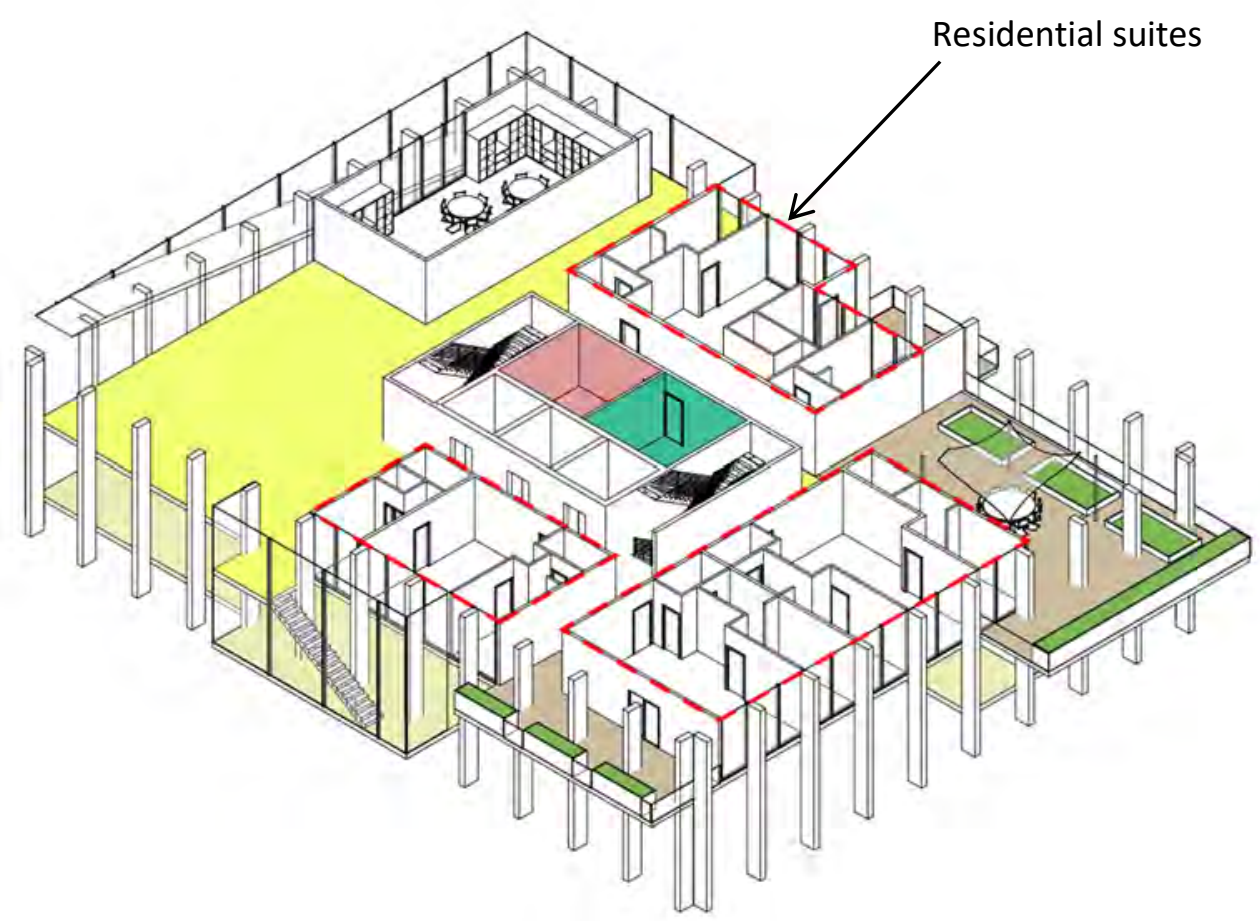

Figure 3.11 - Level 1 Social Bubble

Independent seniors are grouped with 2-3 other suitemates to share a common kitchen and living room similar to a college dormitory. The idea is to offer widowed seniors or any seniors who would find themselves living alone otherwise, to have a companion to live together and share space together as each other's company. There are independent washrooms per room for each senior so privacy can still be maintained. 
Level 1 Social Bubble - Residential Unit (Assisted Living)

Some assisted living seniors are mentally capable, however, their mobility is restricted. The room configuration would adapt to accessibility standards while the program of having shared kitchen and living space would be the same as for the independent seniors.

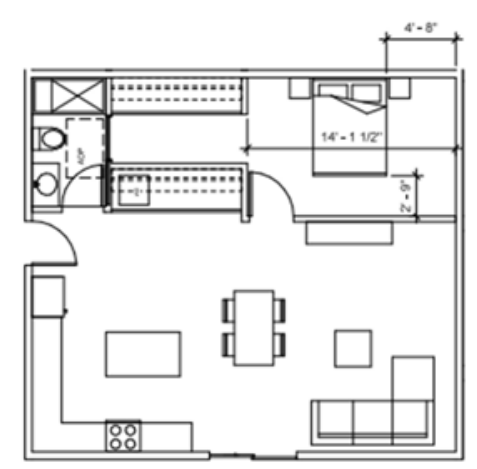

Figure 3.12 - Typical Unit Plan - Independent 
Level 1 Social Bubble - Residential Unit (Nursing Home)

Many seniors in the nursing home zone would require daily medical assistance from resident nurses. Their medical needs may prevent them from sharing too much space with other seniors, thus, these should be be more private. In these cases there would be no sharing of living room and kitchen since food would be delivered to these nursing home units.
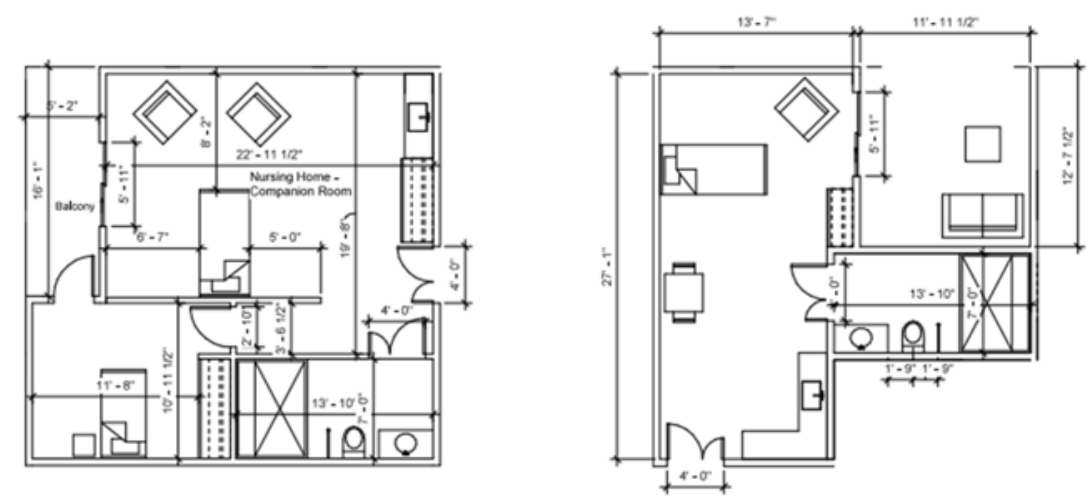

Figure 3.13 - Typical Unit Plan - Nursing Home
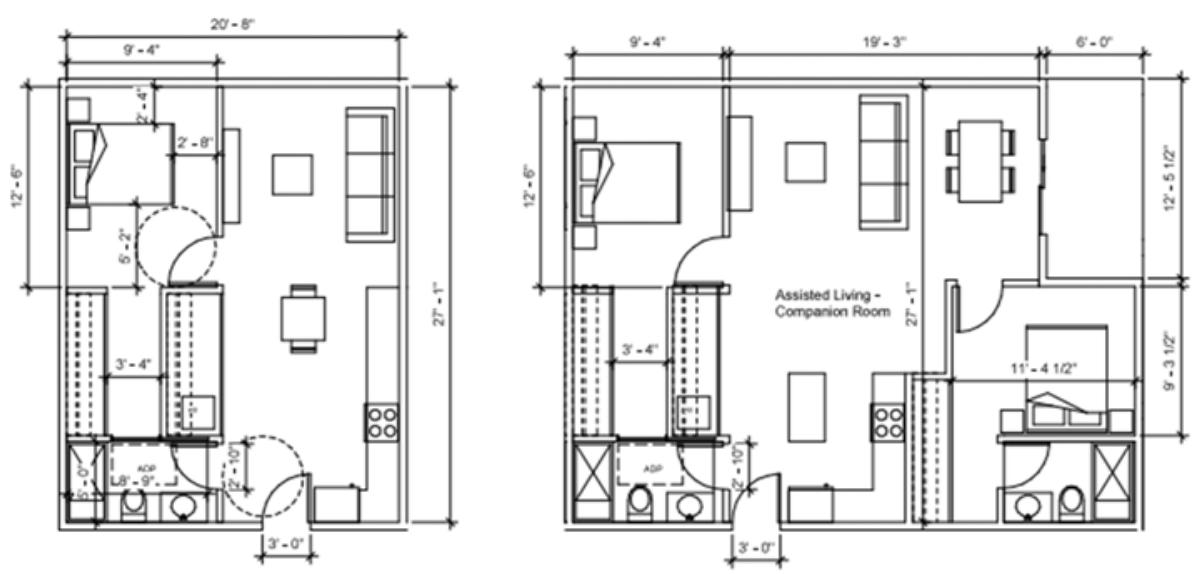

Figure 3.14 - Typical Unit Plan - Assisted Living 


\section{Level 2 Social Bubble - Sky Garden/ Courtyard}

Sky Garden/ courtyards are shared between two to three suites where the number of residents socializing in these area would be no more than 9 people. Smaller group settings decrease the feeling of being intimidated by the social setting. In addition, the three suitemates would already have prior relationship with each other and this promotes the sense of comfort while they meet other suitemates. Together, a sky garden could provide residents with small projects to work on and also to gather during the day. It is in close proximity to their respective suites.

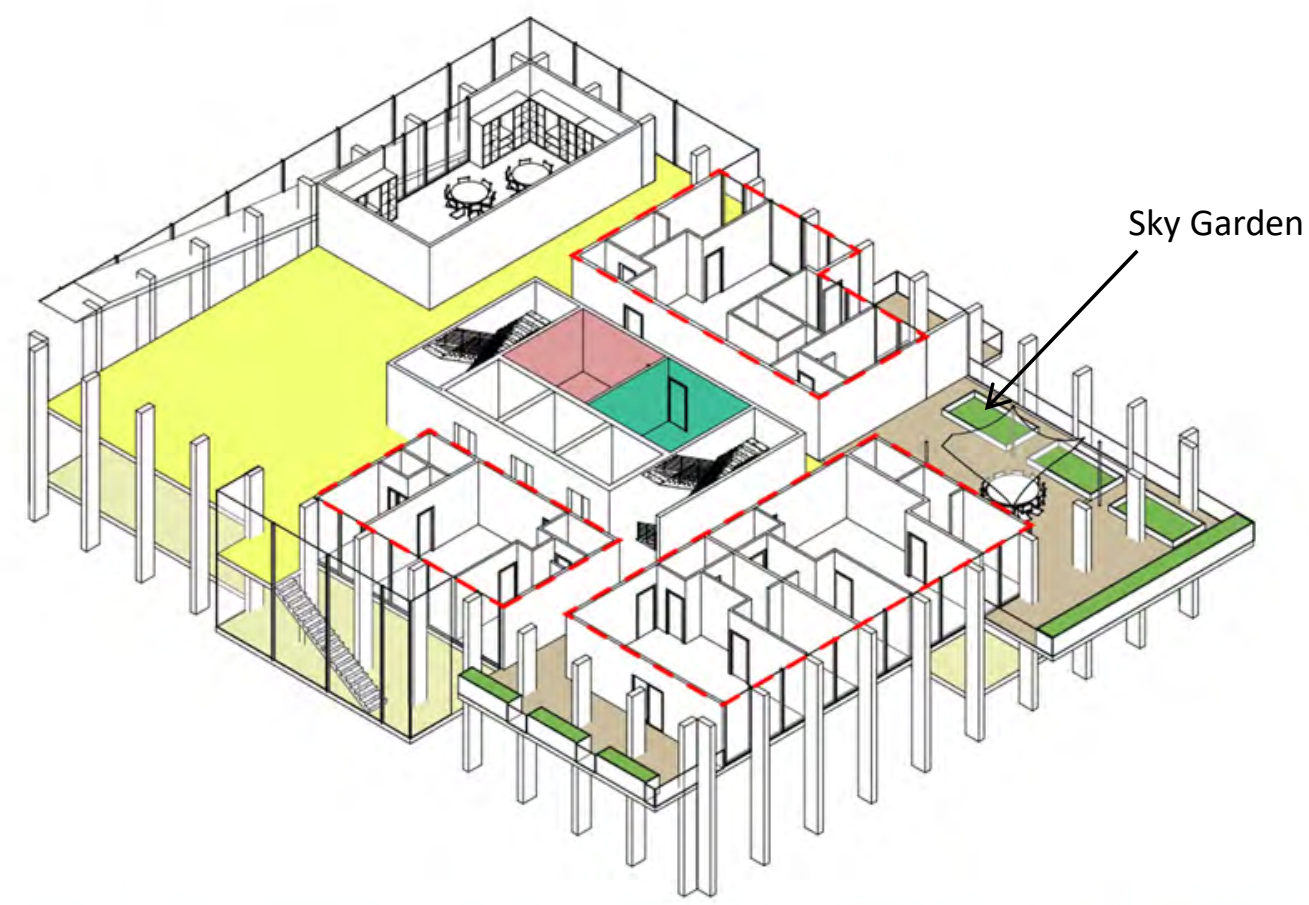

Figure 3.15 - Level 2 Social Bubble
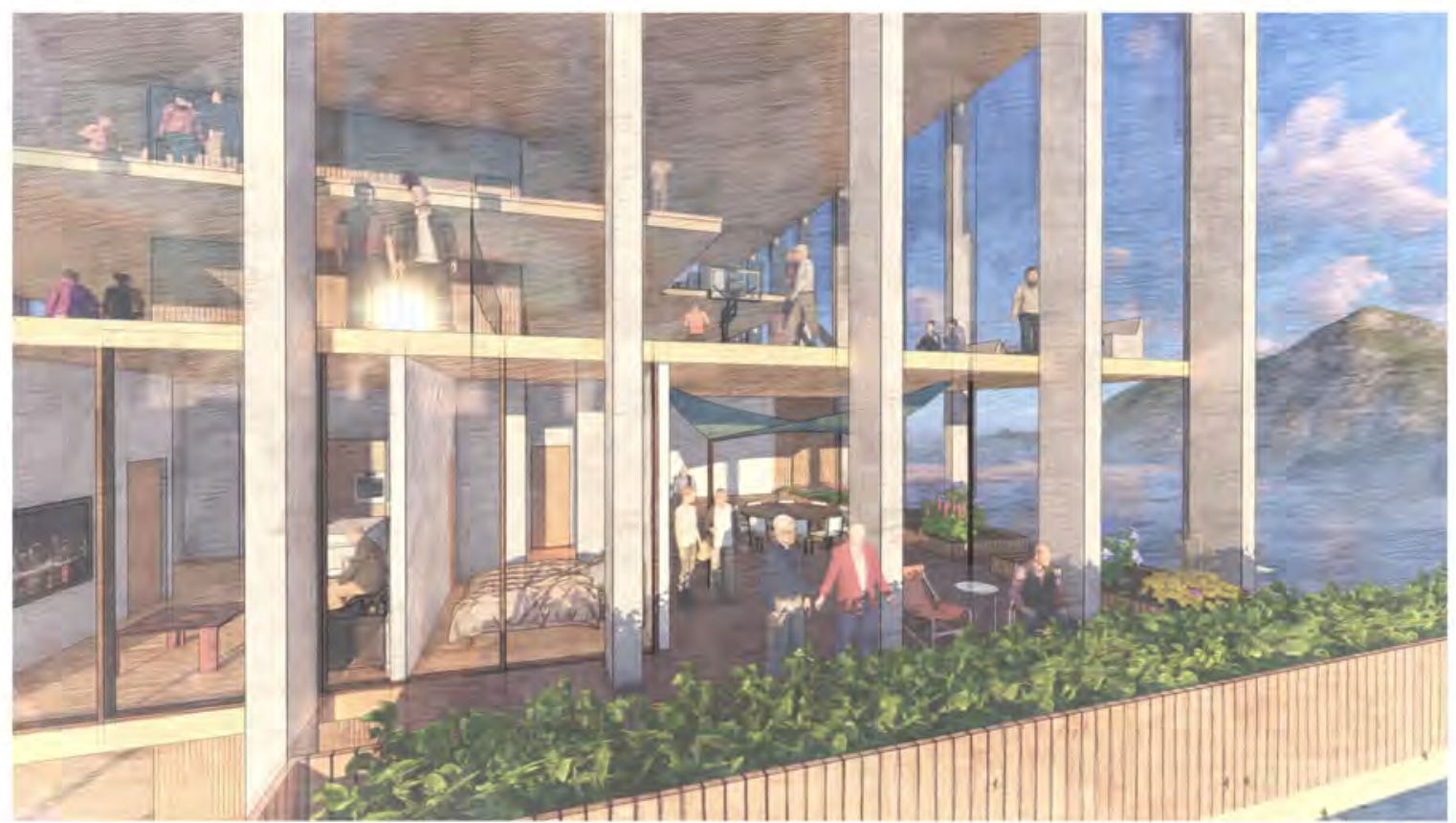


\section{Level 3 Social Bubble - Hub}

The Hub is the largest socializing space within the building. There are a total of 11 hubs with different programs distributed every several floors to service all residents in the tower. These areas would see a higher mix of residents from different residential types and permit them to mingle in one collective space. For example, a large theatre Hub that screens movie for residents would be open for seniors from assisted living, independent living as well as other residential types. It offers the opportunity for residents to learn and share thoughts with seniors outside of their smaller living-suite type.

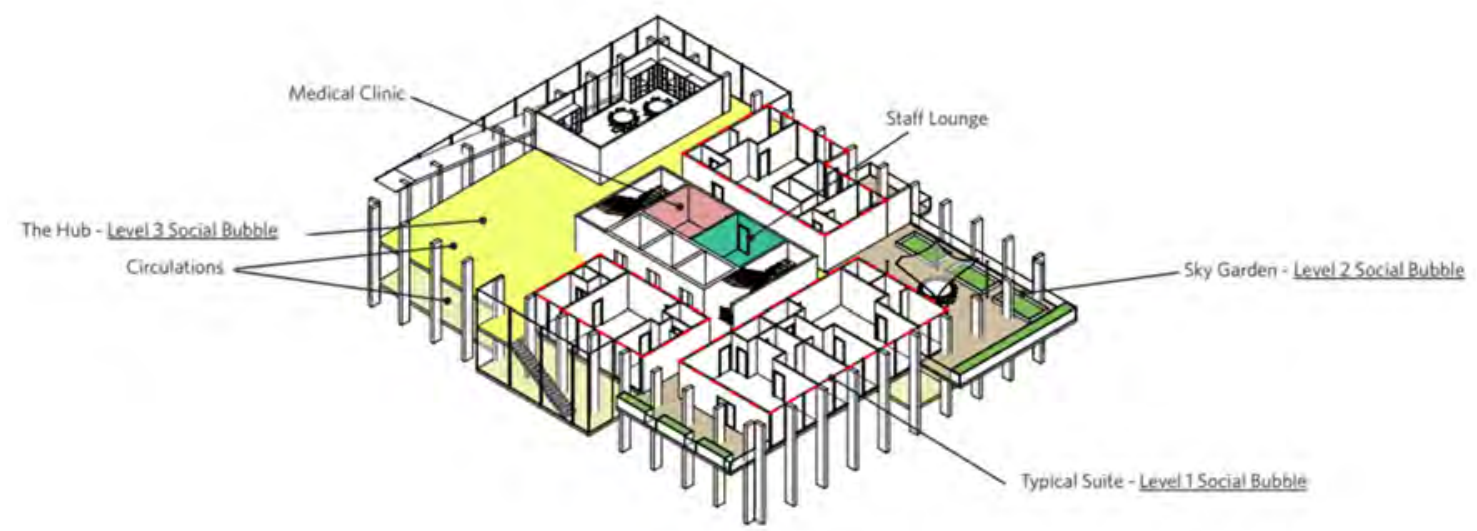

Figure 3.17 - Social Bubble Overview

3.3.3 Hub: Interactive space for residents 
A majority of the residential amenities would be hosted in one of the eleven Hubs throughout the building. Each hub is distributed on different floor and spans multiple floors to create a large volume of space. Located in a different quadrant on each corner of the tower, each Hub offers a different view to the city and cityscape. The hub is also planned according to the residential type where accessibility of different resident are taken into account. More independent residents are in the upper part of the tower, therefore, more physically engaged programs are placed in the upper tower.

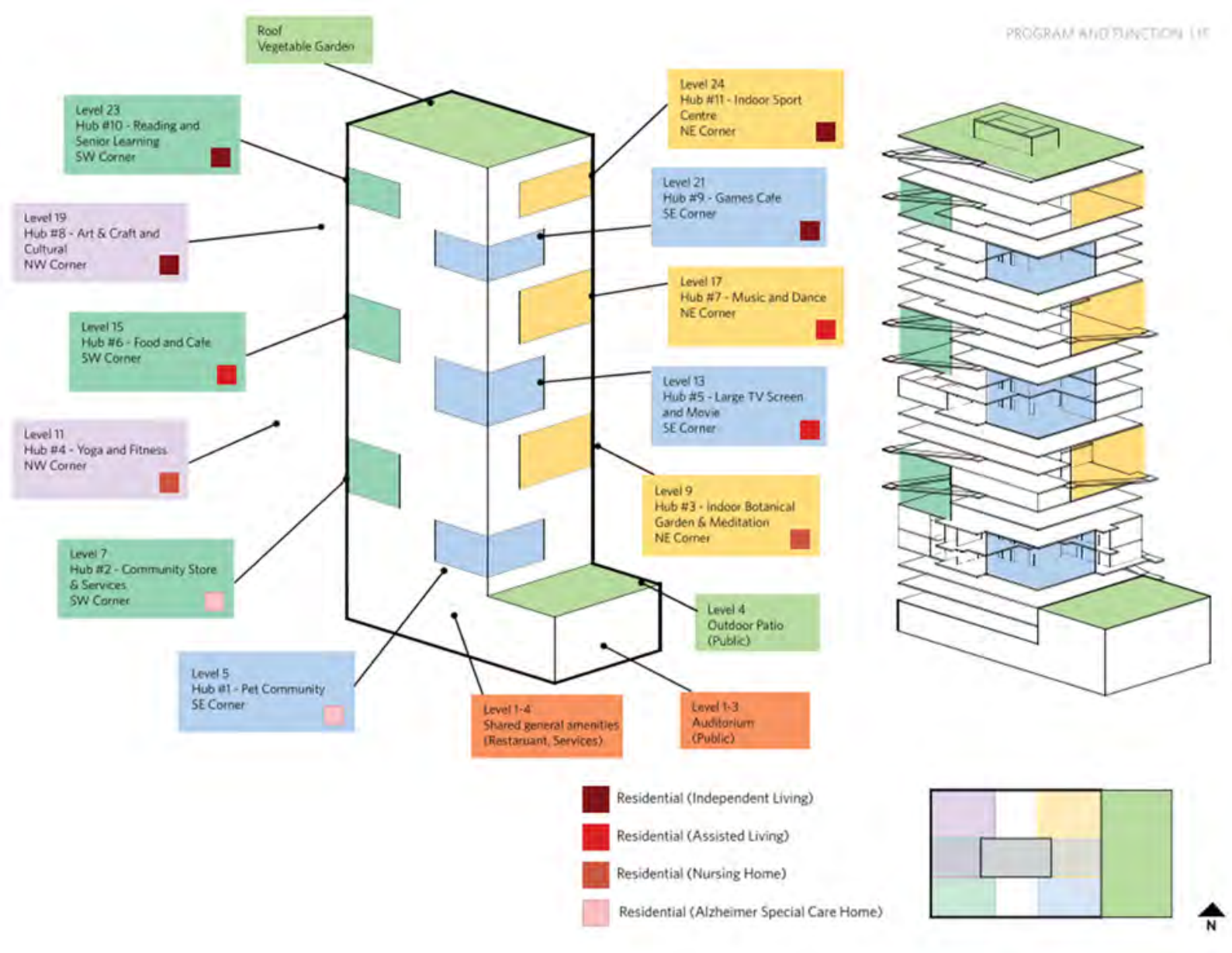

Figure 3.18 - The Hub Overview 


\subsubsection{Medical: Staff role \& operational area}

The medical staff in the building consist of registered nurse and practical nurses. The day-to-day medical check-ups would be administered by registered nurses and depending on the residential type, seniors with different needs will require different levels of attention. Seniors requiring more serious medical attention, such as nursing home residents, will have the most attention from medical staff. Nursing home residents would have a larger medical clinic with more staff as the ratio is different. While a small medical unit would be placed on each floor for other the residential types, the medical units are to be connected by an internal circulation stairs for staff to move up and down.

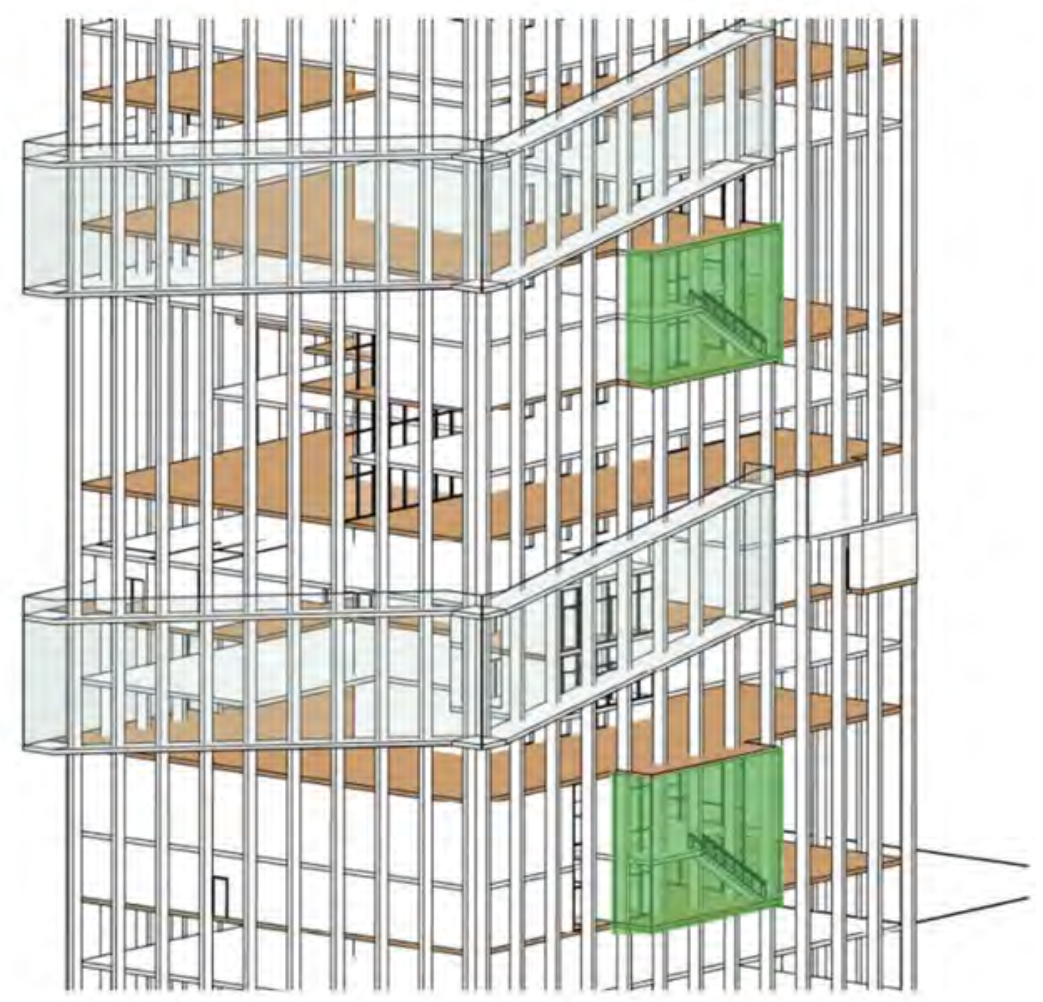

Figure 3.19 - Medical Clinic Exterior Expression

These extruded circulation volumes are located within each residential zone, which allows staff to have quick access between floors. These volumes also serve as a portals to the outside at the central elevator lobby of each floor. 


\subsubsection{Support: Caretaker, Morgue, Administration \& Custodian}

\section{Caretaker}

A staff room is located at the center of the building right next to the core walls. For the designated staff to take care of the seniors on the floor. Their duty would include personal hygiene, meal delivery, accompany for physical activities, and general caretaking of seniors.

Morgue

It is inevitable for humans to reach their end of life and many residents from the nursing home unit would spend their last moment in the facility. In order to maintain a high level of sanitary standards, a deceased body will need to be transported and stored temporarily before being take away for examination. A temporary morgue would be located at the basement level of the tower where it is kept away from the eyes of the resident. This is to decrease the stress of a reminder of death that maybe closely related to their age.

Administration

Office space is allocated in the bottom floor in order to house administration staff. The space will be a modern office setting where staff does not have a designated location to work. It is an open office concept with many seating areas and group meeting rooms.

Custodian

Custodian staff would have designated supply rooms and staff room that will service few floors per residential type. 


\subsubsection{Public Amenities: Gallery and Auditorium}

The intention of public amenities is to attract the general public into the building where they could have the opportunity to interact with the seniors in the tower. Two large programs will take up the underground space of the tower. Partial underground parking is repurposed to create an underground black box gallery space and also an auditorium. The gallery space allows exhibition of art and sculpture and it could also have interactive art programs for seniors and the public. The auditorium is to host guest speakers and art performances. The general public would use the "plinth" on the side building as the main entrance to all public amenities; it is crucial to create a bold and eye capturing structure to draw people into the building

\subsubsection{Loading: Emergency, truck, general public}

General loading will be at the north entrance fronting Cordova St. A ParaTranspo station will also be at the same level as loading. The entrance on Cordova will lead into the core where residents and guest could take an elevator to the main floor access to West Hasting St. Due to the different height of the street, there will be two entrances fronting a city street at the different levels. Emergency vehicle and passenger drop off area is accessed through Cordova St. while truck and morgue vehicle can access the underground via parking entrance on West Hasting St. 
Chapter 03: Design Proposal 


\section{Chapter 04: Design Proposal}

\subsection{Massing Studies}

MASSING STUDY

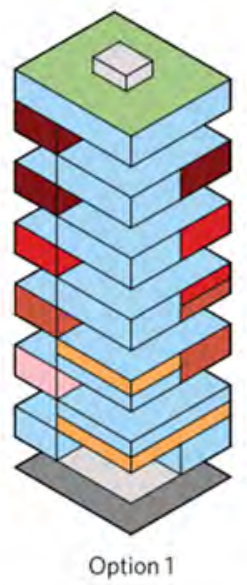

Resident with more independence abilities would occupy the upper floors since there will be less support stafi needed to move up and down to the circulation to those higher floors.

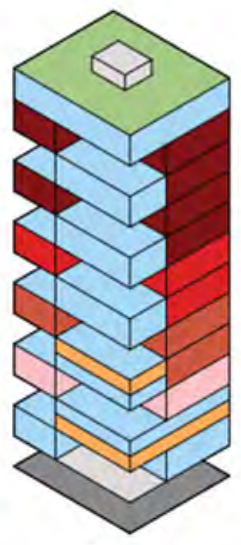

Option 2

Density are added back into the building and it is filled along the North side of the building as priority since the North side has a waterfront frontage

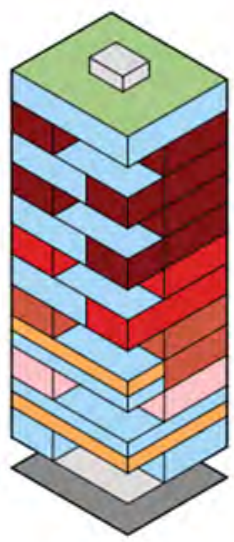

Option 3

Some residential units are facing the South side of the building to increase square footages for residentia!

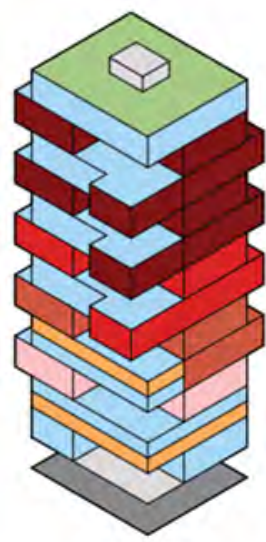

Option 4

In order to increase even more square footages without compromising the amenities volume of the massing some residential mass are extruded beyond the building face.

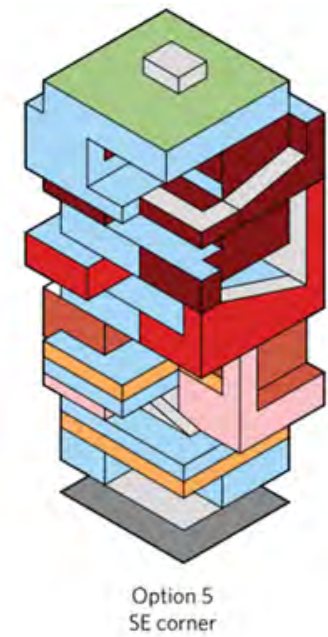

Figure 4.1 - Massing Diagram

\begin{tabular}{|c|c|c|c|}
\hline \multicolumn{3}{|c|}{ Potential Square Footage at $100 \%$} & 23250 \\
\hline \multicolumn{4}{|l|}{ OPTON 1 : so/so } \\
\hline Type & Area (SM) & Percentage & \\
\hline Residential & 6346. & $27 \mathrm{~m}$ & \\
\hline Amenities & 6638 & $29 \%$ & \\
\hline Common Space & 4850 & 210 & \\
\hline \multicolumn{4}{|l|}{ "base option } \\
\hline \multicolumn{4}{|c|}{ OPTION Z: Max North } \\
\hline Type & Area [SM] & Percentage & \\
\hline Residential & 10010 & $43 \%$ & \\
\hline Amenities & 6555 & $28 \%$ & \\
\hline Common Space & 3112 & $13 \%$ & \\
\hline \multicolumn{4}{|c|}{ increased residential area / decreased common space } \\
\hline \multicolumn{4}{|c|}{ OPTION 3: Max North and added South } \\
\hline Type & Area (5M) & Percentage & \\
\hline Residential & 10835 & $47 \pi$ & \\
\hline Amenities & 6555 & $28 \%$ & \\
\hline Common Space & 2425 & $10 \mathrm{~A}$ & \\
\hline \multicolumn{4}{|c|}{ "minor increase in residential area / decreased common space } \\
\hline & & & \\
\hline \multicolumn{4}{|l|}{ OPIION 4: } \\
\hline Type & Area (SM) & Percentage & \\
\hline Residential & 14080 & $60 \pi$ & \\
\hline Amenities & 655 & $28 \%$ & \\
\hline Common Space & 3212 & $14 \%$ & \\
\hline
\end{tabular}


The massing is articulated to include variations of ramps at the exterior and interior that is also integrated into the building envelope. The program follows the arrangement of options 1-4. Efficiency of the residential area was an important exploration in options 14. Once a targeted square footage is proven to be possible, it is then taken into this articulated option to achieve the similar area target with a more interesting massing that expresses the different spaces and zones.

The objective of options 1-4 is to determine a baseline for total square footage of residential area in the building and where the program will roughly located in the building. The adjacency to different residential types and amenities is also considered in all options. These studies served as a reference point for option 5.

Physical Model
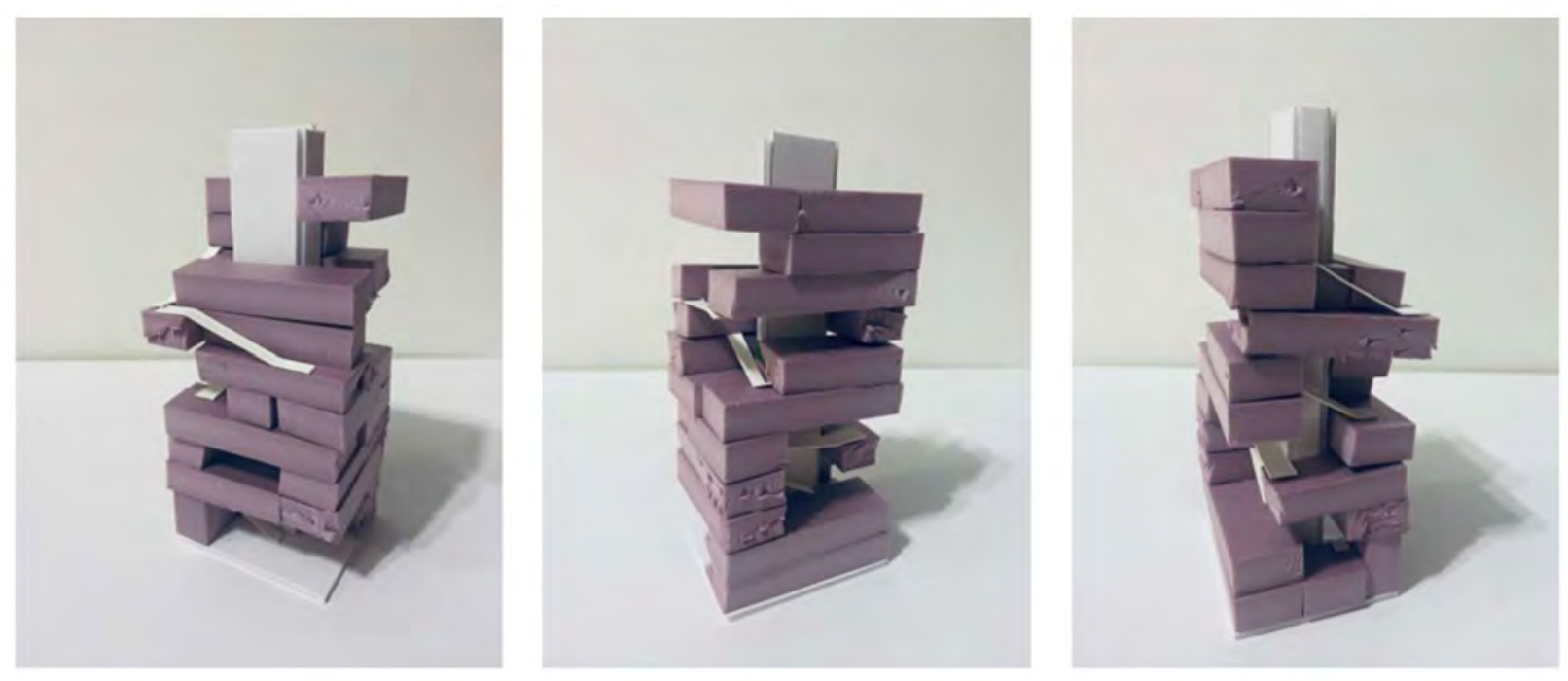

Figure 4.2 - Physical Model

The purpose of the physical model is to demonstrate different ramp conditions and massing variations in the proposed building. Some ramps can be expressed at the exterior, and some ramps wrap around the building core. There are also conditions where a skybridge connects two spaces together within upper levels of the building. The idea of the ramp within the building is to allow occupants to walk from ground floor all the way to the roof of the building. Although ramps take up considerable space, this serves as an important identity in the building as the ramp promotes active living lifestyle for occupants, and also subdivides different spaces and programs. 


\section{$\underline{4.2 \text { Key Residential Plan }}$}

Existing Floor plan

The existing floor plate of the office tower is approximately twelve-thousand square feet with a center core of elevator shafts and service utilities. The floor depth from window to core is approximately thirty-seven feet, which provides sufficient lighting to the interior floor space. There are no structural elements within the floor area, and there is a clear space of eight-foot-four inches in between each structural element at the perimeter/exterior. The floor plate offers an unobstructed space that can be subdivided into different residential units or accommodate a large common space for specific amenities. There is also the opportunity to redirect the building load onto different structural systems if some of the exterior structural columns are to be eliminated to open up the amenities space, and some floor plates can also be removed to create multi-story spaces for collaborative and common spaces.

\section{Existing Room Allocation}

Since the floor plan is open to various subdivisions without any structural columns, the existing units per office floor can vary. Most of the individual offices and meeting rooms are placed at the facade of the building while an interior corridor wraps around the core. This floor planning can be used in a re-purposed building for senior residential applications where residential units or some amenity rooms can be placed along the facade.

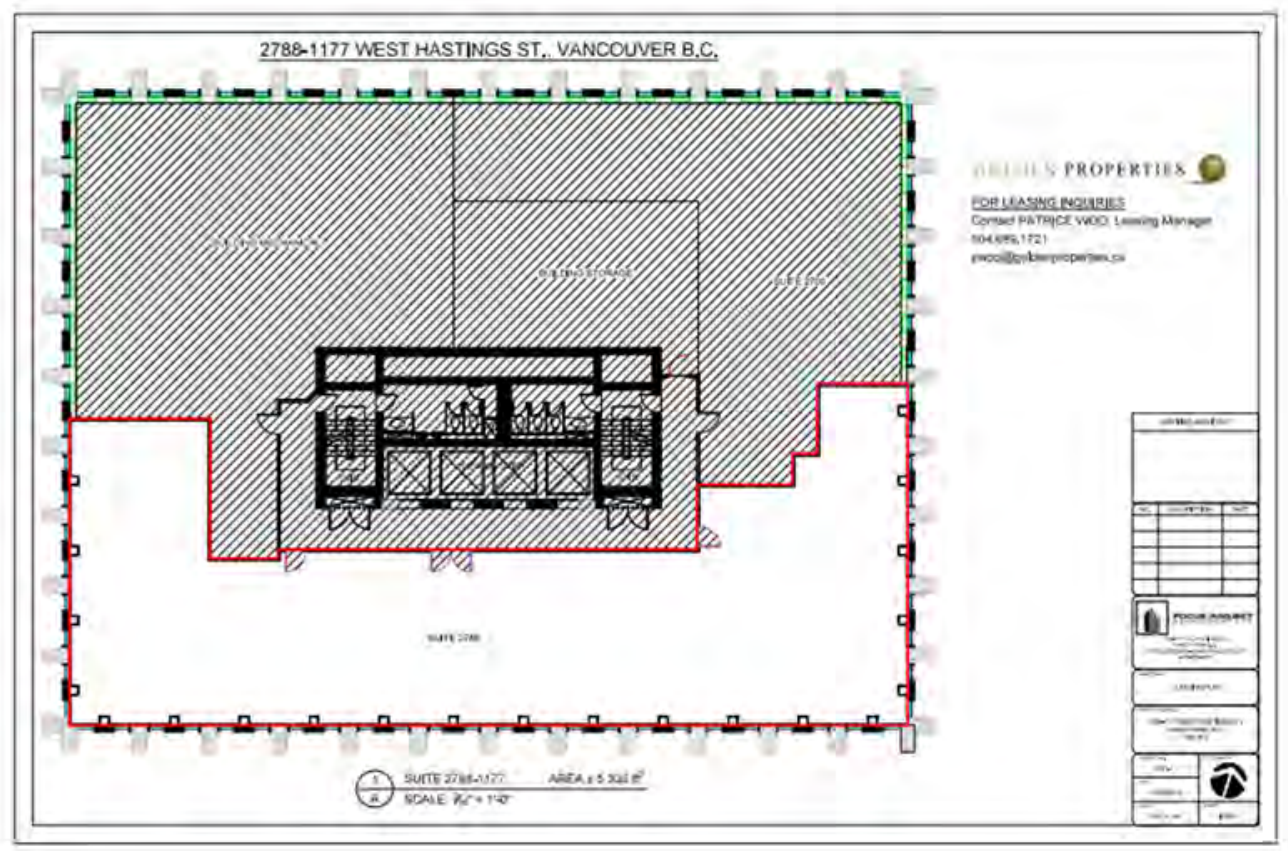

Figure 4.3 - Existing Floor Plan 


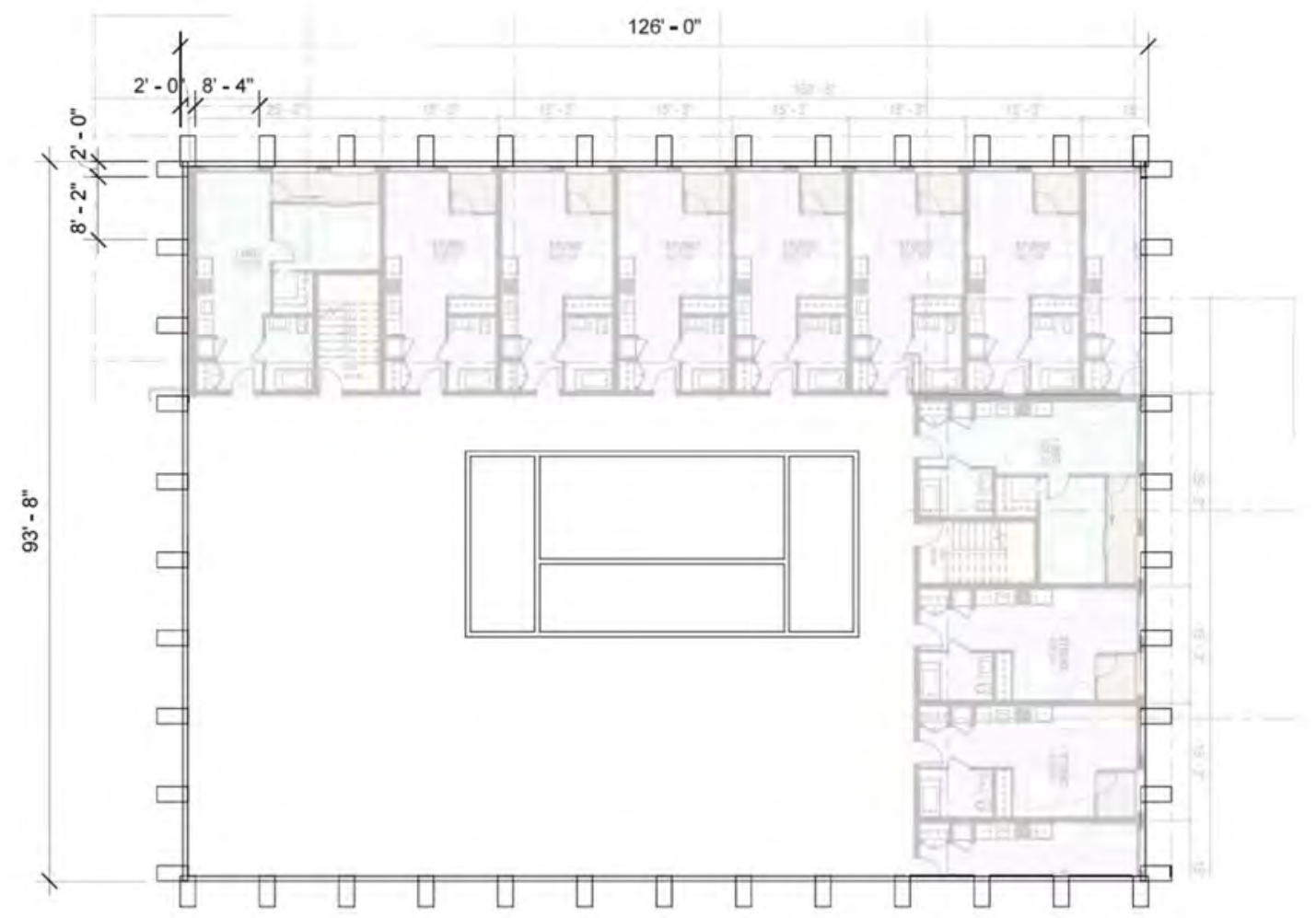

Figure 4.4 - Overlay Typical Residential Unit onto typical project floor plate

A typical unit size of a conventional residential unit is overlaid onto the proposed building. Approximately six units can be arranged along the North side of the building facade. If the entire floor plate is exclusively filled with residential units, 20 units can be fit on the floor. 


\subsubsection{Exterior Expression}

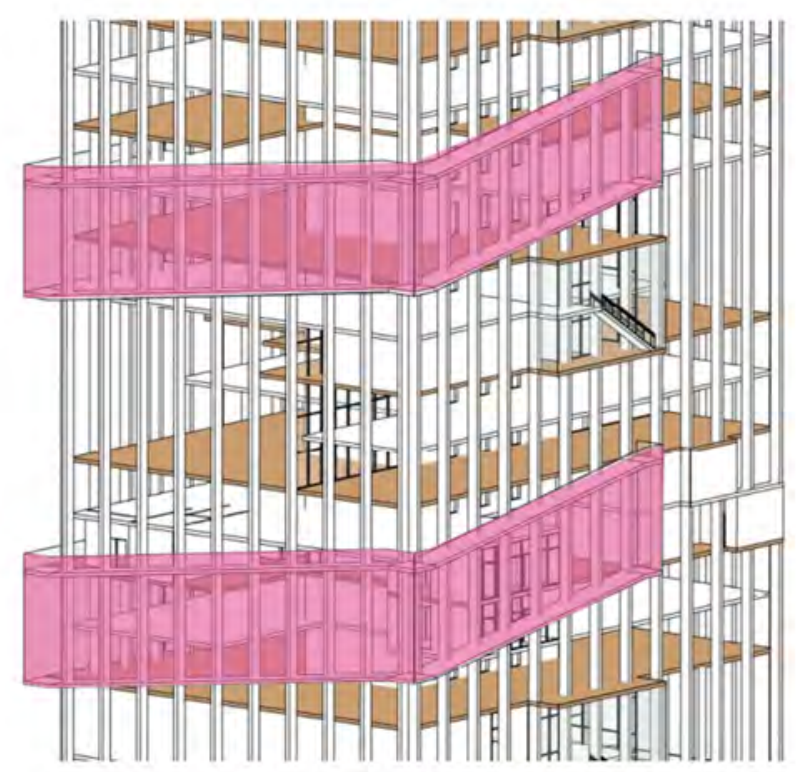

Figure 4.5 - Dual level exterior ramp
The dual level exterior ramps wrap around the existing structure. The purpose of these ramp is to create a double-height volume that also circulates from one zone to another. The lower ramp circulates between two different residential types. The upper ramp circulates within the same residential type. The upper ramp is not an enclosed space since it uses the roof of the enclosed ramp below.

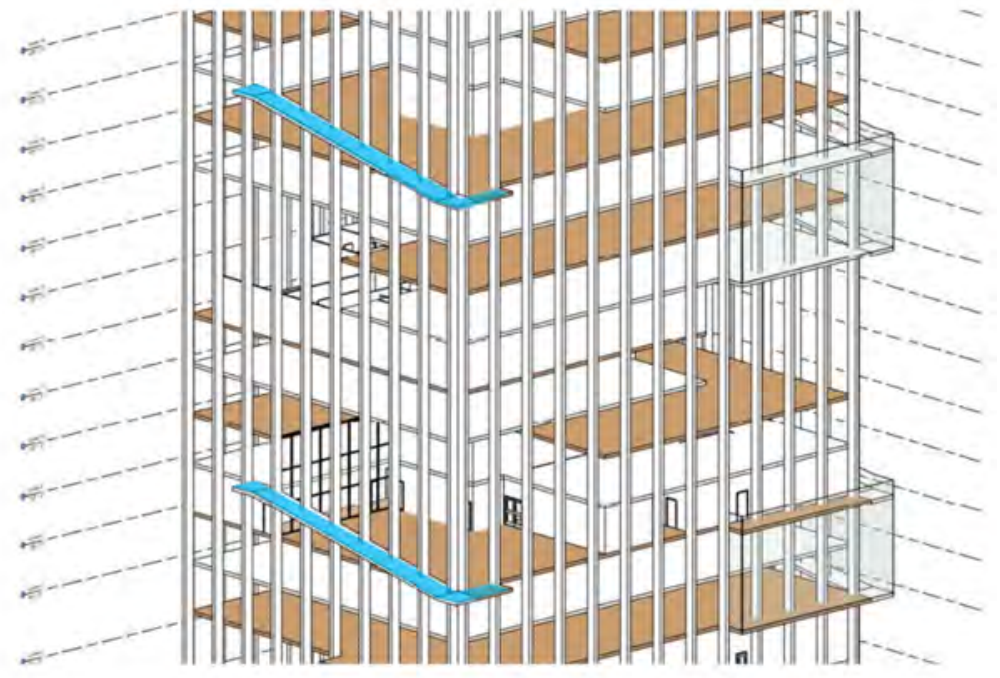

Figure 4.6 - Open exterior ramp
There are also unenclosed exterior ramps that serve areas on the 2nd floor above the Hub, which allows residents from the second floor above the Hub to have quick access to the social area. 


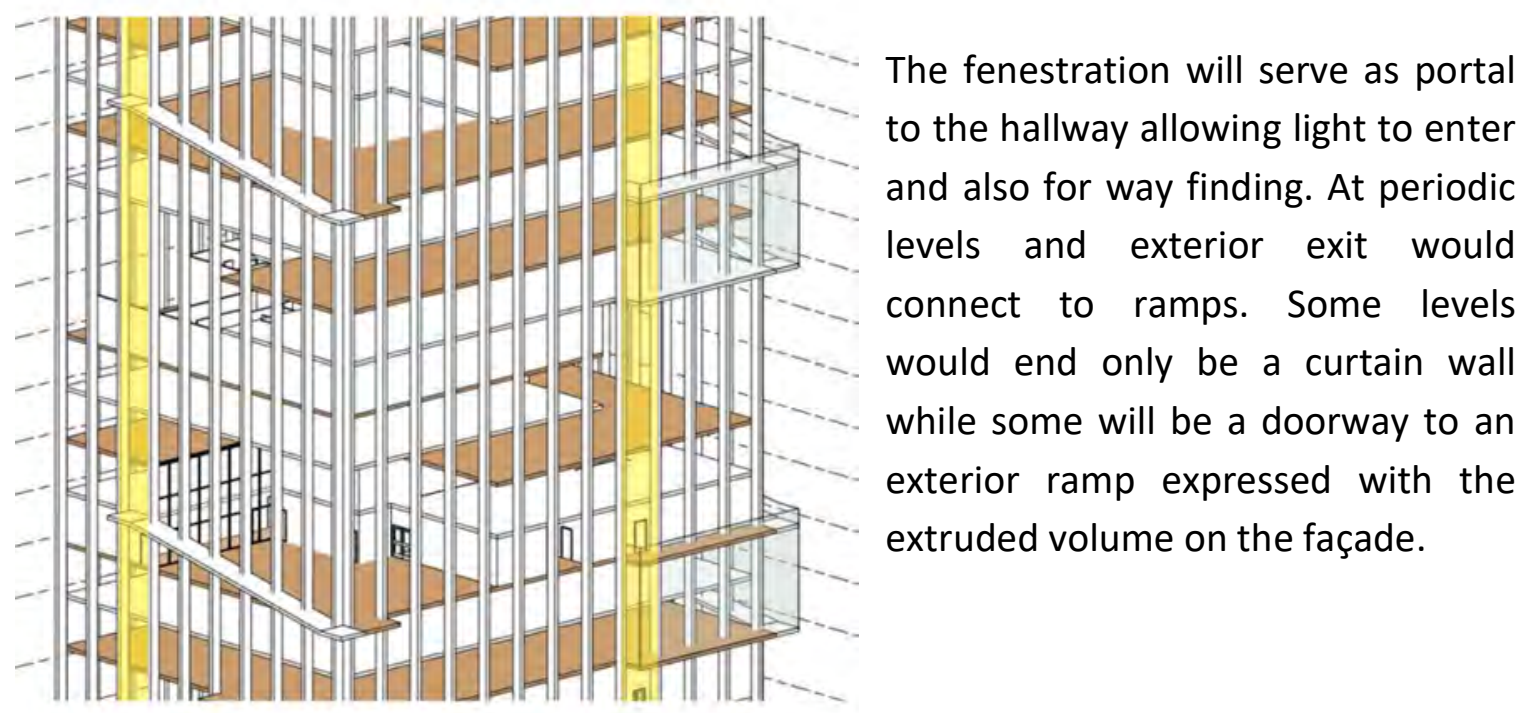

Figure 4.7 - Hallway ends fenestration 


\subsubsection{Residential Type - Alzheimer Special Care Home}

The day-to-day living quarter for an Alzheimer senior would consists of basic necessity furniture such as bed, table, closet and a washroom. A kitchen and large living room are not required since seniors with cognitive impairment would not be able to cook and process information from most digital media such as a TV. However, it is more important for Alzheimer seniors to interact with other faces and function outside of their sleeping area. The Hub and other program within the building are intended to decrease the memory degradation of a senior with cognitive impairment; therefore, the space allocated for a dementia resident would not be significant in the individual room. Other room types are also available for dementia residents. It could be a studio type where a couple would be living together in the same room where one would act as a caretaker while also receiving needed nursing care. Another room type would be the companion room where family members of the dementia resident could occasionally visit and stay overnight for caretaking.

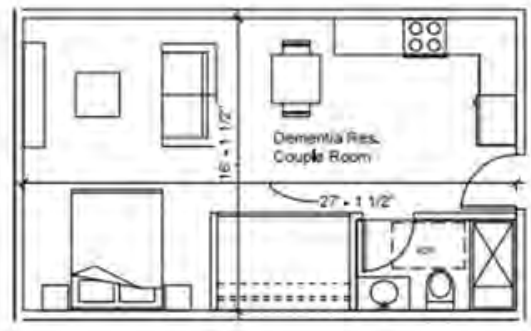

Unit Plan - Dementia Couple (3) Room.

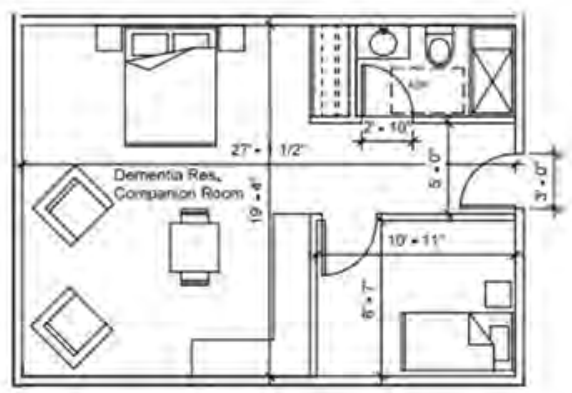

Unit Plan - Dementia (4) Gompanion Room

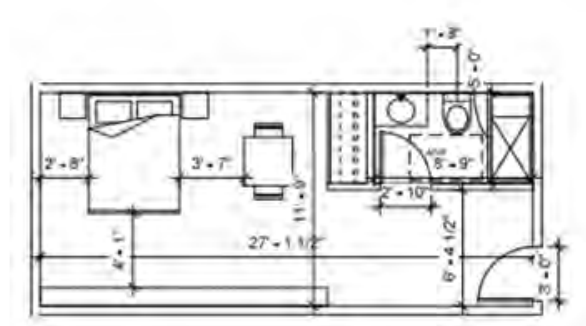

(5) Unit Plan - Dementia Typical

Enlarged Unit Plan - Residental (Alzheimer Special Care Home)

Figure 4.8 - Enlarged Unit Plan: Dementia Special Care 


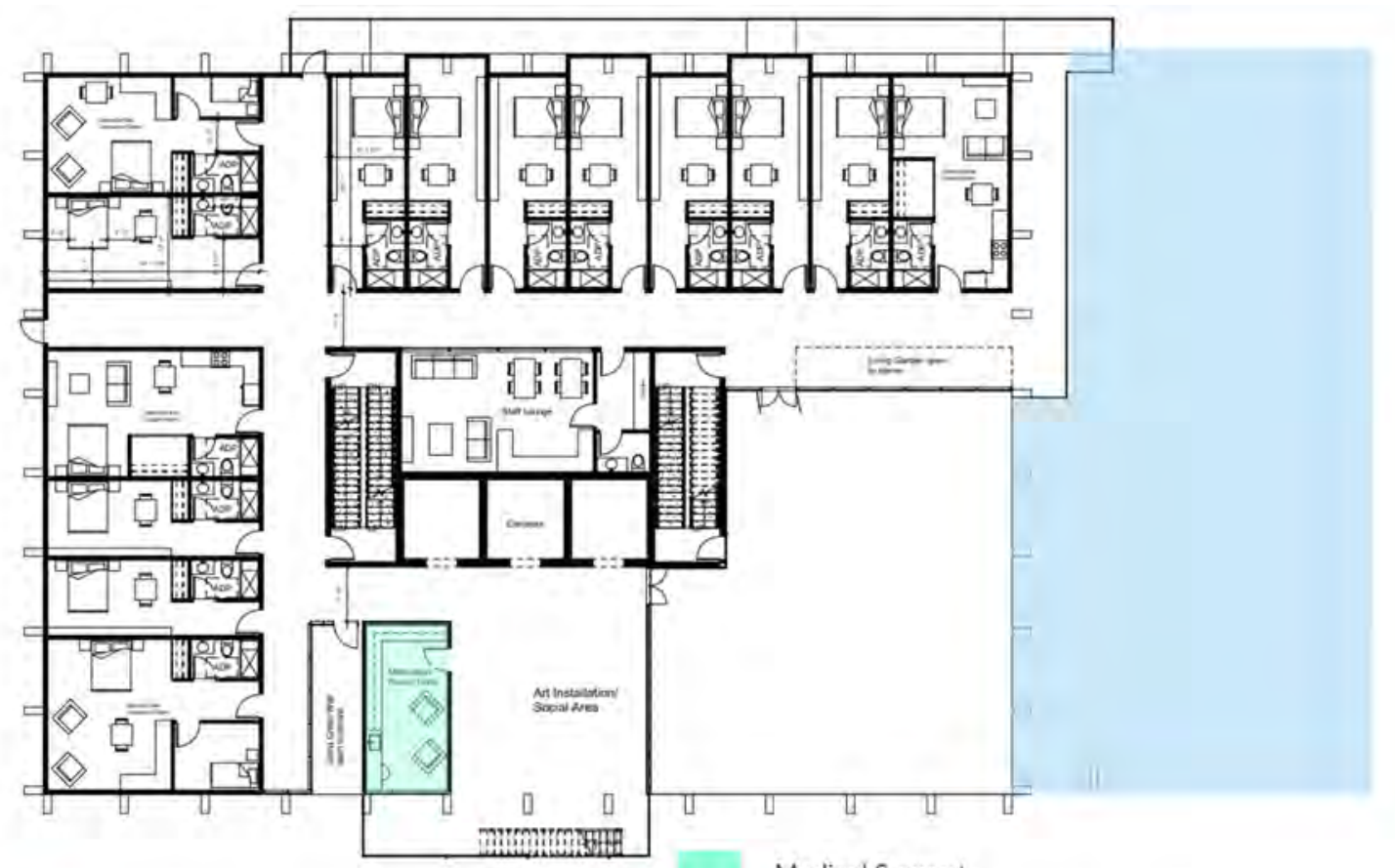

Medical Support

Proposed Typical Floor - Residential (Dementia Special Care Home)

Figure 4.9 - Proposed Residential Floor Plan: Dementia Special Care

Activity rooms for an Alzheimer special care home would be more spacious as some of these rooms are utilized to help treat seniors with memory loss issues. The intention of an irregular spatial experience is to engage new knowledge and help memory loss occupants to lessen the deterioration time for memory loss.

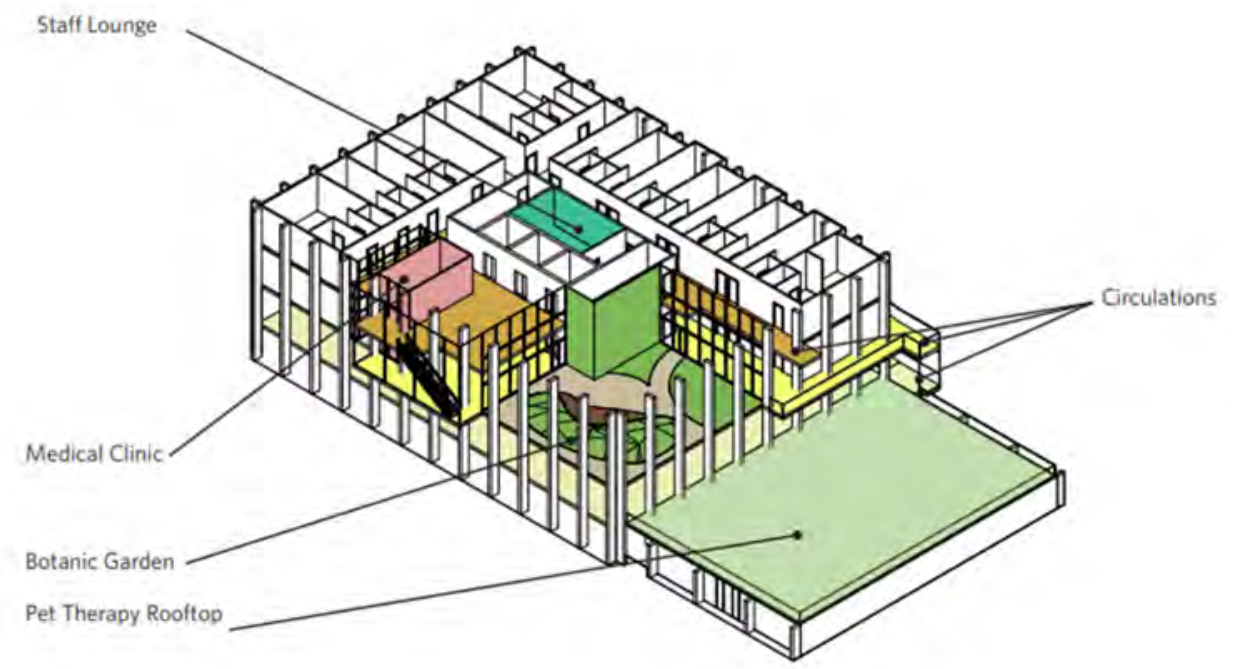




\subsubsection{Residential Type - Nursing Home}

The space requirement of a nursing home needs to adhere to the accessibility standard and nursing home standard allowing the space required for staff to assist the resident with basic needs such as personal hygiene, cleaning, medical check-up or monitoring machines. The door sizes are also larger than other room types in the building because of the need to push rolling bed in and out of the room frequently. Residents in this room type could be at their final stage of life where they would be transported into a morgue in the building via a rolling bed.

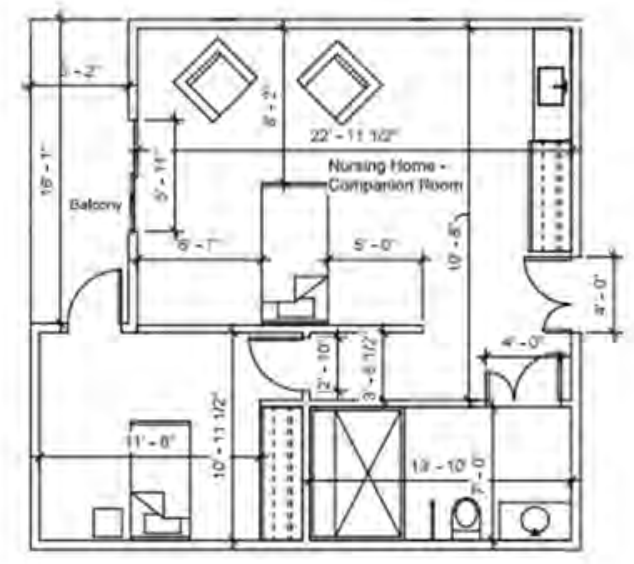

Unit Plan - Nursing (2) Sempanion Roem

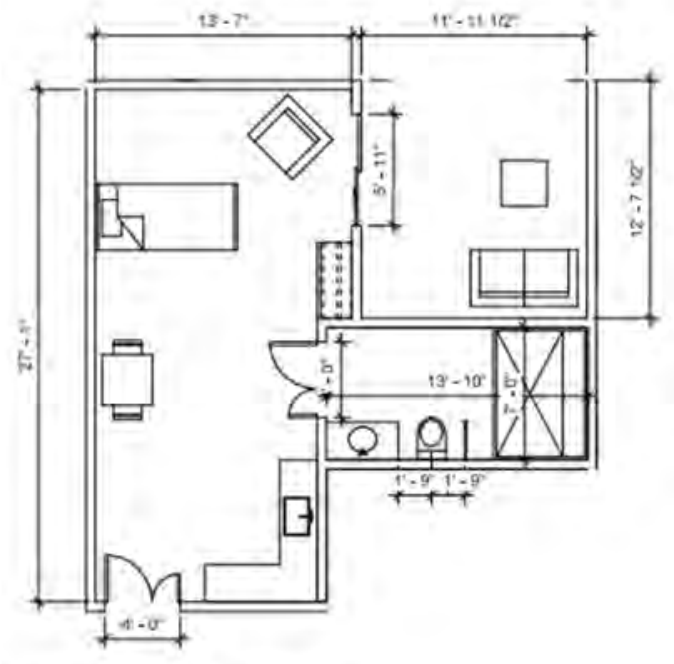

(3) Unit Plan - Nursing Typical

Enlarged Unit Plàn - Residential (Nursing Home)

Figure 4.11 - Enlarged Unit Plan: Nursing Home 


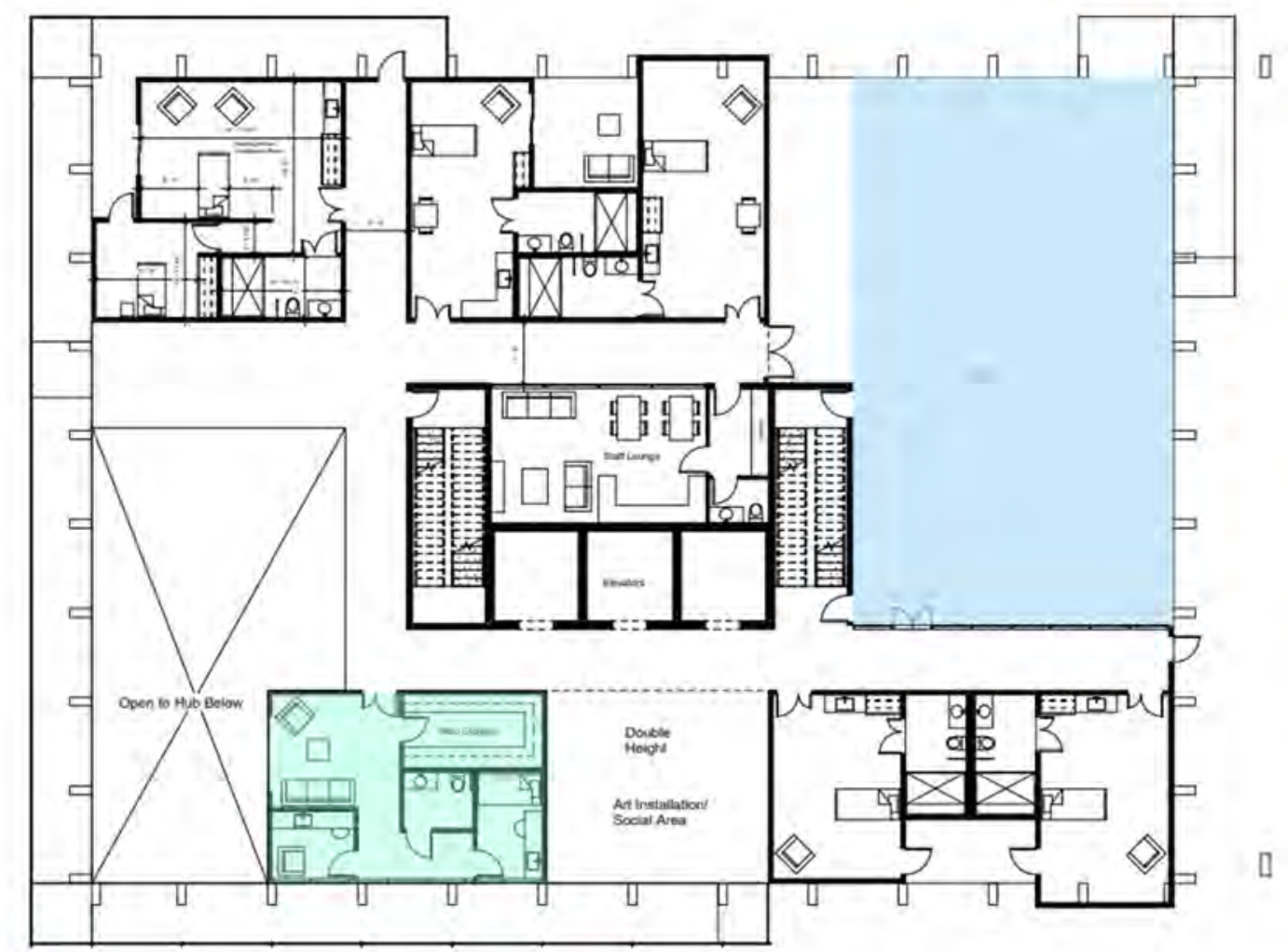

Residential (Nursing Home)

Medical Support

Figure 4.12 - Proposed Residential Floor Plan: Nursing Home 


\subsubsection{Residential Type - Assisted Living}

In an assisted living unit, the room will adhere to accessibility standards where residents with wheelchairs can easily access all spaces in the unit. Medical staff and caretakers would have to dedicate less time for these groups of residents as they have normal cognitive ability. The typical suite type would be a shared room with two other residents where they would share a living room and a kitchen.

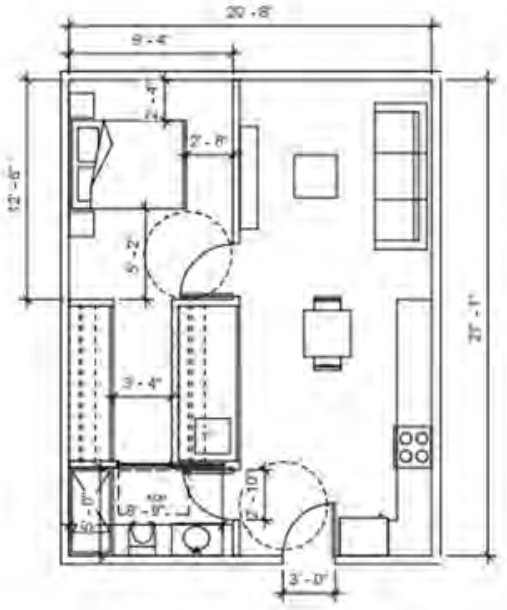
(2) Unit Plan-Assisted Typical

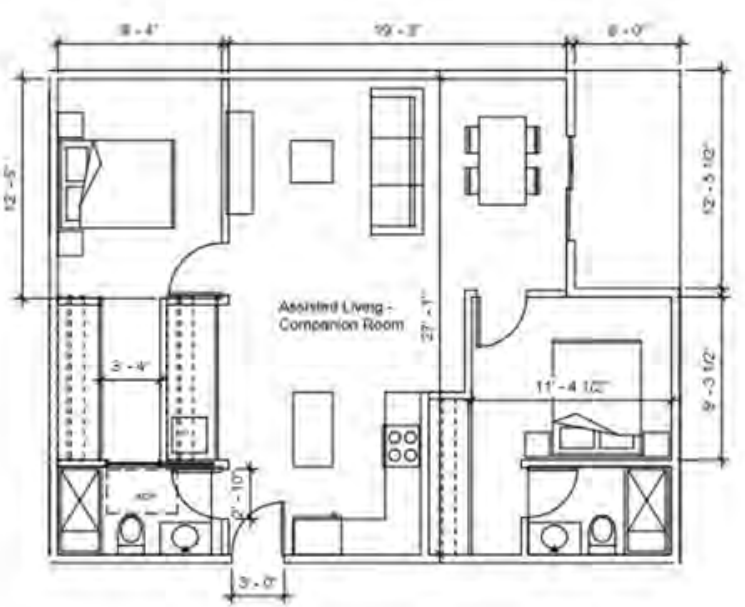

Unit Plan - Assisted (3) Gempgrion Room

Proposed Typical Floor - Residentiar (Assisted tiving) $1 / 16^{\prime \prime}=1 \cdot 0^{\circ}$

Residential (Assisted Liviny)

Figure 4.13 - Enlarged Unit Plan: Assisted Living 


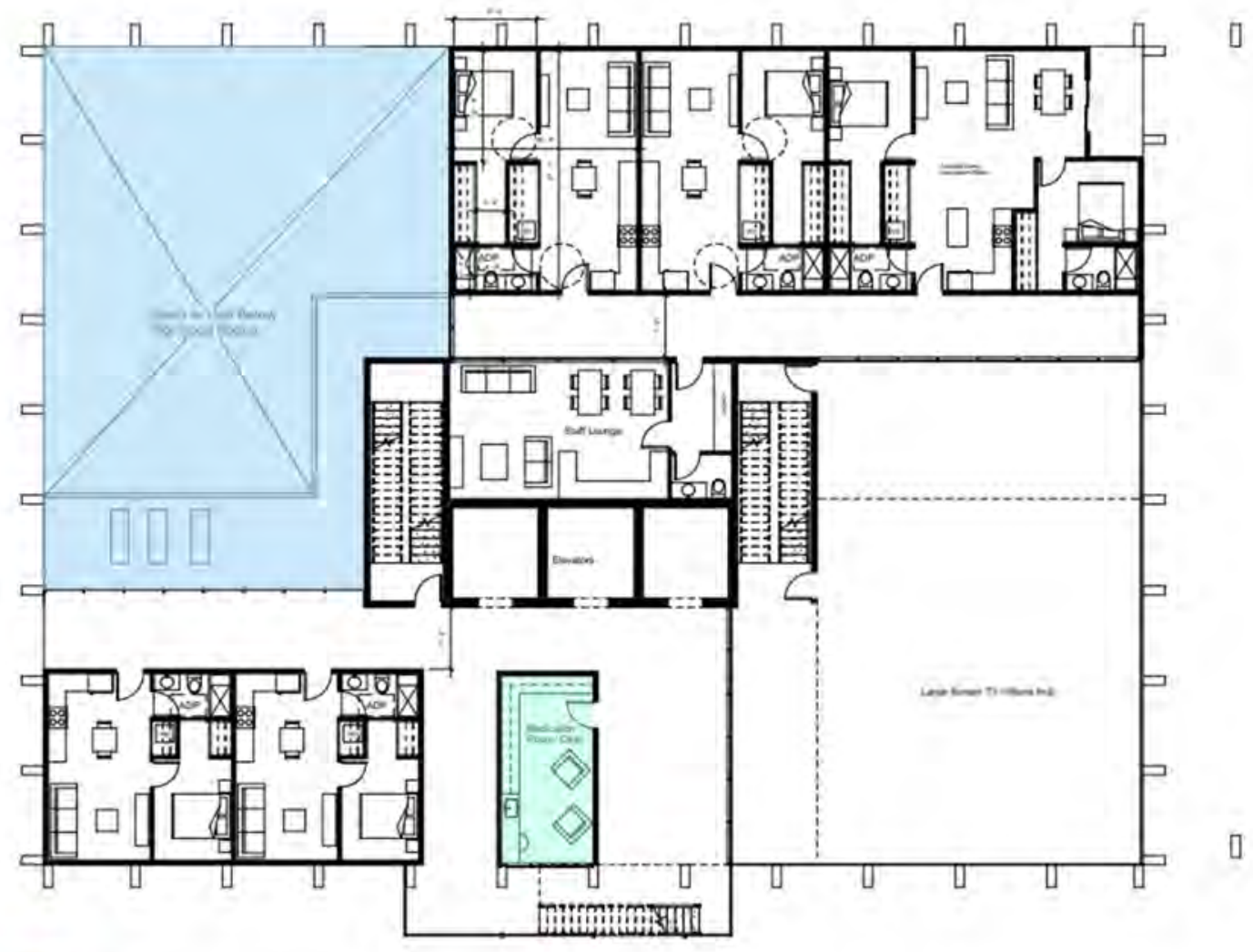

Figure 4.14 - Proposed Residential Floor Plan: Assisted Living

Unit sizes in this category of residential unit are relatively similar to independent units, with the addition of floor staff rooms and medical rooms for regular checkups by caretakers and medical staff. Some staff rooms may not be facing a frontage if it is meant for quick checkups. 


\subsubsection{Independent Living}

The majority of the residential types would fall under the independent living type. Typical residents in this group could be a widow, or a couple to downsize and enjoy the company of other seniors. The common similarity within the seniors in this group is their able body and mental mind. Independent seniors would require the least amount of medical and staff care as they can, and desire to take care of themselves. However, medical professionals would still be made available for them as well as basic caretaking and cleaning services.
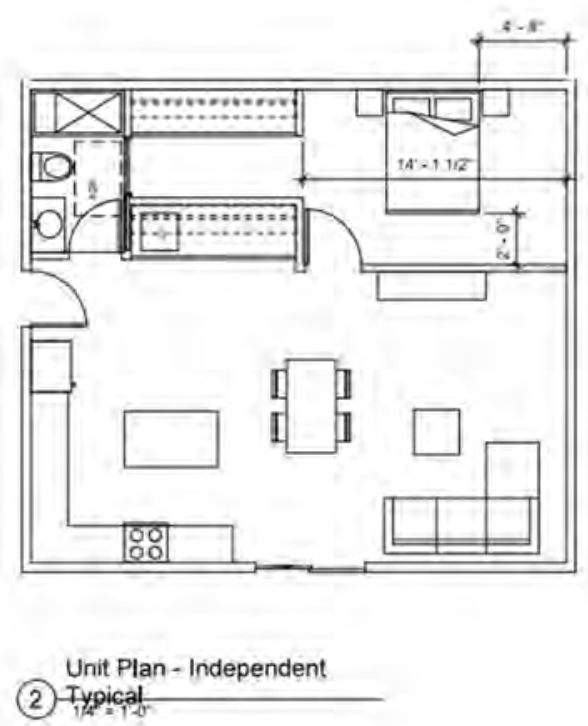

Proposed Typical Fioor-Residemtial (independent) $1 / 16^{\prime \prime \prime}=10^{\prime}-0^{\prime \prime}$

Figure 4.15 - Enlarged Unit Plan: Assisted Living 


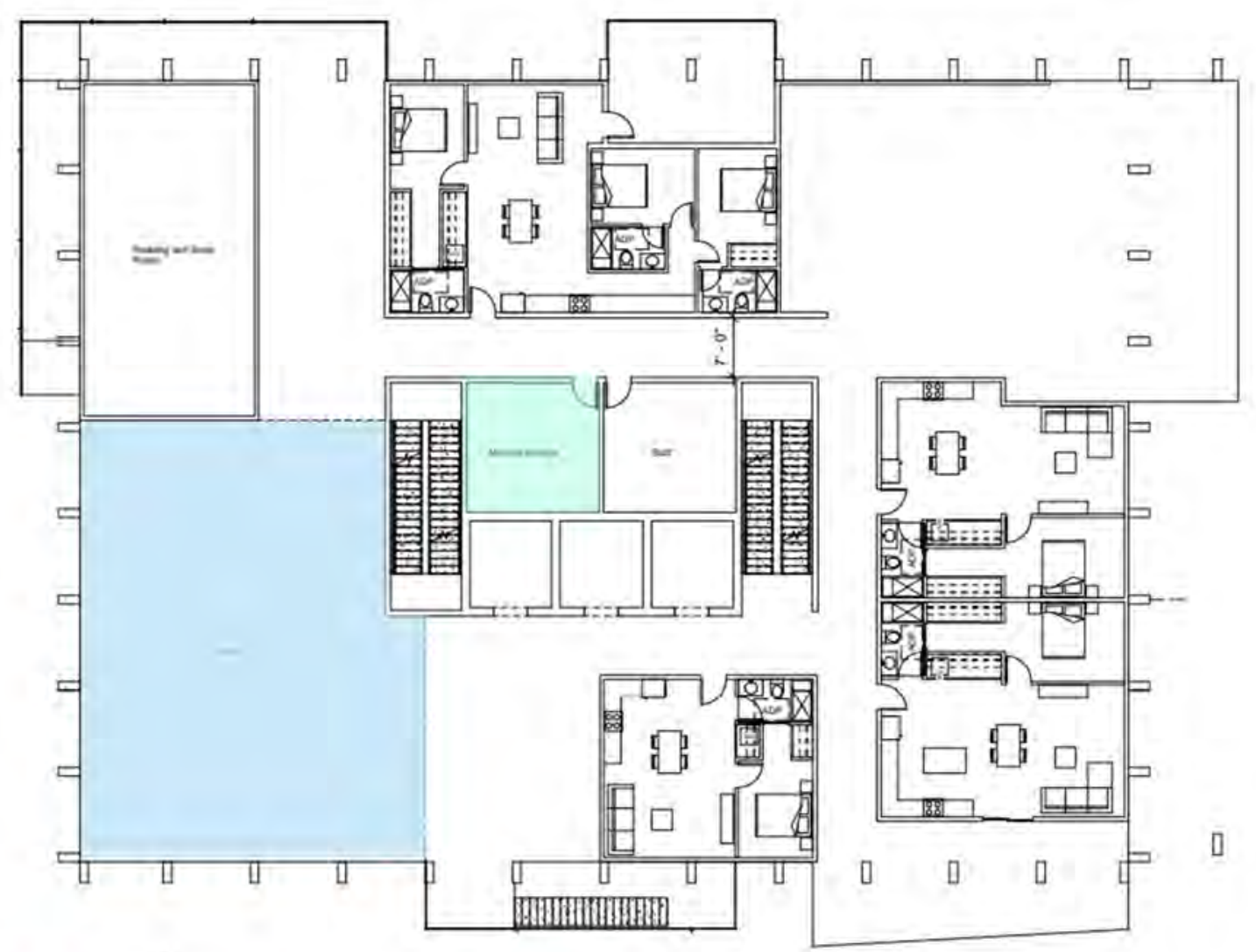

Medical Support

Figure 4.16 - Proposed Residential Floor Plan: Independent Living

In the proposed residential floor plan for independent seniors, units are embedded in a suite where three occupants will share one kitchen and living space within a suite. The option to live in the same household is to increase the interaction between the seniors and also to provide vital checkups of each other in case of emergency. The floor plan also includes a continuous ramp that connects the floors above and below. Some common spaces are featured on each floor and this plan includes exterior walkway to the units as secondary entrance 


\subsection{Section}

4.3.1 The Hubs: The Heart of Vibrant Senior Living

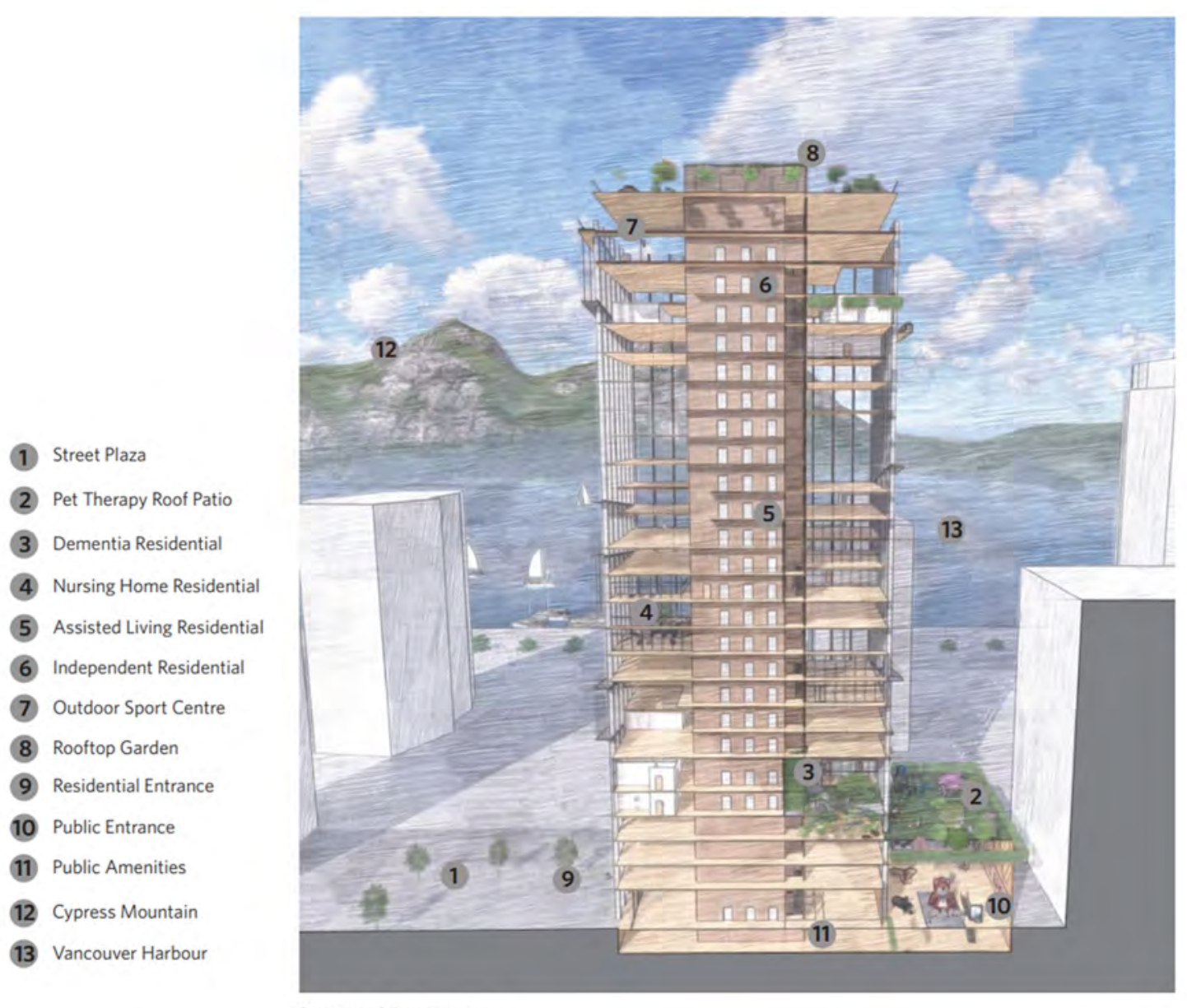

Sectional Perspective

Figure 4.17 - Sectional Perspective

THE HUBS

There are eleven Hubs distributed across the twenty-seven floor senior care tower. Each of these hubs has a unique program that services all residents and their guest and it offers the opportunity for seniors to meet each other outside of their smaller social circle.

The residential types associated with the most dependence are placed on the lower floors. The Hub programs that are the most relevant to that dementia group and nursing home group, are also placed in the lower floors. For example, Pet Therapy and outdoor playground would be placed on the same floor as the dementia group and it is also 
placed next to the outdoor patio for pets to access. More abled bodied, independent seniors would have closer access to Indoor Sport Centre on the upper floor. While some seniors with physical disabilities may not able to participate some sports or program, there are spectator areas where other seniors can passively participate.

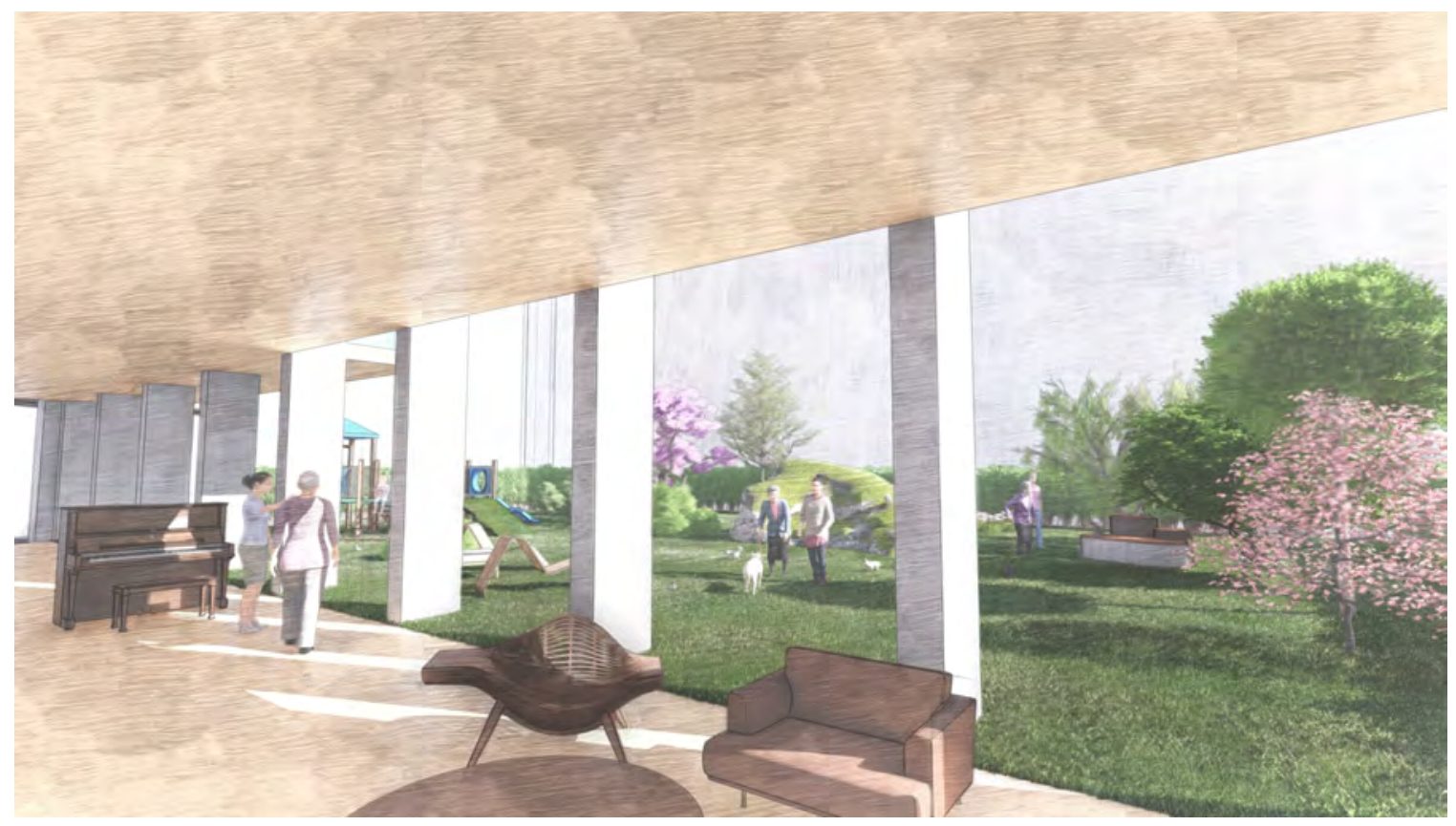

Figure 4.18 - Pet Therapy \& Outdoor Playground Rendering (Hub \#1) View 1

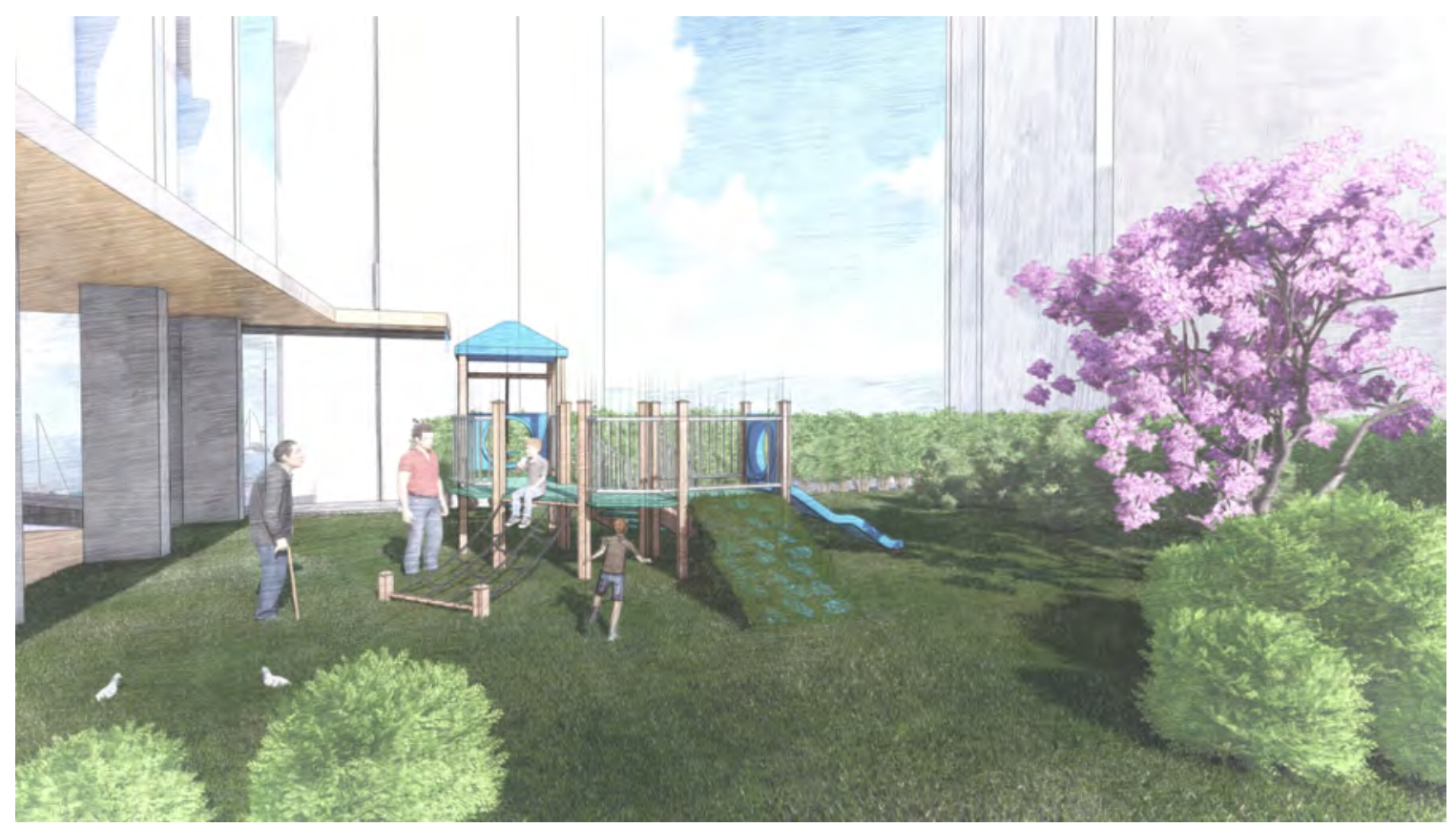

Figure 4.19 - Pet Therapy \& Outdoor Playground Rendering (Hub \#1) View 2 
The Pet Therapy area and outdoor playground acts as a bridge to allow both seniors and public to coexist. The intent of placing completely opposite age group in the same space is to provoke the curiosity of both group and provide the opportunity for the learning of each other.

Dementia special care facilities for senior is very uncommon, however, there are few existing models from Europe where successful architectural intervention offers alternative solution to slow down the degradation of a dementia patient. Public amenities such as a mock supermarket, bus stop or salon are all fabricated in a controlled area where dementia patients can interact. While the supermarket may not be practical for a dementia senior, staff inside the "fabricated supermarket" participates in an act to sell merchandize to dementia senior which said to help with memory degradation. The community store within the tower is functional and residents with a clear conscious could use the supermarket. For dementia seniors, the community stores could be the place to pass their days.

At the North side of the building, the Hub has a view to the North mountain and waterfront, therefore, activities such as Yoga \& Fitness, indoor Botanical Garden \& Meditation, Arts \& Craft, Music and Dance are all located to oversee the breathtaking view.

Meditation helps with reducing stress and the idea is to create a Botanical Garden in the sky above the busy city where one can find peace to meditate.

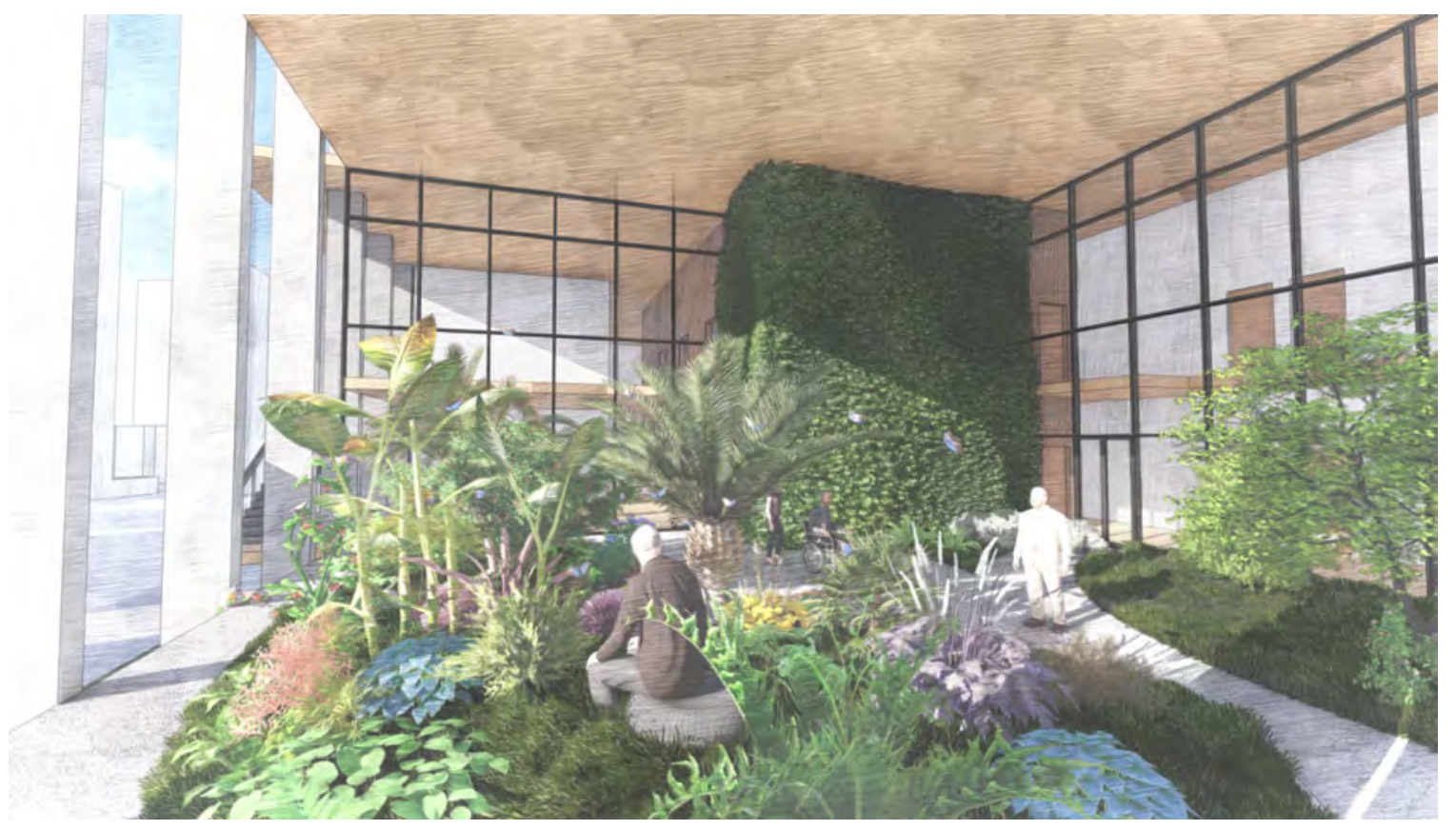

Figure 4.20 - Indoor Botanical Garden and Meditation (Hub \#3) 
Yoga and Fitness also helps with reducing stress where seniors could enjoy the view to the water while taking participating group fitness.

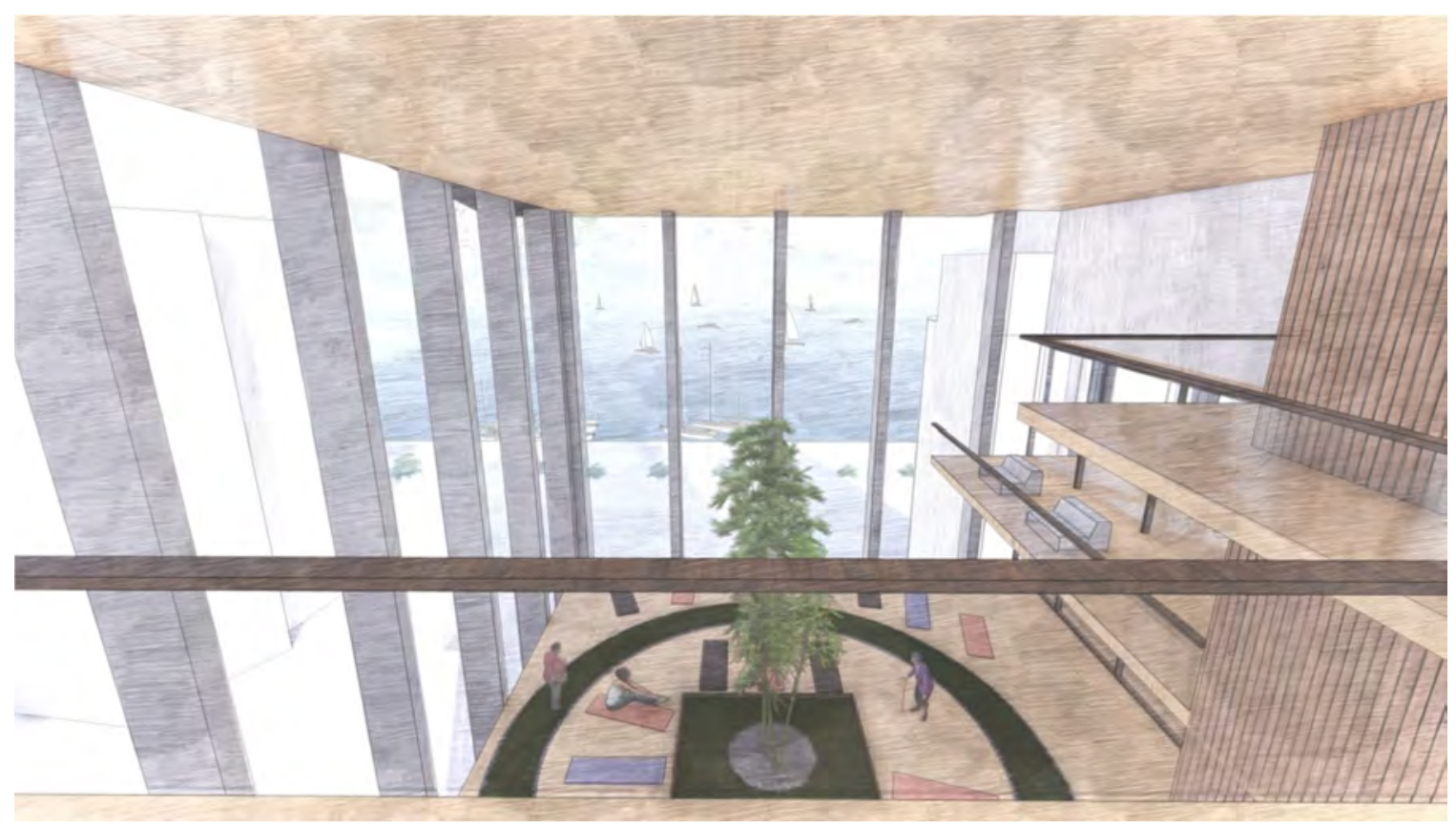

Figure 4.21 - Yoga and Fitness (Hub \#4)

\section{Music and Dance Hub\#7}

Music and Dance allows the more able body senior to mingle with others and different dance them night could happen on this floor. Food and Beverage services and bars would also be located on this floor to add onto the program.

\section{Arts and Craft Hub \#8}

Arts \& Craft are seen in some current senior home amenities which usually would just have tables and chairs inside a multipurpose room. This Hub is specifically design for the function of Arts \& Craft and it will have workspace as well as collaboration and exhibition space for seniors to interact with others and share ideas. 


\section{Large Screen TV Hub \#5}

On the South east corner of the building where there is a large building blocking the sun towards the tower, it would be quite dark throughout the day. In the mid floor of the tower where it is the most convenient for residents to access, a large TV theatre would screen movies and shows throughout the day. There could also be performance where seniors can join any time during the day and night.

\section{Food and Café Hub \#6}

Although there are food services throughout different floors in the tower to service each different residential type, there is a bigger emphasis on food and café on level 15 in the mid tower in one of the Hubs. This is the centralized location where seniors are encouraged to sit with others outside of their immediate residential social circle. Different food vendors are invited to rotate their menu and services to the seniors. It is intended to provide food throughout the day until late night similar to a street food style. There is also a corner where a large communal kitchen is available for seniors to share their cooking skills with each other.

\section{$\underline{\text { Reading and Senior Learning Hub \#10 \& Games Café Hub \#9 }}$}

The last two corners in the upper floor tower are more quiet where Reading and Senior Learning would offer seniors classes and a library, and another Hub offers a games café similar to board game room for seniors to grab and play off the shelves. 


\section{Outdoor Fitness Floor}

Since level 24 has the Hub with Fitness and Indoor Sport Centre, above the fitness centre is a continuation of fitness where an open area allows seniors to walk around the track and also onto the ramp. This floor will be completely open with a large roof overhead, therefore the fitness equipment would be designed to withstand weather. It would be similar to the outdoor fitness set at the beach or park where seniors would wake up early in the morning to exercise.

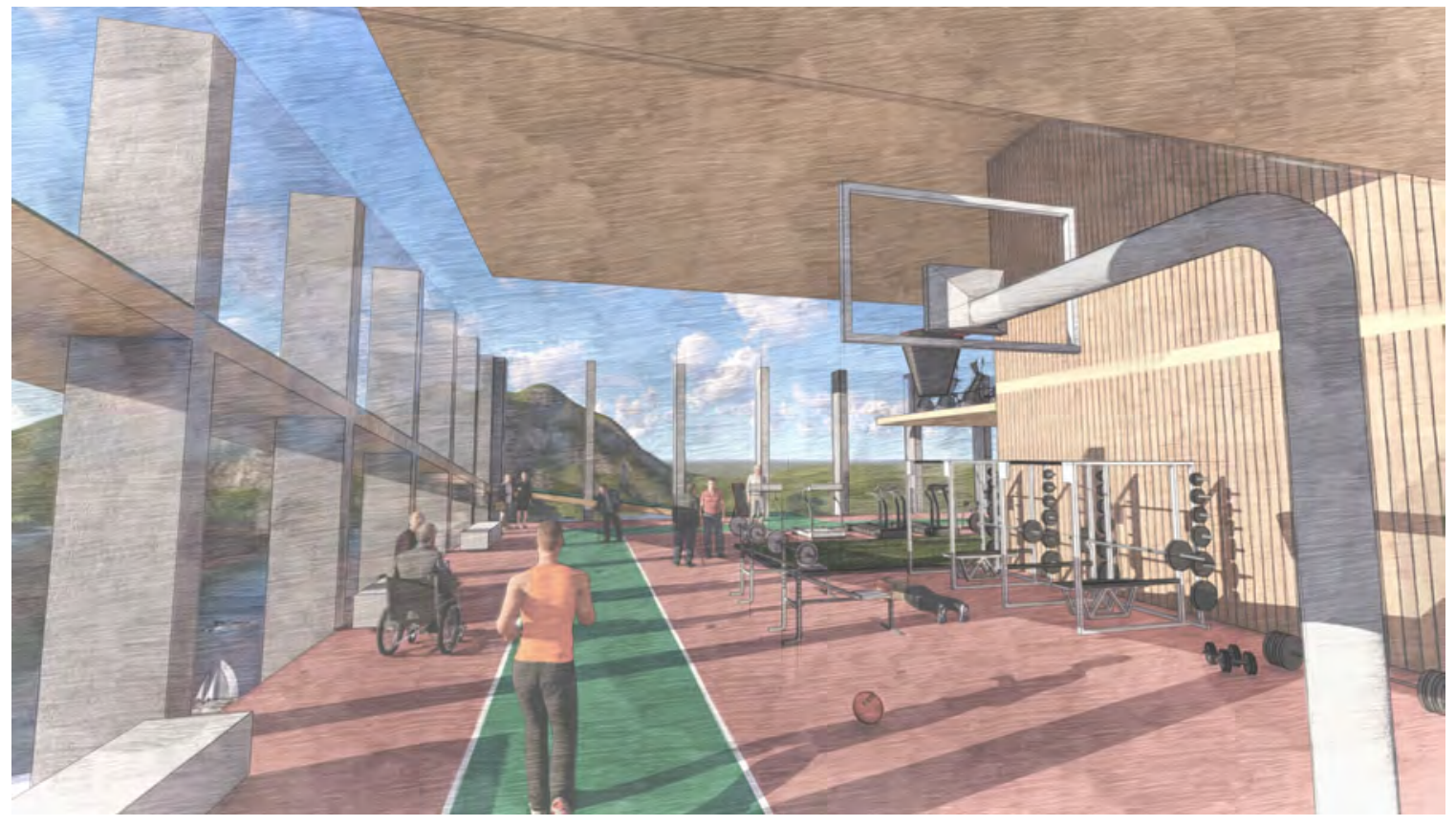

Figure 4.22 - Outdoor Running track and fitness (Level 25) 


\section{$\underline{\text { Roof Vegetable Garden }}$}

Above the outdoor fitness ground, it would be the roof where seniors can help grow vegetables and plants around the entire floor plate. A rain capture system will also be used to store non-potable water to sprinkle the plants throughout the day as a supplementary water source for watering the plants.

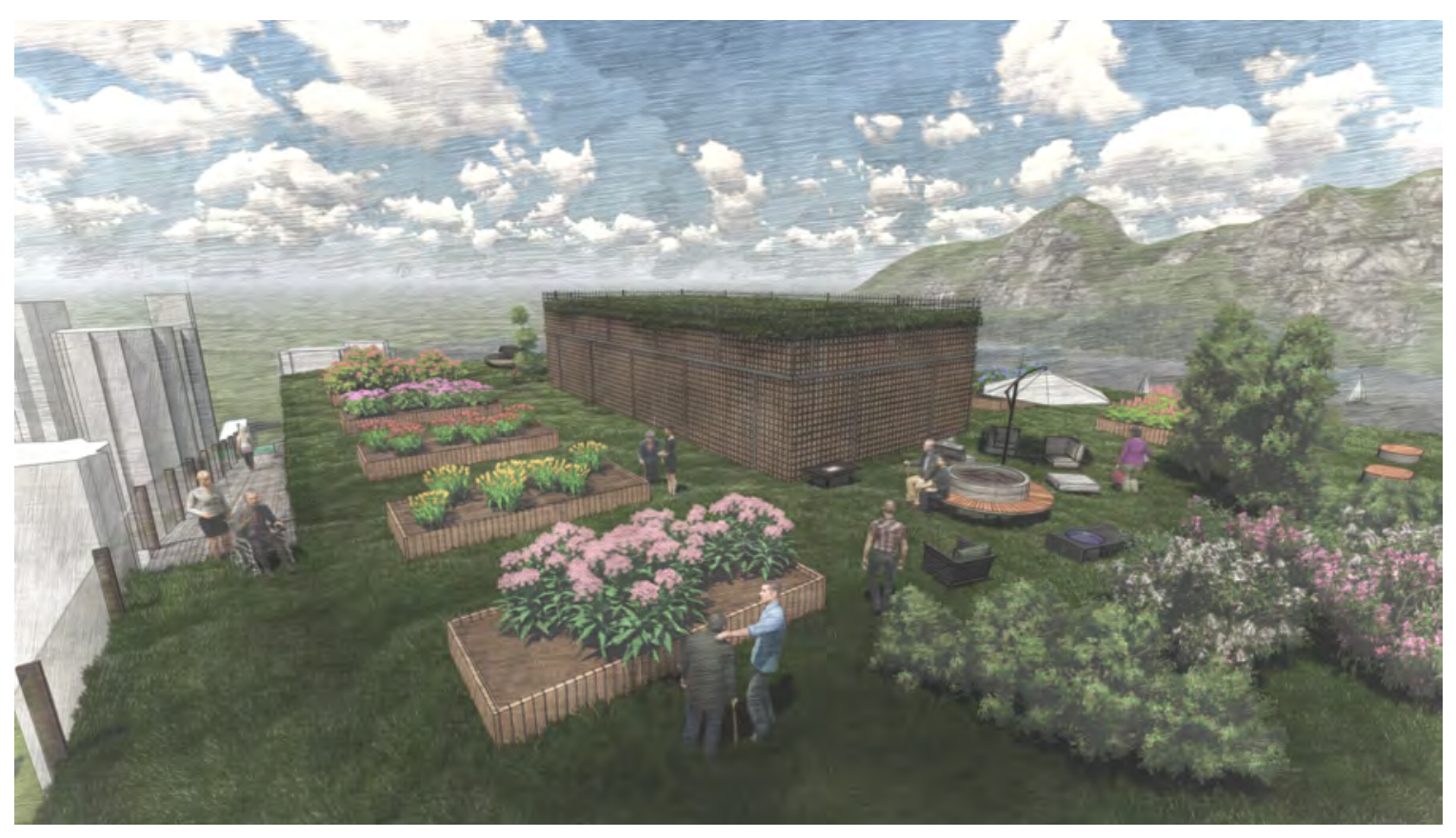

Figure 4.23 - Roof Vegetable Garden 


\subsubsection{Public Realm: Engaging street front}

Three public programs would draw general public into this building to interact with seniors. The most commonly used space would most likely be the restaurants at the street front. It will have a strong presence on the street front with patios and outdoor space for people to service the general public on a daily basis. Beside the restaurant, would be an entrance that brings people into an atrium that leads into the two other programs: the auditorium and underground museum.

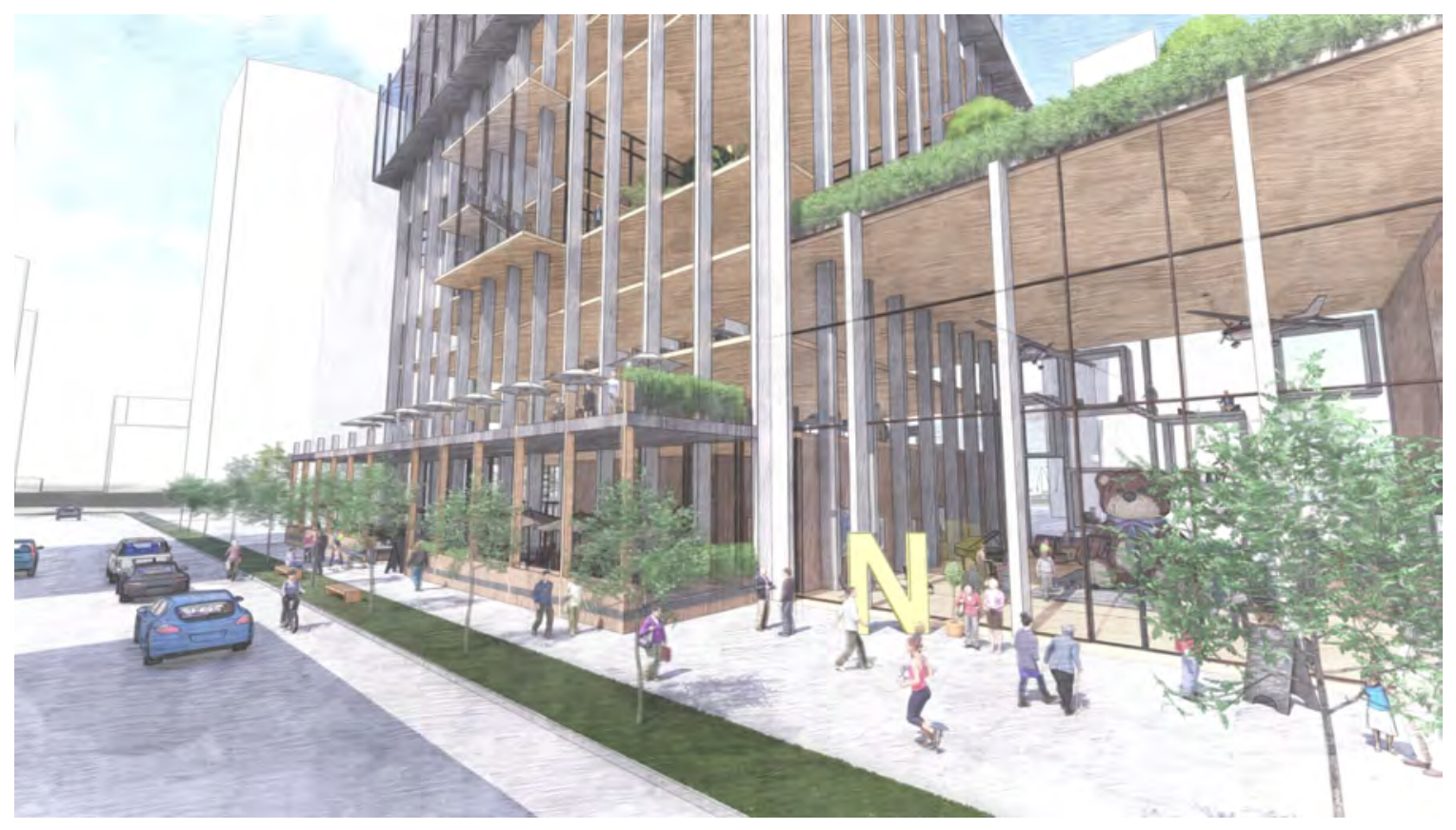

Figure 4.24 - Public Realm Rendering 


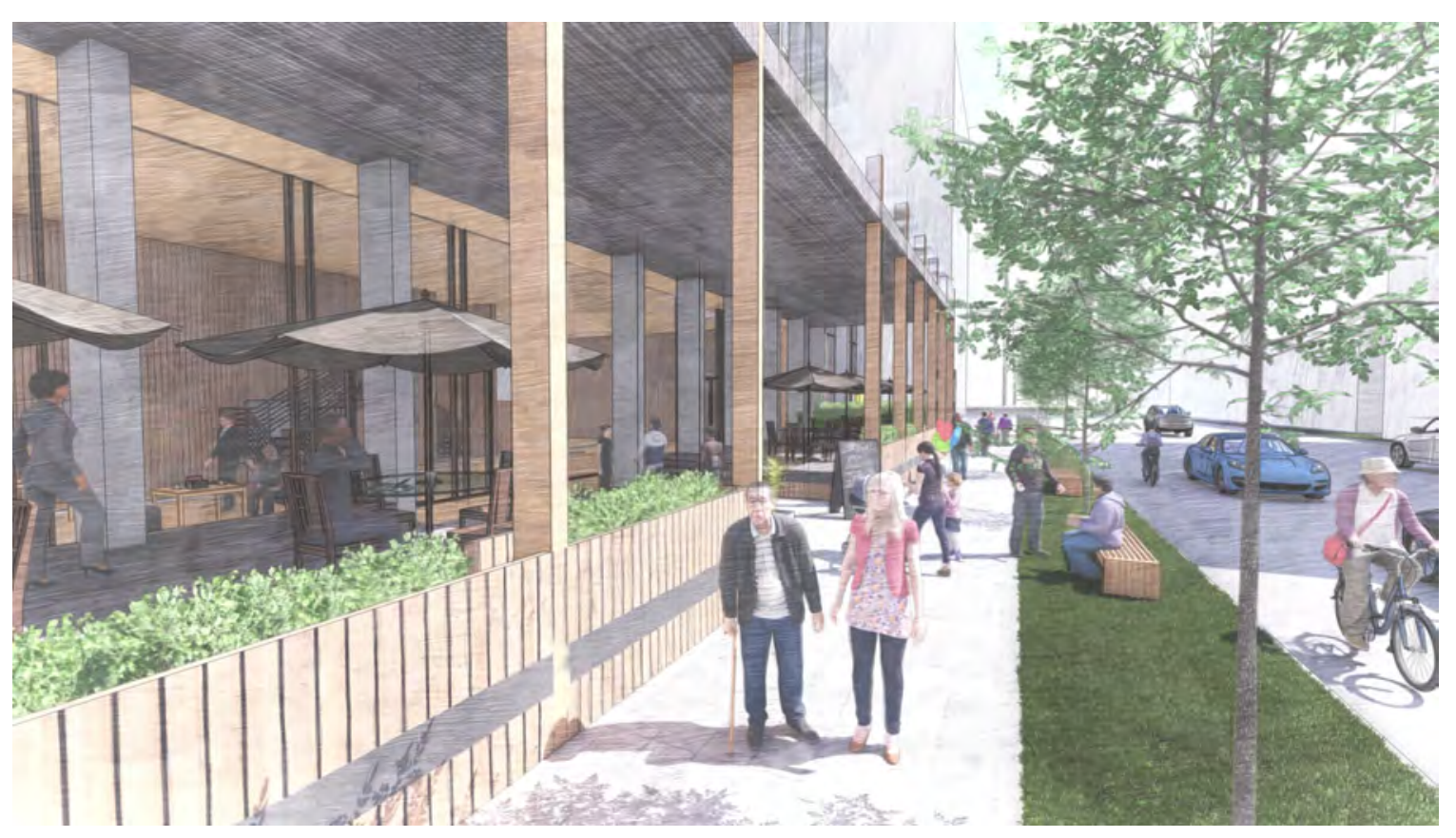

Figure 4.25 - Public Realm Rendering (Restaurants)

\section{Public Amenities: Museum \& Auditorium}

The auditorium would host lectures and it could invite other guests for conference or presentation. The underground museum is a black-box space that allows junior artists to showcase work; in this way the space converts a large parking garage into interactive public amenities. Both seniors living in the tower and public can utilize these spaces and as such are intended to cross paths and interact.

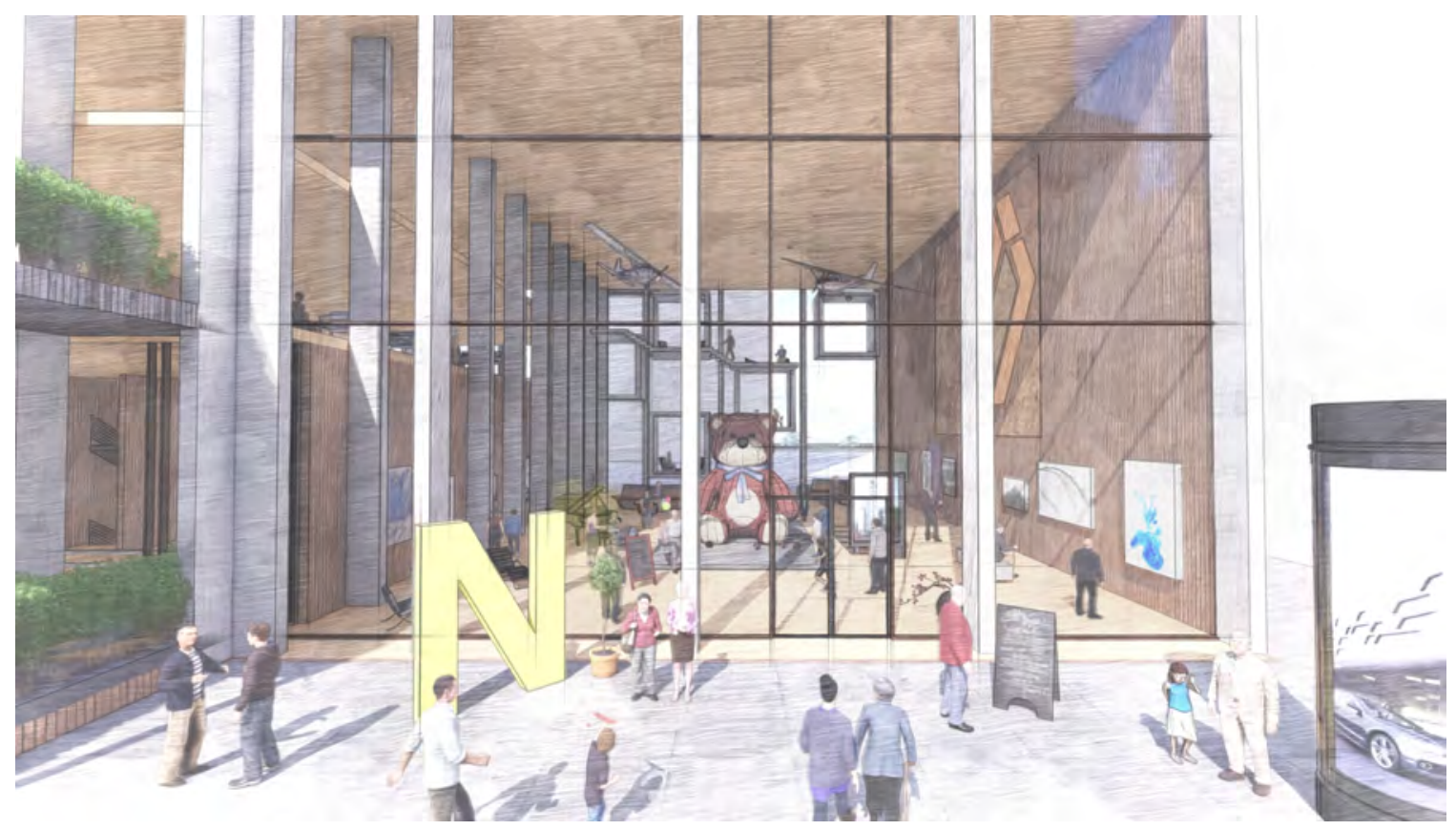

Figure 4.26 - Public Realm Rendering (Art Gallery/ Exhibition Space Entrance) 


\section{$\underline{4.4 \text { Elevation \& Axonometric }}$}

The Roof top features multi-level amenities for both residents and their guests to use. A community vegetable garden allows residents to grow herbs and plants while in conjunction with a water capture system that regularly hydrate the plants.

An exterior ramp is a continuous track from the outdoor fitness floor which is paved with synthetic track that allows more grips for slow jog or outdoor running. Residents and their companions can use the ramp to access one of the three amenities floor at the top level of the tower.

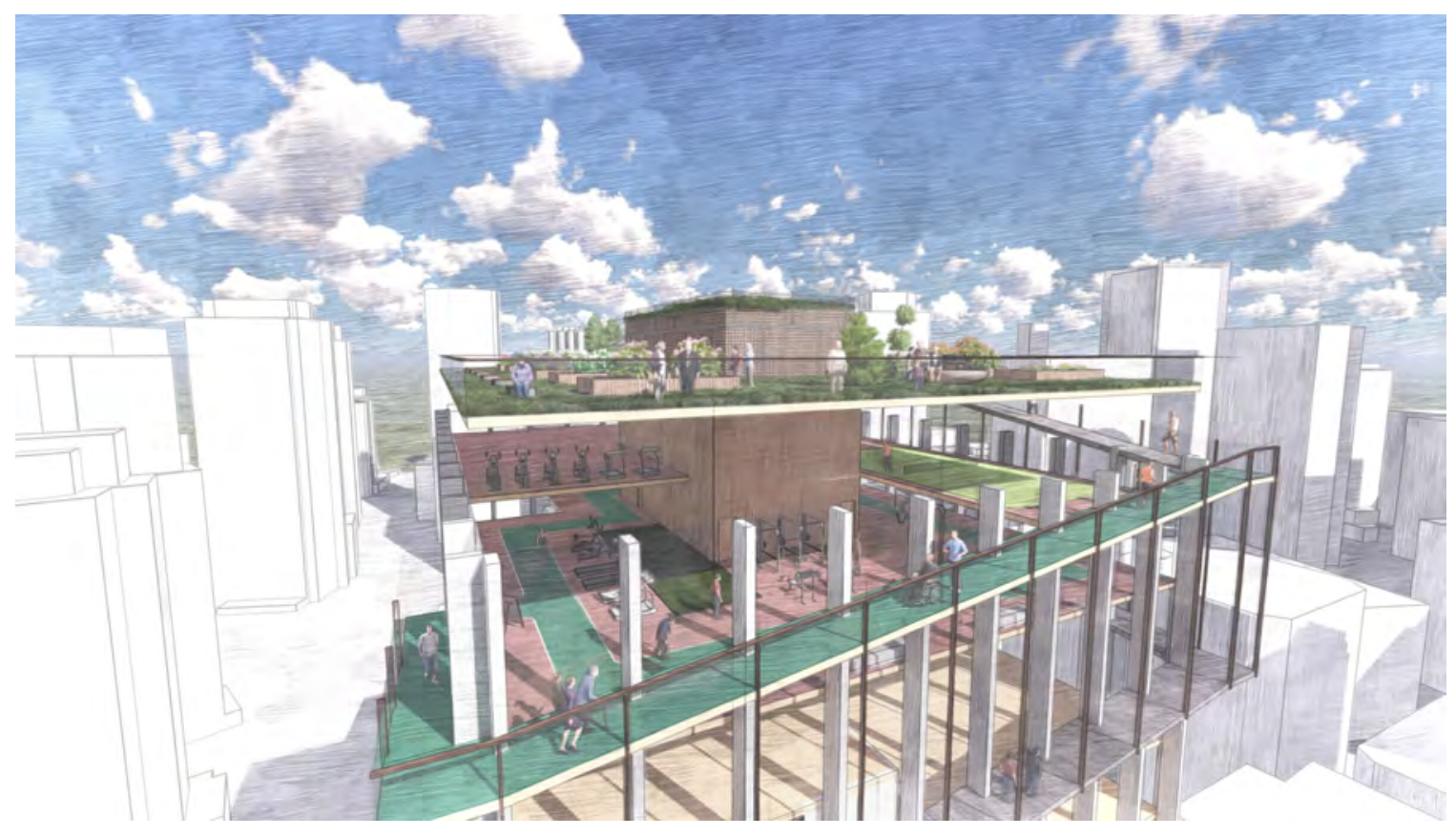

Figure 4.27 - Roof Top 
The Indoor Botanic Garden is an amenity space adjacent to the dementia residents, however, any residents and their guests in the building are also welcome to occupy any amenities. The dementia residential units are much more practical in size as the room does not include kitchen or large living room. The intent is to bring dementia residents out of their room to wander in a controlled space and interact with others in different Hubs.
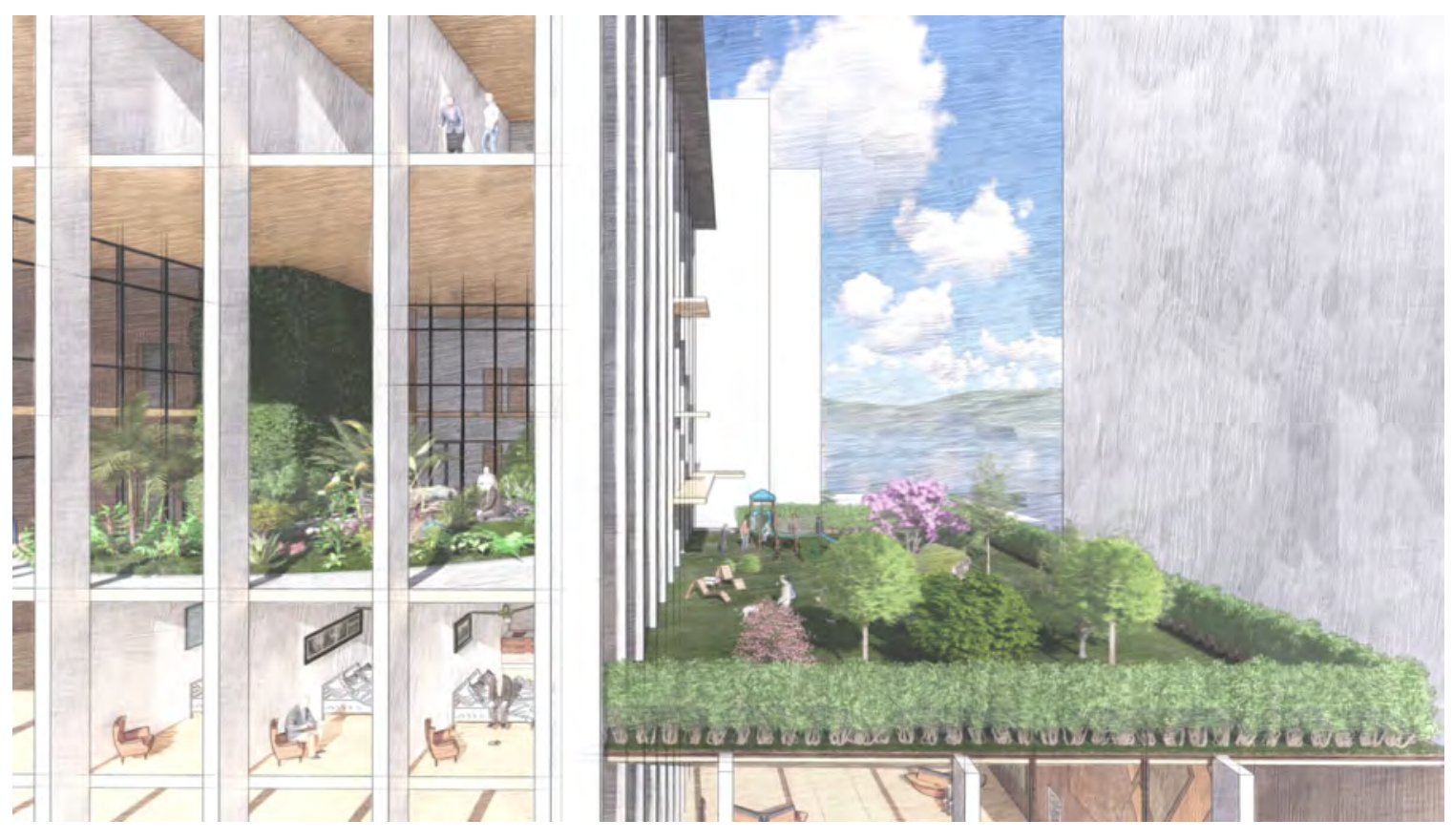

Figure 4.28 - North Elevation 


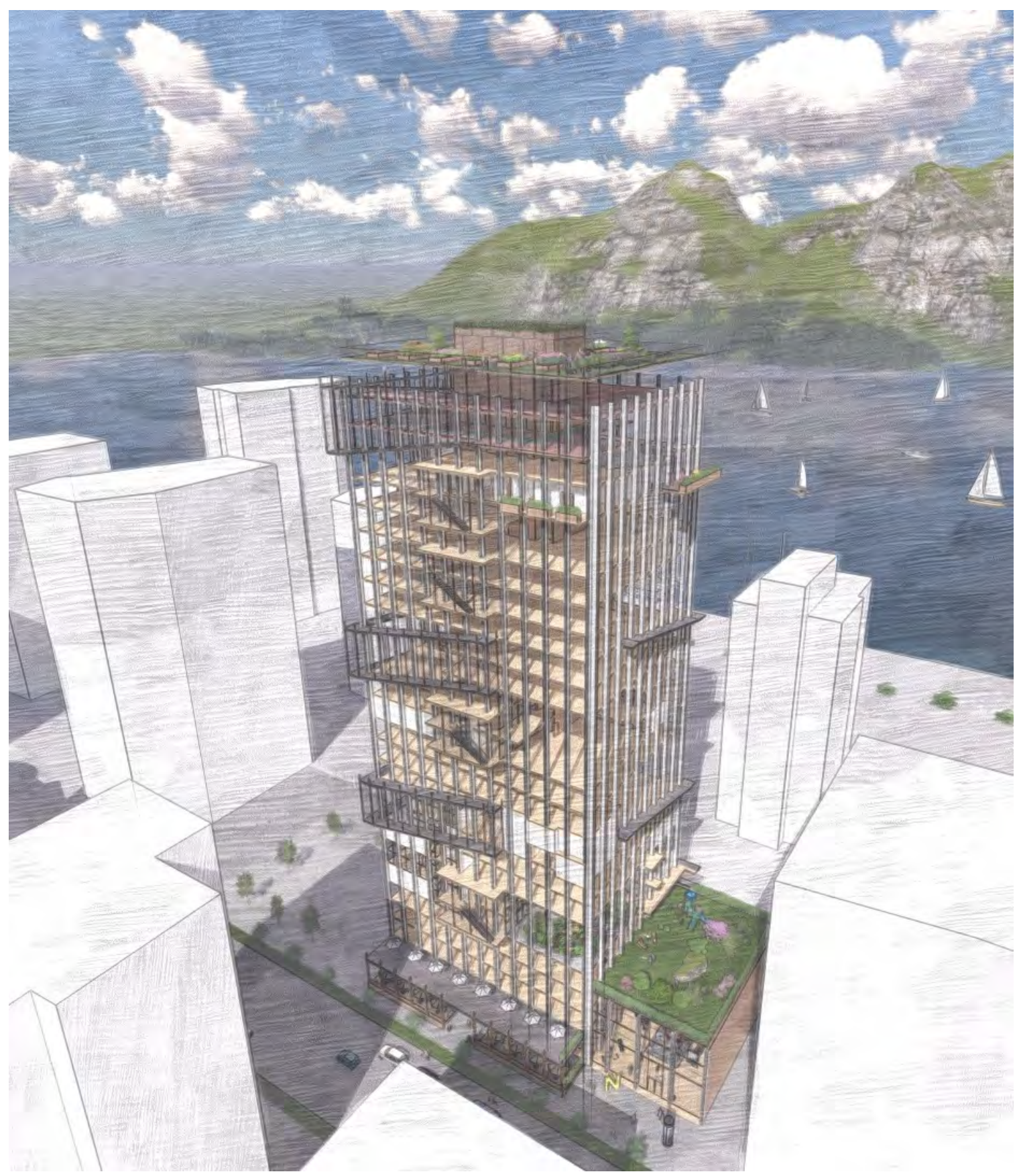

Figure 4.29 - Southeast corner view 


\section{$\underline{4.5 \text { Building for Sustainability }}$}

Sustainability principles for the senior home tower

- Improve day lighting in common spaces to reduce the need of artificial light during day-time period.

- Capture of wind-blown rain and other rain capture collection system for nonpotable water usage for the building

- Improved natural ventilation of the building and provide spaces for fresh air at high level for seniors

- Increase the landscape area at the ground plane to increase the water absorption rate in order to reduce water drainage load to city sewer

- Ensure no blockage to nearby building to the view cone of the mountains in West Vancouver

- Enhance the urban identity within Downtown Vancouver by creating an iconic statement to the cityscape

\subsubsection{Vision for the city}

The senior home tower will support the social sustainability goal of the City of Vancouver including education and culture, health and welfare and inclusion goals. It will be planned, designed and operate according to the sustainability systems application to the project. Some of the large spaces in the building consume great energy resources, largely because of the climate control requirement. 


\subsubsection{Water Capture system}

The Rooftop Vegetable garden would require a higher consumption of water and as Vancouver has many rainy days, water can easily be captured for non-potable use such as watering the plants on the roof top as well as the Botanic Garden.

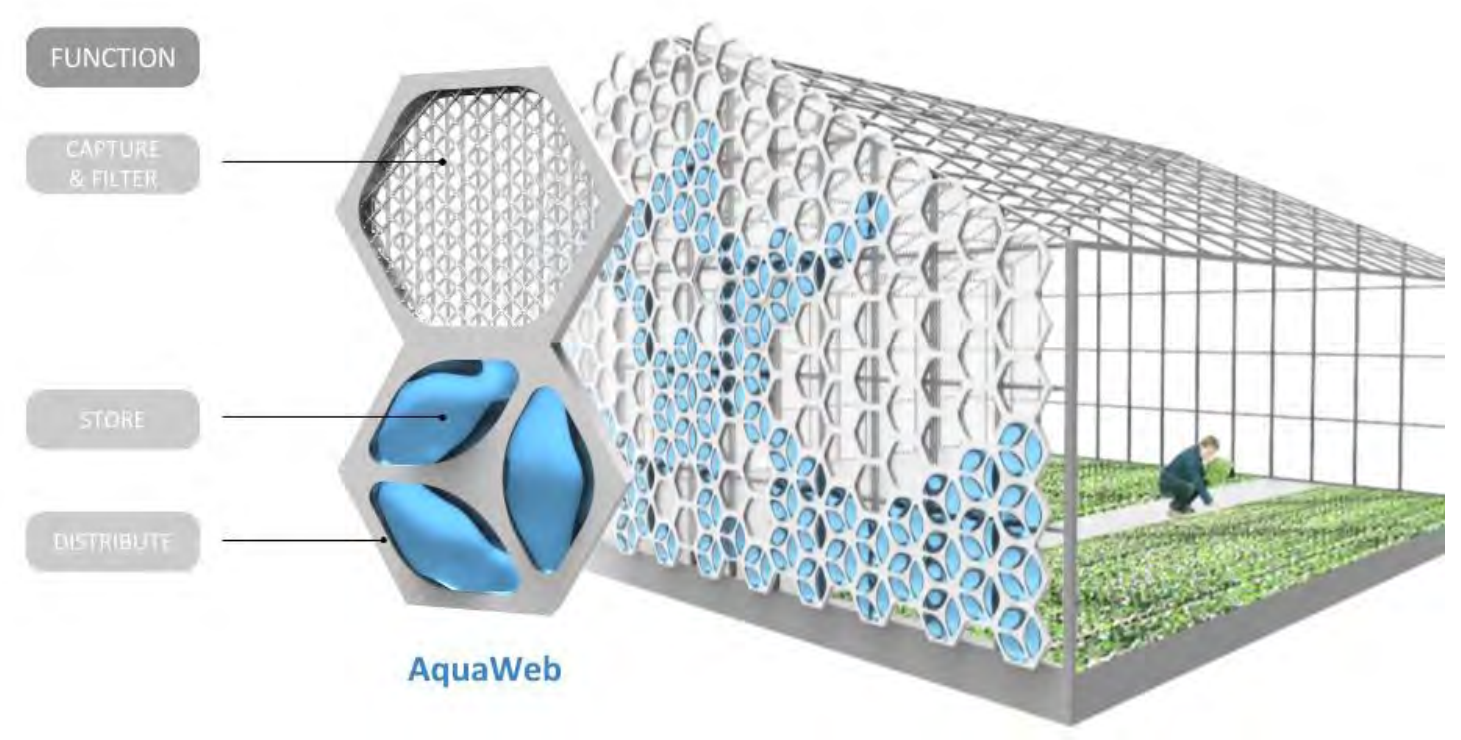

Figure 4.28 - AquaWeb developed by NexLoop

A web system designed by the company NexLoop has invented the Aquaweb system to capture rain and fog and uses passive strategies to distribute water for urban farming in particular. They drew inspiration in Biomimicry in the living system. The mesh allows water to grow surface tension onto those webs where water is then collected and dropped into a channel for water storage.

The senior living tower could deploy a similar system on the façade of the building to capture wind-blown rainwater, which would then channel into a water tank reservoir for filtering before reusing. The location of the water reservoir could be placed in one of the shafts of the tower where the top two levels of elevator core space would be taken out for water storage. The upper tower do not need three elevators to service the top two floors.

\footnotetext{
${ }^{1}$ NexLoop. Renewable Water for Sustainable Food
} 


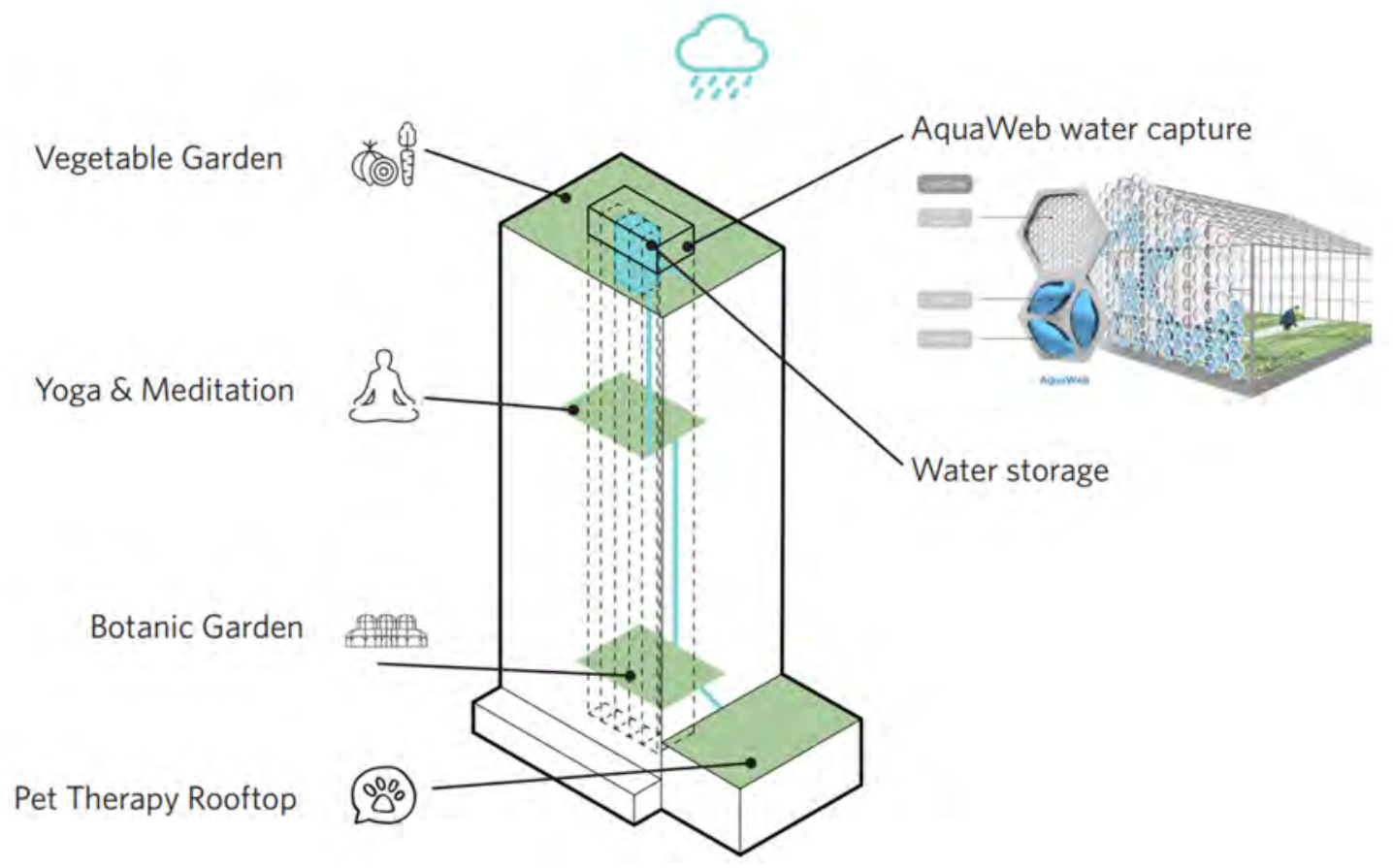

Figure 4.29 - Water Capture System Diagram 
Chapter 05: Conclusion 


\section{Chapter 05: Conclusion}

Every human will inevitably reach the end of their life's journey and one's senior years are the final moment to live life to its fullest, and to enjoy moments with family and friends. Some old friends may already passed and family may not be always be there for the senior, so as a society we need to create opportunities for these seniors to meet others to walk their final journey together. Aside from caring for their loneliness, practical needs and support from medical staff and caretakers would also make available accommodations for the seniors' day to day activities. The senior tower is similar to a living organism where it takes care of the mental well-being of the senior by offering a wide range of amenities and social and recreational programs. But also, it provides medical staff and caretaker to look after their physical well-being.

The emphasis of this thesis is to create spaces for physical care and social gathering in order to stimulate greater communal interest in the different personalities among the seniors; this project aims to increasingly draw seniors out of their rooms and spend the least amount of time inside an isolated bedroom, and instead into our shared urban realm. In addition to increase activity time outside of their room, the public amenities allow engagement between seniors and young age group to coexist in the same space. At the end of life's journey, one would not be afraid of death but rather be afraid of being alone and neglected. While much discussed in this document is bound up with social policy that is beyond an architect's control, it is hoped that progressive architectural examples can also usher in social policy changes. 


\section{Bibliography}

BC Care Providers Assocation. (2019). Filling the Gap: Determining Appropriate Staffing \& Care Levels for Quality in Long Term Care

Canada Mortgage and Housing Corporation. (2016). Senior's Housing Report British Columbia

Culbert, Lori,. Shore, Randy. (2018). Finding care for B.C. seniors: How the system works, what is missing, and why you need deep pockets. Vancouver Sun.

https://vancouversun.com/news/local-news/finding-care-for-b-c-seniors-how-the-systemworks-what-is-missing-and-why-you-need-deep-pockets

Culbert, Lori. (2018). Senior and food: The dish on care home menus. Vancouver Sun. https://vancouversun.com/health/seniors/seniors-and-food-the-dish-on-care-home-menusand-tips-for-cooking-alone-at-home

Culbert, Lori. (2019). Loneliness, falls and over-medicating afflict seniors in B.C. care homes. Vancouver Sun. https://vancouversun.com/health/seniors/loneliness-falls-and-over-medicatingafflict-seniors-in-b-c-care-homes

Department of Social Development. (2015). Design Standards for Nursing Homes version 3.0 Kloppenborg, Anne. (2010). Seniors in Vancouver, A discussion paper prepared by the social policy group, social development department, City of Vancouver

Michael, Liu., Colleen J. Maxwell., Armstrong, Pat., Schwandt, Michael., Moser, Andrea., McGregor, Margaret J., Bronskill, Susan., Dhalla, Irfan. (2020). COVID-19 in long-term care homes in Ontario and British Columbia. https://www.cmaj.ca/content/cmaj/192/47/E1540.full.pdf

Ministry of Health BC. (2017). Residential Care Staffing Review

NexLoop. Renewable Water for Sustainable Food. https://nexloop.us/

Office of the Senior Advocate. (2017). Monitoring Senior's Services

Office of the Senior Advocate. (2015). Senior's Housing in BC, May 2015 Report \#

U.S. Department of Health and Services. (2018). Physical Activity Guidelines for Americans, $2^{\text {nd }}$ edition. Washington, DC. US. Department of Health and Human Services https://health.gov/sites/default/files/201909/Physical_Activity_Guidelines_2nd_edition.pdf\#page=67

Zussman, Richard. (2020). B.C's seniors advocate finds multiple problems with long-term care home sector. Global News. https://globalnews.ca/news/6505320/b-c-s-seniors-advocate-findsmultiple-problems-with-long-term-care-home-sector/ 